\title{
The 22q11.2 region regulates presynaptic gene-products linked to schizophrenia
}

Ralda Nehme ${ }^{1,2 \#^{*}}$, Olli Pietiläinen ${ }^{1,2, \#^{*}}$, Mykyta Artomov ${ }^{1,3}$, Matthew Tegtmeyer ${ }^{1,2}$, Christina Bell $^{15}$, Andrea Ganna ${ }^{1}$, Tarjinder Singh ${ }^{1}$, Aditi Trehan ${ }^{1,2}$, Vera Valakh ${ }^{1,2}$, John Sherwood ${ }^{1,2}$, Danielle Manning ${ }^{1}$, Emily Peirent ${ }^{1,2}$, Rhea Malik ${ }^{2}$, Ellen J. Guss ${ }^{2}$, Derek Hawes ${ }^{1,2}$, Amanda Beccard $^{1}$, Anne M. Bara ${ }^{1,2}$, Dane Z. Hazelbaker ${ }^{1}$, Emanuela Zuccaro ${ }^{2}$, Giulio Genovese ${ }^{1}$, Alexander A Loboda ${ }^{1,4}$, Anna Neumann ${ }^{1}$, Christina Lilliehook ${ }^{1}$, Outi Kuismin ${ }^{5,6,7,8}$, Eija Hamalainen $^{9}$, Mitja Kurki ${ }^{1,5,9}$, Christina M. Hultman ${ }^{10}$, Anna K. Kähler ${ }^{10}$, Joao A. Paulo ${ }^{15}$, Jon Madison $^{1}$, Bruce Cohen ${ }^{11}$, Donna McPhie ${ }^{11}$, Rolf Adolfsson ${ }^{12}$, Roy Perlis ${ }^{13}$, Ricardo Dolmetsch $^{14}$, Samouil Farhi ${ }^{1}$, Steven McCarroll ${ }^{1}$, Steven Hyman ${ }^{1,2}$, Ben Neale ${ }^{1}$, Lindy E. Barrett $^{1,2}$, Wade Harper ${ }^{15}$, Aarno Palotie ${ }^{1,5,16,9,17}$, Mark Daly ${ }^{1,5,15,9,17}$, Kevin Eggan ${ }^{1,2^{*}}$

${ }^{1}$ Stanley Center for Psychiatric Research, Broad Institute of Harvard and MIT, Cambridge, MA 02142, USA

${ }^{2}$ Department of Stem Cell and Regenerative Biology, and the Harvard Institute for Stem Cell Biology, Harvard University, Cambridge, MA 02138, USA

${ }^{3}$ Analytic and Translational Genetics Unit, Department of Medicine, Massachusetts General Hospital, Boston, MA, 02114, USA.

${ }^{4}$ ITMO University, St. Petersburg, Russia

${ }^{5}$ Psychiatric \& Neurodevelopmental Genetics Unit, Massachusetts General Hospital, Boston, MA, 02114, USA

${ }^{6}$ PEDEGO Research Unit, University of Oulu, FI-90014, Oulu, Finland

${ }^{7}$ Medical Research Center, Oulu University Hospital, University of Oulu, FI-90014, Oulu, Finland.

${ }^{8}$ Department of Clinical Genetics, Oulu University Hospital, 90220, Oulu, Finland.

${ }^{9}$ Institute for Molecular Medicine Finland, University of Helsinki, FI-00014, Helsinki, Finland

${ }^{10}$ Department of Medical Epidemiology and Biostatistics, Karolinska Institutet, SE-171 77

Stockholm, Sweden

${ }^{11}$ McLean Hospital, 115 Mill St., Belmont, MA 02478

${ }^{12}$ Umea University, Faculty of Medicine, Department of Clinical Sciences, Psychiatry, 90185 Umea, Sweden

${ }^{13}$ Psychiatry Dept., Massachusetts General Hospital, Boston, MA 02114, USA

${ }^{14}$ Novartis Institutes for Biomedical Research, Novartis, Cambridge, MA 02139, USA

${ }^{15}$ Department of Cell Biology, Blavatnik Institute of Harvard Medical School, Boston, MA, USA

${ }^{16}$ Institute for Molecular Medicine Finland, University of Helsinki, FI-00014, Helsinki, Finland

${ }^{17}$ Department of Neurology, Massachusetts General Hospital, Boston, MA, 02114, USA.

${ }^{18}$ BioMarin Pharmaceutical, San Rafael, CA 94901

\# Contributed equally

* Co-senior authors, and correspondence:

rnehme@broadinstitute.org

ollip@broadinstitute.org

eggan@mcb.harvard.edu, kevin.eggan@bmrn.com 
$\underline{\text { Abstract }}$

49 To study how the $22 q 11.2$ deletion predisposes to psychiatric disease, we generated induced

50 pluripotent stem cells from deletion carriers and controls, as well as utilized CRISPR/Cas9

51 to introduce the heterozygous deletion into a control cell line. Upon differentiation into

52 neural progenitor cells, we found the deletion acted in trans to alter the abundance of

53 transcripts associated with risk for neurodevelopmental disorders including Autism

54 Spectrum Disorder. In more differentiated excitatory neurons, altered transcripts encoded

55 presynaptic factors and were associated with genetic risk for schizophrenia, including

56 common (per-SNP heritability $\left.p\left(\tau_{c}\right)=4.2 \times 10^{-6}\right)$ and rare, loss of function variants $(p=$

$571.29 \times 10^{-12}$ ). These findings suggest a potential relationship between cellular states,

58 developmental windows and susceptibility to psychiatric conditions with different ages of

59 onset. To understand how the deletion contributed to these observed changes in gene

60 expression, we developed and applied PPItools, which identifies the minimal protein-

61 protein interaction network that best explains an observed set of gene expression

62 alterations. We found that many of the genes in the $22 q 11.2$ interval interact in

63 presynaptic, proteasome, and JUN/FOS transcriptional pathways that underlie the broader

64 alterations in psychiatric risk gene expression we identified. Our findings suggest that the

$65 \quad 22 q 11.2$ deletion impacts genes and pathways that may converge with risk loci implicated

66 by psychiatric genetic studies to influence disease manifestation in each deletion carrier. 
$\underline{\text { Introduction }}$

Heterozygous deletions of the 22q11.2 chromosomal interval occur approximately once

73 in every 4,000 live births ${ }^{1}$. This deletion confers a risk of developing several symptomatically

74 diverse neuropsychiatric conditions including intellectual disability (ID), Autism Spectrum

75 Disorder (ASD) and schizophrenia ${ }^{2-7}$. In fact, deletion of $22 q 11.2$ confers the largest effect of

76 any known genetic risk factor for schizophrenia ${ }^{8}$.

Unlike the 22q13.3 deletion syndrome, where risk of mental illness can largely be

explained by reduced function of a single gene $(S H A N K 3)^{9}$, mutations in no one gene within the

22q11.2 deletion can explain the predisposition for psychiatric disease it confers. As a result, the pathways through which the 22q11.2 deletion contributes to ASD and schizophrenia risk remain

81 poorly understood. Mouse models have served as an initial in road for identifying genes within

82 the deletion that function in brain development and behavior. Overall, studies with rodent models

83 suggest that several genes in the syntenic chromosomal interval including $D g c r 8, \operatorname{Ranbp} 1, \operatorname{Rtn} 4 r$,

84 and $Z d h h c 8$ have important nervous system functions ${ }^{10-21}$. However, imperfect alignment

85 between mouse behavioral phenotypes and psychiatric symptoms have left uncertainty

86 concerning which, or how many of their human orthologs play a role in mental illness.

88 contributes meaningfully to their likelihood of developing one psychiatric condition or another.

89 For instance, deletion carriers that also harbor an additional copy number variant (CNV)

90 elsewhere in the genome displayed a higher risk of developing schizophrenia ${ }^{22}$. Additionally,

91 analysis of polygenic risk scores calculated using data from genome wide association studies

92 (GWAS) suggests that an increased burden of common risk variants can act in concert with the

$9322 q 11.2$ deletion to further increase overall risk for psychosis ${ }^{23-25}$. These observations clearly 
94 indicate the $22 \mathrm{q} 11.2$ deletion can at least act together with alterations in genetic pathways

95 affected by additional risk variants. This raises the possibility that the deletion may converge on

96 disease mechanisms that act in both ASD and schizophrenia.

97 We reasoned that finding the points of convergence between the effects of the $22 \mathrm{q} 11.2$

98 deletion and other human genetic variants implicated in psychiatric disorders could provide a

99 view into which genes present in the deletion, or pathways altered by it, contribute to mental

100 illness. To identify such intersections, we opted to examine transcriptional changes in multiple

101 stages of excitatory neuronal differentiation, given that genetic studies of ASD and schizophrenia

102 have implicated genes that act during neuronal development and differentiation ${ }^{26-29}$, and in

103 neuronal processes including excitatory transmission ${ }^{30-32}$. We therefore carried out RNA

104 sequencing at three distinct stages of excitatory neuronal differentiation using induced

105 pluripotent stem cells (iPSCs) from 22q11.2 carriers and non-carrier controls. In order to

106 establish a causal link between the deletion and the transcriptional effects we also utilized gene

107 editing to delete the chromosomal region in a control cell line. To robustly induce neuronal

108 differentiation, we utilized an approach we previously described where Ngn2 expression ${ }^{33}$ is

109 coupled with forebrain patterning to produce homogenous populations of excitatory neurons with

110 features similar to those found in the superficial layers of the early cortex ${ }^{34}$. We have previously

111 characterized the cells generated by this approach using immunostaining, qPCR, single-cell RNA

112 sequencing, whole-cell patch clamp, multi-electrode arrays and optical electrophysiology, and

113 demonstrated reproducibility across multiple cell lines ${ }^{34-37}$.

114 Over the course of excitatory neuronal differentiation, we found that the $22 \mathrm{q} 11.2$ deletion

115 acted in trans to significantly alter the expression of many genes with established genetic

116 associations with neurodevelopmental disorders in progenitors, and schizophrenia in 
117 differentiated neurons. To ask, in an unbiased manner, which pathways and genes were likely

118 responsible for these changes, we developed an approach for identifying protein-protein

119 interaction (PPI) networks that best explain a particular change in gene expression. This method,

120 called PPItools, suggested that the 22q11.2 interval regulates the expression of genes in

121 proliferative, presynaptic, proteasomal and JUN/FOS pathways. Finally, we found that cell lines

122 with isogenic deletion of $22 \mathrm{q} 11.2$ recapitulated most of the changes observed in the patient-based

123 cohort, including increased levels of the $M E F 2 C$ transcription factor in neuronal progenitor cells

124 and decreased expression of presynaptic proteins such as SV2A and NRXN1 in neurons.

$126 \underline{\text { Results }}$

127 Pilot study and power calculations

128 The $22 \mathrm{q} 11.2$ deletion syndrome is associated with a wide spectrum of psychiatric

129 conditions, which differ from person to person, and by age of diagnosis. To study the effects of

130 the deletion, we both collected and derived hiPSC lines from patient carriers as well as non-

131 carrier controls (Fig.1a-f, Extended Data Fig. 1a and Extended Data Table 1).

132 To estimate the sample size needed to be powered to detect gene expression changes, we

133 performed a pilot study with two control and two 22q11.2 deletion iPSC lines, each from a

134 distinct donor. The presence of the $3 \mathrm{Mb} 22 \mathrm{q} 11.2$ deletion provided an internal control with a

135 built-in expectation for a set of known deleted genes and their anticipated magnitude of change.

136 Thus, we reasoned this small study would allow us to detect the $50 \%$ reduction in the abundance

137 of transcripts originating from within the deletion as well as changes in expression of genes

138 outside of the deletion that were of a similar magnitude. We induced neuronal differentiation

139 using a published, well-characterized approach, combining the overexpression of Ngn2 with 
140 small molecule patterning ${ }^{37}$ (Fig. 1g), and completed RNA-sequencing at three cellular stages:

141 human pluripotent stem cells (hPSCs, day 0 of differentiation), neuronal progenitor-like cells

142 (NPCs, day 4 of differentiation) ${ }^{37}$, and in functional excitatory neurons displaying synaptic

143 connectivity ${ }^{34}$ (day 28 of differentiation) (Extended Data Table 1, Extended Data Fig. 1b-e).

144 Following RNA-sequencing, we mapped reads to the Ensembl human genome assembly

145 (GRCh37/hg19). We detected one or more reads for 51 protein coding genes that mapped to the

$14622 q 11.2$ deletion region, in the four lines at any one differentiation stage. On one hand, we were

147 reassured to observe a systematic reduction in the abundances of RNAs encoded by genes

148 mapping in the deletion, with the majority exhibiting fold-changes between -1.5 and -2 in

149 deletion cells relative to controls. On the other hand, this decrease in RNA levels was

150 indistinguishable from sample-to-sample variance on an individual gene level (after correcting

151 for multiple testing), underscoring the limitations of a small sample size (Extended Data Fig. 1c-

152 e). Only when we considered reads from the genes in the deleted region in aggregate could we

153 observe a statistically significant reduction in gene expression between the deletion carriers and

154 controls $\left(\mathrm{p}(\mathrm{hPSCs})=4.13 \times 10^{-19}, \mathrm{p}(\mathrm{NPCs})=1.58 \times 10^{-18}\right.$, and $\mathrm{p}($ neurons $)=2.93 \times 10^{-15}$, Mann-

155 Whitney test).

156 Using our pilot sequencing data, we estimated that for genes expressed above the median,

157 a sample size of $>20$ carrier and $>20$ control iPSC lines would yield on average $>80 \%$ power to

158 detect fold-changes of 1.35 across each of the three cell stages (Fig. 1h, Extended Data Fig. 1e,f).

160 Profiling an expanded $22 q 11.2$ cohort

161 Guided by our power calculations, we assembled a collection of 20 (7 female, 13 male)

162 22q11.2 deletion carrier and 29 (14 female, 15 male) control iPSC lines, each derived from a 
163 distinct individual. It has been found that the size of the deletion doesn't seem to correlate with

164 diagnosis or severity of the conditions, as patients with either the most common $3 \mathrm{Mb}$ deletion or

165 smaller nested deletions appear to have similar diagnoses ${ }^{3,7,38,39}$. We thus decided to examine the

166 impact of the deletion (agnostic to size or diagnosis) on gene expression during neuronal

167 development. We performed RNA sequencing in hPSCs, NPCs and excitatory neurons for each

168 of the 49 cell lines (in triplicates, $\mathrm{N}=441$ total RNA sequencing libraries in mixed pools of both

169 genotypes to minimize technical biases). With these data in hand, we revisited our initial power

170 estimates and found that in the larger data set we achieved over $80 \%$ power to detect fold

171 changes $\geq 1.5$ of all detected protein coding genes (Extended Data Fig. $1 \mathrm{~h}$ ) across developmental

172 stages.

173 Consistent with previous findings using the same neuronal differentiation approach ${ }^{34,37}$,

174 differentiation down a neuronal trajectory resulted in a global change of gene expression

175 between each cellular stage analyzed (day 0 iPSC, day 4 NPC, day 28 excitatory neuron).

176 Principal component analysis (PCA) indicated that the primary component of variation between

177 the samples was days of neuronal differentiation $(\mathrm{PC} 1+2=46 \%$ of variance) (Fig. 1i, Extended

178 Data Fig. 1g). We found close clustering of the samples from the 49 lines within a given

179 differentiation time point within PC1 and PC2, suggesting a reproducible and reliable

180 differentiation had occurred across the entirety of our experiments (Fig. 1g). This conclusion was

181 supported by joint analysis of the data indicating that across the 49 cell lines, 4 pluripotency

182 associated genes were robustly expressed at day 0 and then rapidly silenced, while 7

183 representative NPC genes became expressed at day 4 with the strong emergence of 7 prototypical

184 neuronal genes at day 28 (Fig. 2a, Extended Data Fig. 2c). 


\section{$22 q 11.2$ effects on transcript abundance}

We next proceeded to ask the important question of how the $22 \mathrm{q} 11.2$ deletion status

188 influenced gene expression during neuronal differentiation and first considered genes within the

189 deletion. We observed a nominally significant reduction in RNA levels for 51 protein coding

190 genes in the deletion region $(\mathrm{p}<0.05$, red and blue dots, Fig. 2c-e) with 49 of these transcripts

191 yielding significantly reduced abundance in at least one time point (FDR $<0.05)$ and 25

192 significantly reduced in all 3 stages (FDR <0.05) (Fig. 2b, Extended Data Fig. 2a). These

193 findings in excitatory neuronal cells were in line with previous reports using either mixed

194 monolayer cultures of inhibitory and excitatory neurons carrying the $22 \mathrm{q} 11.2$ deletion $^{40}$ or

195 organoids consisting of multiple cell types including glutamatergic neurons and astrocytes ${ }^{41}$. We

196 found that for genes mapping to the deletion, which showed a significant change in their

197 expression, the deletion genotype explained, on average, 42 to $52 \%$ of all variance in their

198 expression (Extended data Fig. 3a-d). Included in these 49 significantly less abundant transcripts

199 originating from the 22q11.2 locus, were seven that are highly intolerant for loss of function

200 variants as measured by pLI score ${ }^{42}$, which ranks genes from most tolerant $(\mathrm{pLI}=0)$ to most

201 intolerant $(\mathrm{pLI}=1)$. These seven genes that have a $\mathrm{pLI}$ score $>0.9(U F 1 D L, H I R A, D G C R 8$,

$202 Z D H H C 8, M E D 15, T B X 1)$ have been previously suggested to play role in some of the congenital

203 phenotypes associated with the deletion in other tissues ${ }^{43}$. Together, our analyses indicate that

204 our transcriptional phenotyping was sufficiently sensitive to allow the successful detection of the

$20550 \%$ decrease in expression of the hemizygote genes found in the deletion region. 


\section{Cell-type specific effects of $22 q 11.2$ deletion}

After validating our ability to detect the altered expression of many genes within the

211 deletion, we next explored differentially expressed transcripts originating from loci outside of the

212 deletion. In fact, the majority (89\%) of the genes differentially expressed in 22 q11.2 carrier's

213 cells were located outside the deletion region ( $n=383$ genes) (Fig. $2 b)$. In total, the trans effects

214 of the deletion explained on average $18 \%$ of the total variance in gene expression across all data

215 sets (Extended data Fig. 3a-d). Plotting the test statistic from the differential expression for every

216 gene relative to its position in the genome suggested that there was no major positional clustering

217 of differentially regulated genes to specific chromosomal regions outside the deletion area

218 (Extended data Fig. 3e, day 28 example). Notably, only one gene, CAB39L on chromosome 13,

219 was significantly induced in carriers at all stages (Extended Data Fig. 2b). Upon reviewing

220 published data sets, we found that $C A B 39 L$ expression was also induced in blood cells isolated

221 from $22 \mathrm{q} 11.2$ deletion carriers ${ }^{44}$, suggesting that upregulation of this gene is likely to be

222 associated with the $22 \mathrm{q} 11.2$ deletion in many cell types.

While genes within the $22 \mathrm{q} 11.2$ deletion region were regulated in the same direction at

224 all developmental stages, the set of differentially expressed genes outside the deletion region was

225 different for each stage. In contrast to the conserved downregulation of genes within $22 \mathrm{q} 11.2$

226 across the three distinct time points we analyzed, except for $C A B 39 L$, the specific identity of the

227 remaining differentially expressed genes was distinct at each differentiation stage assessed (372

228 cell stage-specific genes). Importantly, the apparently discontinuous effects of the deletion

229 between the cell stages were not the trivial result of certain transcripts failing to be detected

230 because of barely falling outside a certain significance threshold. That is, in controls, the

231 affected genes were expressed in all cell stages with little change in their overall average RNA 
232 abundance between stages, ensuring reliable detection across all stages (Table S4 and Extended

233 Data Fig. 4a,b). As a result, fold-changes in "trans" genes between carriers and controls were

234 only modestly correlated between NPCs and hPSCs $\left(\rho=0.28, p=3 \times 10^{-8}\right)$ and NPCs and neurons

$235\left(\rho=0.23, p=3 \times 10^{-6}\right)$, while no correlation was observed between fold changes in hPSCs and

236 neurons $(\rho=0.06, p=0.25)$. Overall, these findings suggest that the $22 q 11.2$ deletion has a

237 temporally-dependent influence on gene expression, altering the abundance of distinct sets of

238 transcripts as neuronal differentiation unfolds.

239 Lastly, our cohort included 18 cell lines with full length 22q11.2 deletion, along with two

240 cell lines with nested 22q11.2 deletion. To verify that the cell lines with shorter deletion did not

241 result in a different transcriptional signature, we repeated the differential gene expression

242 analysis in day 28 neurons without the lines with short, nested deletions (SCBB-1430 and

243 SCBB-1961, Table 1). We found that the differences in gene expression between the remaining

244 deletion carriers and controls correlated strongly with those obtained in the complete data set

$245 \quad(\mathrm{r}=0.92$ for genes with adjusted $\mathrm{p}$-value $<0.05)$, suggesting that the observed gene expression

246 differences were robust also in the presence of the shorter deletions.

\section{Transcript alterations in hPSCs and NPCs}

The phenotypes that are found in a subset of 22q11.2 deletion carriers during early

250 childhood $^{3}$ led us to ask if the genes we identified to be differentially expressed in deletion

251 carriers at initial differentiation stages (hPSCs and NPCs) were genetically associated with

252 neurodevelopmental disorders, including autism and intellectual disability. We included likely

253 disease-causing genes from the Deciphering Developmental Delay (DDD) project, and a recent,

254 large exome-sequencing study in autism ( $\mathrm{n}=295$ total neurodevelopmental disorders, NDD, 
255 genes) $)^{27,45,46}$ (Table S5). Of the 432 genes we found differentially expressed in deletion carriers,

25610 were NDD genes (hPSCs: FOXG1, ELAVL3; NPCs: PAX6, MEF2C, FOXP2, NR2F1, MAF,

257 PAX5; neurons: KMT2C, $M K X$; OR $=1.85, \mathrm{p}=0.046$ (for all 432 genes) (Tables S1-S3). We took

258 particular note of $M E F 2 C$ as it is also implicated in schizophrenia through $\mathrm{GWAS}^{47}$ and is

259 known to encode a transcriptional regulator that participates in activity-dependent regulation of

260 immediate early genes such as $J U N$ and $F O S^{48}$. MEF2C has been shown to be repressed by the

261 transcription factor $T B X 1$, which is encoded by a gene within the $22 \mathrm{q} 11.2$ interval ${ }^{49,50}$.

262 Proteins encoded by genes harboring causal mutations for a particular phenotype in

263 Mendelian disorders have been shown to have more physical connections between one another

264 than unrelated proteins ${ }^{51}$. We therefore wondered whether the transcripts expressed from within

265 the 22q11.2 deletion and the transcripts with altered abundance in trans in deletion carriers

266 encoded proteins that together had more than the expected number of interactions with proteins

267 originating from loci genetically linked with NDD. As this is a question of broader relevance for

268 connecting protein interaction data, changes in gene expression, and genetic data, we wrote a

269 software package (PPItools, https://github.com/alexloboda/PPItools) to enable this analysis.

270 In this instance we used PPItools to identify the protein-protein interactions (PPI) from

271 the InWeb database ${ }^{52}$ of the differentially expressed gene products that we identified at each

272 stage of neural differentiation and analyzed them for an apparent excess of genes implicated in

273 NDD in this network. We used a curated list of NDD genes that comprised 295 genes that have

274 been previously reported to have excess of deleterious variants in patients with ASD, and ID

$27545,46,53$ (Table S5). To ask whether this enrichment for NDD implicated interacting proteins was

276 likely to have occurred by chance, we performed 1000 random permutations of sets of expressed

277 proteins of the same size while constraining the scale and complexity of the network. These 
278 analyses confirmed that genes we found to be differentially expressed early in differentiation (in

279 hPSCs and NPCs) were significantly more likely to interact with gene products associated with

280 NDD $(p<0.001$, Extended Data Fig. 4c). While there remained a modest enrichment for

281 differentially expressed genes in excitatory neurons for interaction with NDD gene products, this

282 enrichment was not significant.

283 To further control our observation, we asked whether the protein interaction network we

284 identified at each time point showed any enrichment for genes linked with an unrelated

285 condition, inflammatory bowel disease (IBD), or with a neurological condition, Parkinson's

286 Disease (PD). As expected, there were no significant enrichments for IBD related gene products

287 within the protein interaction networks identified at any of the differentiation time points

288 analyzed, and no enrichment for PD related gene products in NPCs or neurons (Extended Data

289 Fig. 4c, Table S5). Thus, our results demonstrate that within hPSCs and NPCs, there is indeed a

290 convergence between genes within the 22q11.2 deletion and the transcripts altered in trans by the

291 deletion with genes products that when mutated cause human neurodevelopmental disorders.

\section{Schizophrenia heritability enrichment in neurons}

Given that we had found an initial convergence between the effects of the $22 \mathrm{q} 11.2$

295 deletion and the abundance of certain transcripts linked through rare variant analyses to NDD as

296 well as with a broader collection of PPI networks implicated in NDD, we next proceeded to ask

297 whether the transcripts that we had found to be altered in deletion carrier cells were enriched for

298 additional genetic signals in mental illness. To investigate this possibility, we utilized the genes

299 we identified to have significantly altered expression $(\mathrm{FDR}<0.05)$ in differentiating cells from

3002 2q11.2 carriers as a substrate for linkage disequilibrium (LD)-score regression ${ }^{30}$. For this 
analysis we used GWAS summary statistics from the psychiatric genomics consortium (PGC), as well as educational attainment studies ${ }^{54-59}$ to ask whether variants in 22 q11.2-differentially expressed genes and their surrounding genomic regions contribute disproportionately to the

304 polygenic heritability of five neuropsychiatric disorders (schizophrenia, bipolar disorder, major 305 depressive disorder, autism spectrum disorder, and ADHD). We applied two statistics to

306 estimate heritability enrichment in LD-score regression: per-SNP heritability and total

307 heritability enrichment. We found suggestive evidence for a modest increase in per-SNP

308 heritability for schizophrenia among genes differentially expressed in neurons $\tau_{c}=6.1 \times 10^{-8}$;

$309 \mathrm{p}=0.0088$ for 196 genes, $\mathrm{FDR}<5 \%$ and $\tau_{c}=1.5 \times 10^{-8} ; \mathrm{p}=0.01$ after examining all 4,192 genes

310 with nominally significant differences in expression, $\mathrm{p}<0.05,2,864$ up genes and 1,328 down

311 genes, respectively) (Fig.3a). Analysis of up- and down-regulated genes $(\mathrm{p}<0.05)$ separately

312 revealed that the increase in the per-SNP heritability was accounted for by transcripts that were

313 more abundant in deletion carrier neurons $\left(\mathrm{p}\left(\tau_{c}\right)=4.2 \times 10^{-6} \mathrm{p}(\right.$ Bonferroni $\left.)=0.0003\right)($ Fig.3a,

314 Table S6). Our findings were unlikely to be the result of neurons merely expressing increased

315 levels of genes relevant for these psychiatric conditions: permutation with 100 random gene lists

316 produced from our neuronal data and matched for expression level, indicated that the per-SNP

317 heritability enrichment in genes we found to be induced in deletion carrier neurons was $\sim 10,000$ -

318 times more significant than any random gene set (Extended Data Fig.5a-c). We found a similar

319 trend when examining the total heritability accounted for by variants in these genes, where we

320 found an increase in heritability enrichment for bipolar disorder and educational attainment in

321 addition to schizophrenia (Extended Data Fig. 5d,e, Table S6).

322 To again query the relationship between differentially expressed genes in $22 \mathrm{q} 11.2$

323 deletion neurons and common genetic variants more broadly associated with psychiatric illness, 
324 but with a different set of statistical assumptions, we applied multiple-regression for competitive

325 gene-set analysis in MAGMA-software ${ }^{60}$. Like results from the LD-score regression analysis,

326 genes whose transcripts were more abundant in 22q11.2 deletion neurons were more strongly

327 associated with schizophrenia than the rest of the genome $\left(p=5.6 \times 10^{-7}, p(\right.$ Bonferroni $)=4.03 \times$

$32810^{-5}$ ) (Extended Data Fig. 6a). Altogether, 20 genes with nominally significant gene-wise

329 association to schizophrenia from MAGMA $\left(\mathrm{p}_{\mathrm{g}}<0.05\right)$ were significantly differentially expressed

330 in deletion neurons (Fig. 3b, Extended Data Fig. 6c). Repeating the analysis with 100 random

331 gene lists generated from our expression data confirmed that this result was unlikely to have

332 arisen merely as a result of examining these neuronal cells (Extended Data Fig. 6b).

333 To determine if this association between $22 \mathrm{q} 11.2$ deletion induced genes and

334 schizophrenia heritability was replicable and to determine the specificity of this signal, we used

335 summary statistics from an independent GWAS dataset of 650 heritable traits from the UK-

336 biobank. Strikingly, LD-score regression showed the genes upregulated in 22q11.2 deletion

337 neurons harbored significant heritability enrichment for schizophrenia, but not for the other traits

338 (Fig.3c). Overall, our findings indicated that excitatory neurons harboring the 22q11.2 deletion

339 exhibited increased abundance of transcripts from genes that underlie schizophrenia heritability,

340 but that the deletion did not have such a detectable effect at earlier stages of differentiation.

\section{Schizophrenia rare variant enrichment in neurons}

343 Exome sequencing at increasing scale has begun to reveal a burden of rare protein

344 damaging variants in schizophrenia patients, complementing the genetic signal of common

345 regulatory variants emerging from $\mathrm{GWAS}^{61-63}$. In contrast to the common variant polygenic risk,

346 which arises incrementally from many small-effect variants, the schizophrenia-associated rare 
347 variants identified so far act with strong individual effects. While there is evidence for common

348 and rare risk variants in schizophrenia mapping to shared chromosomal intervals ${ }^{32}$, so far the two

349 forms of variation implicate largely distinct sets of genes. We therefore asked whether the

$35022 q 11.2$ deletion also effects the expression of genes that harbor rare coding variants, identified

351 by the schizophrenia exome meta-analysis consortium (SCHEMA) in schizophrenia patients ${ }^{63-65}$.

352 We initially focused on genes upregulated in neurons from $22 q 11.2$ carriers $(n=2,864$ genes at $p$

$353<0.05)$ and used 100 random gene lists matched for their expression levels in our excitatory

354 neurons as controls. This analysis revealed two interesting results: First, alterations in the

355 expression of genes harboring a burden of loss of function mutations in schizophrenia were

356 significantly enriched in excitatory neurons from 22q11.2 carriers (Fig. 3d red dots, 57/100

357 random gene lists assessed $\mathrm{p}<0.05)$. Second, that the 2,864 transcripts within these neurons

358 whose expression were increased in 22q11.2 deletion carriers were substantially more

359 significantly enriched for loss of function variants than any of the random gene lists we sampled

360 (Fig. 3d, red dot black circle; $p=1.29 \times 10^{-12}$ ). This enrichment signal was substantially reduced

361 for missense mutations in schizophrenia patients and absent for synonymous variants (green and

362 blue dots Fig. 3d). We further examined the differential expression results for genes with

363 significant burden of deleterious mutations in schizophrenia patients in SCHEMA. One transcript

364 encoded by ZMYM2 out of 32 significant genes from SCHEMA was significantly changed in the

365 deletion lines (FDR $<5 \%$ ). Seven additional genes (RB1CC1, AKAP11, ASH1L, GRIA3, SV2A,

366 PCLO, DNM3) were nominally significantly changed in the deletion neurons. Remarkably, all

367 eight SCHEMA genes were upregulated in the deletion carrier neurons.

368 Consistent with the notion that we were analyzing a disease relevant cell type, our rare-

369 variant burden analyses indicated that the excitatory neurons we produced from both cases and 
370 controls expressed a significant excess of genes harboring rare pathogenic coding variants in

371 schizophrenia patients. However, our analysis further indicated that in excitatory neurons the

372 22q11.2 deletion was specifically associated with alterations in a set of genes that were even

373 more markedly enriched for rare loss of function variants in schizophrenia patients (Fig. 3d,

374 circled dot). Like our common variants analyses, genes whose expression we found altered in

375 pluripotent stem cells and NPCs harboring the 22q11.2 deletion did not exhibit this excess of rare

376 coding variants schizophrenia (Extended data Fig. 7a, Table S7).

\section{Protein-protein interaction networks associated with transcriptional changes}

As the number of trans acting effects of the deletion on transcripts linked to psychiatric

380 illness were substantial, we sought an unbiased approach for identifying the pathways that could

381 be contributing to their alterations. Ideally, such a method would also have the capacity to

382 identify potential connections to gene products originating from within the deletion interval

383 itself. To this end, we used PPI data ${ }^{52}$ to search for the smallest number of biochemical

384 interactions that could explain the most prominent transcriptional changes in deletion carriers. To

385 facilitate this effort, we developed a new tool (included in the R-package "PPItools", see

386 methods) that scores observed p-values from differential expression to construct a node weighted

387 graph with the strongest cumulative association with the deletion genotype at each cell stage

388 (most-weighted connected subgraph, MWCS). We then performed 1000 permutations on p-

389 values from differential expression while preserving the node degrees, to ensure that the

390 connected gene-products were unlikely to occur in the subgraph by chance alone ( $p<0.05$, Table

391 S8) (Extended Data Fig. 8a). This analysis revealed that the minimal interaction networks for

392 each of the three stages of differentiation were predominantly composed of proteins encoded by 
genes located within the 22q11.2 deletion, that were in turn interconnected with proteins encoded by genes residing outside of the deletion (Extended Data Fig. 8b,c and Fig. 4g). In pluripotent stem cells, we found that the most weighted subgraph contained 53 node

396 proteins, 26 of which were encoded by genes mapping to the deletion (Extended Data Fig. 8b).

397 These nodes were organized around several hub proteins encoded by genes that map outside the 398 deletion. These included MYC, p53 (TP53) and the autism associated protein p21 (CDKN1A) 399 suggesting that the deletion disrupts regulation of the cell cycle and directly impacts expression.

400 Our analyses suggest alterations in the expression of these well-known cell cycle regulators 401 could be mediated by reduced expression of several interacting proteins that map to the deletion 402 including CDC45, a regulator of DNA replication, TRMT2A, which encodes a known cell cycle 403 inhibitor, as well as LZTR1 a known tumor suppressor. Another notable hub observed in stem 404 cells was that encoding the low affinity nerve growth factor receptor and known NOGO Co405 receptor P75, which was increased in expression. The minimal network implicated the NOGO 406 receptor (RTN4R) and the mediator of protein degradation through the proteasome UFD1L, both 407 of which are encoded within the deletion.

408 In neural progenitor cells (Extended Data Fig. 8c), we continued to see evidence for 409 disruption in NOGO signaling through increased expression of both NOGO (RTN4) and the

410 TRKA receptor, which is associated with autism through rare protein-coding variation and is also 411 a known interactor with P75 and whose signaling is modulated by NOGO signaling. These

412 findings suggest that reduced expression deletion proteins such as the NOGO receptor and less 413 appreciated interacting proteins encoded within the deletion such as PIK4A and ARCV4 are 414 disrupting signaling. Another significant signal emerging from the minimal network in NPCs 415 was for a disruption in RNA metabolism. This was exemplified by a hub centered around The 
416 TFIID transcription factor, TAF1 which interacted with the tumor suppressor proteins LZTR1

417 and LZTS2, the transcriptional activator NFKBIA, an RNA helicase associated with ASD,

418 MOV10, and GNB1L, encoded within the deletion, with roles in cell cycle progression and gene

419 regulation. TAF1 was also connected to the protein-ubiquitination pathways via interactions with

420 HSPA1B and its interactors, both from within and outside the deletion region.

421 In neurons (Fig. 4g), we identified three major hubs consisting of 1) interactors of the

422 activity-dependent transcription factor $J U N$, including the proteasome subunit PSMD12 and the

423 kinesin KIF2A, both associated with NDD, and BANP, a cell cycle regulator, along with several

424 proteins encoded in the 22q11.2 interval: TRMT2A, RANBP1, GNB1L, MRPL40, SCL25A1,

425 CRKL, with connections to the transcriptional (POLR2A) and chromatin remodeling (HIRA)

426 machineries; 2) components of the protein ubiquitination / metabolism pathway, including

427 SMAD2, COPS5 and WWP2 along with UFD1L, KLHL22, both encoded within the deletion

428 region; and 3) synaptic vesicle trafficking, including CLTCL1 encoding clathrin, the

429 synaptobrevin VAMP2, which is associated with NDD, and SNAP29 located in the 22q11.2

430 locus and encoding a synaptosome associated protein (Fig. 4g). Overall, our analyses support the

431 notion that multiple distinct but connected pathways are at the core of the transcriptional changes

432 that we observe in deletion carrier neurons: activity-dependent gene expression, protein

433 homeostasis, and synaptic biology.

\section{Enrichment of synaptic and protein homeostasis ontologies in deletion altered transcripts}

437 impact neurobiological processes. To this end, we employed recently reported synaptic gene

438 ontologies $^{31}$ to search for potentially converging synaptic biology among the genes differentially 
expressed in 22q11.2 patient neurons. Strikingly, 239 of the 2,864 transcripts with increased

440 abundance in 22q11.2 neurons possessed a synaptic process annotation in SynGO ${ }^{31}$

$441\left(p=1.1 \times 10^{-10}\right)$, with a particular enrichment for transcripts with presynaptic functions in

442 synaptic vesicle cycle (GO:0099504, p FDR adj $=6.12 \times 10^{-9}$, Fig. 4a, Table S9), while 35 of the

4431,328 downregulated transcripts, including five cis genes, had a SynGO annotation. We next

444 wondered whether these 239 synaptic genes were a major contributor to the schizophrenia

445 heritability enrichment we detected in the overall set of transcripts induced in deletion neurons.

446 Indeed, we found a marked reduction in the per SNP heritability for schizophrenia after

447 removing these 239 transcripts from the 2,864 that showed increased abundance in $22 \mathrm{q} 11.2$

448 deletion neurons (Fig. 4b). This reduction was greater than that observed when randomly drawn

449 lists of 239 transcripts were removed from the overall pool of 2,864 more abundant transcripts,

450 suggesting that this modest number of synaptic transcripts explained proportionally more of the

451 heritability than the rest.

452 A further gene ontology enrichment analysis revealed that genes induced in $22 \mathrm{q} 11.2$

453 neurons were significantly enriched for functions particularly in the protein ubiquitination

454 pathway $\left(\mathrm{GO}: 0000209,87\right.$ genes, $\left.\mathrm{OR}=2.13, \mathrm{q}=7.5 \times 10^{-8}\right)$ and with the largest individual

455 enrichment for regulation of synaptic vesicle exocytosis (GO:2000300, 14 genes $\mathrm{OR}=4.0$, q

$\left.456=2.3 \times 10^{-4}\right)($ Table S10). This enrichment with functions in protein homeostasis and synaptic

457 signaling was specific for induced genes in neurons. Conversely, in the genes induced in earlier

458 developmental stages, the enriched functions were related to developmental processes, including

459 tube morphogenesis and development, along with cell motility, migration and differentiation in

460 hPSCs and embryonic development and cardiac epithelial to mesenchymal transition in NPCs.

461 In comparison, genes reduced by the deletion in neurons highlighted exclusively functions in 
462 cilium assembly (GO:0060271, 54 genes, $\left.\mathrm{FC}=2.2, \mathrm{q}=6.4 \times 10^{-5}\right)$, while genes reduced in

463 hPSCs and NPCs were not enriched for any biological processes (Tables S11-S13). Together the

464 results of our gene ontology and PPI analyses converge on the same key pathways that are

465 regulated by the $22 \mathrm{q} 11.2$ deletion in each cell type. These results further demonstrate that the cell

466 type-specific effects of the deletion involve distinct biological functions that may have clinical

467 relevance for the phenotypic presentation in patients.

469 Enrichment for programs associated with activity dependent gene expression

To further investigate which cellular programs might mediate the changes in synaptic

471 gene expression and protein homeostasis observed upon 22q11.2 deletion, we carried out motif

472 enrichment analysis on the genes upregulated $(\mathrm{p}<0.05)$ in deletion carrier neurons to identify

473 transcription factor binding motifs that are enriched in this gene set. The motif that was most

474 significantly enriched was for binding of the $J U N / F O S$ transcription factors (1.6-fold

475 enrichment, $\mathrm{p}=10^{-14}$; Fig. 4c, Table S14). The $J U N$ and FOS transcription factors are immediate

476 early genes that are activated in response to neurotransmitter release and activate a downstream

477 “activity-dependent" transcriptional cascade to regulate downstream programs, such as protein

478 homeostasis and synaptic transmission ${ }^{48}$.

479 Notably, there was significant overlap $\left(p=5.57 \times 10^{-16}\right)$ between the genes altered in

480 deletion neurons that had synaptic ontologies (Table S9) and the altered genes that were targets

481 of $J U N / F O S$ (Table S14) suggesting that activity dependent gene expression downstream of

$482 J U N / F O S$ is a contributor to the synaptic signal that we detected in $22 \mathrm{q} 11.2$ deletion neurons.

483 Additionally, a further gene ontology enrichment analysis of the unique $J U N / F O S$ targets we 
484 identified (Table S14) revealed an enrichment of components of the protein ubiquitination

485 pathway (GO:0016567, 29 genes, $\mathrm{OR}=2.9$, $\mathrm{p}_{\text {FDR adj }}=0.00098$, Table $\left.\mathrm{S} 15\right)$.

486 Furthermore, transcript levels of $M E F 2 C$, an activity-dependent transcription factor

487 acting upstream of the JUN / FOS signaling pathway to regulate the expression of immediate

488 early genes ${ }^{48}$, are increased in 22 q11.2 deletion carrier NPCs in our discovery dataset (Table S2,

489 Fig. 4d, and validated by qPCR and immunoblotting, Extended Data Fig. 2f,g). MEF2C has been

490 shown to negatively regulate synaptic transmission by restricting the number of excitatory

491 synapses ${ }^{66,67}$. Additionally, TBX1, a transcription factor located in the 22q11.2 deletion region

492 and significantly downregulated in these same NPCs (Extended Data Fig. 2d,e), is a known

493 repressor of $M E F 2 C^{49,50}$. Thus, decreased $T B X 1$ levels due to loss of a copy of 22q11.2 likely

494 result in de-repression of the $M E F 2 C$ transcription factor, a regulator of the $J U N / F O S$ signaling

495 pathway, which in turn might reduce synaptic transmission.

496 Taken together, these results indicate that activity dependent gene expression is changed

497 in deletion carrier cells, likely impacting downstream protein homeostasis and synaptic

498 transmission.

\section{Reduced network activity in $22 q 11.2$ deletion neurons}

Overall, our data suggests that changes linked to the 22q11.2 deletion during the

502 development of excitatory neurons alter the balance of the $J U N / F O S$ transcriptional pathway,

503 which has well established roles in activity dependent gene expression ${ }^{48}$. We thus hypothesized

504 that the transcriptional activation of this pathway and its targets, which plays a role in reducing

505 synaptic transmission upon sustained activity ${ }^{48}$ might result in decreased network activity in

506 neuronal cultures with 22q11.2 deletion. 
We thus asked whether neurons from 22q11.2 deletion carriers exhibited changes in network activity. Previously, we had shown that by 42 days of excitatory differentiation, neurons

509 derived from control cell lines were spontaneously active and that their rate of firing was

510 governed almost entirely by network activity mediated through synaptic connectivity ${ }^{34}$. We used

511 multielectrode arrays (MEAs) to monitor neuronal network development and activity over 42

512 days of neuronal differentiation ${ }^{34}$. In neurons derived from patients with $22 \mathrm{q} 11.2$ deletion, we

513 detected a significantly lower spiking rate from 21 days of differentiation and onward, when

514 compared to controls $(\mathrm{N}=\mathrm{a}$ total of 162 wells from 21 cell lines) (Fig. 4e,f). We found this

515 result striking, as it was consistent with the notion that the altered abundance of synaptic

516 transcripts and activity-dependent gene expression we observed by RNA sequencing was

517 associated with functional effects on network activity in 22q11.2 deletion neurons.

519 Gene editing of the $22 q 11.2$ deletion

To complement our patient driven study and assess whether the 22q11.2 deletion was

521 sufficient to explain the transcriptional changes we observed in our patient-based discovery

522 cohort, we used CRISPR/Cas9 to engineer the 22q11.2 deletion in a human embryonic stem cell

523 line (H1/WA01). Using guide RNAs that cut within the low copy repeats (LCRs) flanking the

$5243 \mathrm{Mb} 22 \mathrm{q} 11.2$ deletion, we generated heterozygous $22 \mathrm{q} 11.2$ deletion cell lines at a very modest

525 frequency (2/1000), as well as many non-targeted but otherwise isogenic controls (Fig. 5a-d). We

526 then subjected the two deletion clones and two non-targeted control clones to neuronal

527 differentiation and performed RNA sequencing at the same differentiation stages we assessed

528 previously (d0 hPSCs, d4 NPCs and d28 excitatory neurons). In PCA, components one and two

529 separated each of the samples by differentiation state, with the stem cell, NPC and neuronal cell 
530 lines showing strong reproducibility of differentiation across replicates (Fig. 5e). Impressively,

531 components three and four then separated each of the samples based on their deletion status, with

532 22q11.2 deletion samples substantially separated from their non-targeted counterparts (Fig. 5f,

533 Extended Data Fig. 9a). This separation was not solely due to deleted cis genes as it persisted

534 upon removal of these genes from the PCA, indicating that it was a more global phenomenon in

535 the transcriptome of the edited lines. Importantly, the genes driving the separation in PC3 and

536 PC4 were largely shared by those detected differentially expressed in the discovery cohort. Out

537 of the top 100 negative and positive loadings for PC3, 79 and 83, respectively, were nominally

538 significantly changed also in neurons in the discovery cohort $(\mathrm{p}<0.05)$. For PC4, this overlap

539 was 39 and 60 out of 100, for negative and positive loadings, respectively.

540 We next proceeded to perform differential expression analysis to delineate transcriptional

541 changes present in clones edited to contain the 22q11.2 deletion (Tables S16-S18). As expected,

542 the edited lines showed systematic downregulation of genes in the deletion region at all cell

543 stages ( $\mathrm{p}=6 \times 10^{-61}$, Mann-Whitney test) (Fig. 5g) with 26, 25, and 29 deleted genes passing

544 individually FDR $<5 \%$ cutoff in the isogenic hPSCs, NPCs, and neurons. This further confirmed

545 successful introduction of the heterozygous $3 \mathrm{Mb}$ deletion in this background. Notably among

546 these and like the discovery set, $C A B 39 L$ was consistently upregulated at all differentiation

547 stages in lines with isogenic 22q11.2 deletion. Overall, we also observed a highly significant

548 number of genes exhibited aligned changes in transcript abundance between the discovery cohort

549 and edited samples $(\mathrm{p}<0.05)$ across all differentiated stages analyzed: hPSCs, 75\% $(200$ out of

$550268 \mathrm{p}=3 \times 10^{-16}$, binomial test); NPCs, $83 \%\left(124\right.$ out of $150 \mathrm{p}=1.7 \times 10^{-16}$, binomial test $)$ and

551 neurons, $76 \%$ (604 out of $791 p=5.6 \times 10^{-9}$, binomial test) with strongly correlated effect sizes

$552\left(\mathrm{r}_{\mathrm{hPSC}}=0.7, \mathrm{r}_{\mathrm{NPC}}=0.82, \mathrm{r}_{\text {neuron }}=0.56\right.$, Pearson correlation $)$; (Fig. 5h, Extended Data Fig. 9b,c). 
We next wondered whether the pathways and cellular programs that were altered in a

554 cell-type specific manner in our discovery dataset were also altered in the edited lines. To this

555 end, we examined the expression of genes contributing to the minimal PPI networks identified at

556 each cell stage in the discovery dataset (Fig 4g and Extended Data Fig. 8) and found that an

557 overwhelming majority of these genes are changed in the same direction in cells with isogenic

$55822 \mathrm{q} 11.2$ deletion at each stage, with $90 \%, 88 \%$ and $86 \%$ of the genes contributing to the PPI

559 network in stem cells, NPCs and neurons respectively, being altered in the same direction in the

560 isogenic dataset compared to the discovery dataset. Notably, the activity dependent gene

$561 M E F 2 C$ was also increased in NPCs of $\mathrm{H} 1$ deletion carrier cells compared to isogenic controls

562 (Fig. 5i, Extended Data Fig. 9d,e).

563 Furthermore, upon synaptic process annotation in SynGO we observed a replication of

564 the induction of genes $(p<0.05)$ involved in synaptic vesicle cycle and endocytosis in the edited 565 neurons with 22q11.2 deletion (GO: 0099504, pFDR adj = 0.0029) (Fig. 5j, Table S19). Overall, of 566 the 239 transcripts with synaptic functions in the discovery dataset (Fig. 4a), 49 were also more 567 abundant in neurons $(\mathrm{p}<0.05)$ harboring the engineered $22 \mathrm{q} 11.2$ deletion $($ Expected $=39$ genes, $568 \mathrm{p}<0.012$, binomial test), out of which 21 passed the FDR $<5 \%$ cutoff for significance.

570 be more abundant in 22q11.2 deletion carrier neurons were on average 0.29 standard deviations

571 (SDs) higher expressed in the edited lines (95\%-CI:0.18-0.41 SDs, $\mathrm{p}=3.9 \times 10^{-7}$, $\mathrm{t}$-test).

572 Moreover, 19 of these transcripts were individually significantly (FDR $<5 \%$ ) more abundant

573 after gene editing of the deletion ( $\mathrm{p}=0.03$ binomial test) supporting a causative connection

574 between the deletion genotype and altered transcript abundance for components in the ubiquitin-

575 proteasome system in neurons. Furthermore, 28 out of the $99 \mathrm{JUN}$ target genes induced in the 
576 discovery dataset were also induced in neurons with isogenic $22 \mathrm{q} 11.2$ deletion $(\mathrm{p}<0.05)(\mathrm{p}=$

5770.00046 , binomial, expected overlap $=14$ genes). Finally, encouraged by the replication of the

578 differential expression signal in the edited deletion lines, we examined these genes $(\mathrm{p}<0.05)$ for

579 association to schizophrenia. Remarkably, variants surrounding the induced genes in the edited

580 lines revealed significant gene-wise association to schizophrenia consistent with the observation

581 in the discovery cohort $\left(\beta=0.11, \mathrm{SE}=0.029, \mathrm{p}=6.6 \times 10^{-5}, \mathrm{~N}=1611\right.$ genes, MAGMA). Thus, we

582 conclude that the $22 \mathrm{q} 11.2$ deletion is indeed sufficient to explain most transcriptional effects we

583 found to be associated with the deletion in our case-control cohort, including those related to the

584 genetic risk for schizophrenia.

\section{Reduced pre-synaptic protein abundance in $22 q 11.2$ deletion neurons}

As an independent means of examining whether the 22q11.2 deletion impinged on

presynaptic components in excitatory neurons, we performed whole cell proteomics on day 28 neurons from two patients and two controls (Fig. 6a) As expected, peptides mapping to genes within the 22q11.2 interval were reduced in neurons harboring the deletion relative to levels in

591 controls (Fig. 6b; Table S20). Importantly, consistent with the altered expression of activity-dependent genes (Fig.

$5934 \mathrm{c}, \mathrm{d}, \mathrm{g}$ and Table 14), and the reduced synaptically-driven network activity in 22q11.2 deletion 594 neurons (Fig. 4 e,f), we found that proteins downregulated in 22q11.2 deletion neurons were 595 enriched for synaptic gene ontologies (Fig. 6c). In total, 184 of the proteins that were 596 downregulated in deletion carrier neurons had SynGO annotations. Of these, 68 were 597 upregulated at the transcriptional level. Additionally, 31 proteins were upregulated in deletion 
carrier neurons and had SynGO annotations; 4 of which were also upregulated at the mRNA level (Extended Data Fig. 9f).

601 presynaptic and specifically involved in synaptic vesicle cycle $\left(\mathrm{p}_{\mathrm{FDR} \text { adj }}=3.5 \times 10^{-19}\right)($ Fig. $6 \mathrm{c}$;

602 Table S21), and included Synaptotagmin 11 (SYT11), Neurexin-1 (NRXN-1), and Synaptic

603 Vesicle Glycoprotein 2A (SV2A). SV2A (Fig. 6d) regulates vesicle exocytosis into synapses

604 and works in presynaptic nerve terminals together with Synaptophysin and Synaptobrevin ${ }^{68,69}$.

605 We note this finding also converges with genetic studies as rare variants in SV2A have been

606 shown to be significantly associated with schizophrenia ${ }^{65,70}$. Similarly, $N R N X 1$ has established

607 roles in schizophrenia ${ }^{65,71,72}$ and SYT11, located on the chromosome locus 1q21-q22 may be a

608 risk gene for schizophrenia ${ }^{73}$. We confirmed the decreased expression of SV2A (Fig. 6e), along

609 with the reduction of protein levels of SYT11 (Extended Data Fig. 9g) and NRXN1 (Extended

610 Data Fig. 9h) in 22q11.2 deletion neurons by immunostaining or immunoblotting. Additional

611 proteins with schizophrenia rare variant associations (via the SCHEMA consortium ${ }^{65}$ ) altered in

612 22q11.2 deletion neurons included DNM3, MAGI2 and TRIO (downregulated in patient

613 neurons) and HIST1H1E, SRRM2 and ZMYM2 (upregulated in patient neurons) (Table S21).

\section{Discussion}

Here we have explored the transcriptional and functional consequences of the $22 \mathrm{q} 11.2$

617 deletion on human neuronal differentiation. Our findings lead to several new insights into the

618 biology of 22q11.2 deletion syndrome and how it confers risk for the development of varied

619 psychiatric disorders as neural development and differentiation unfold. Notably, we found that

620 the genes whose expression is perturbed in deletion carriers directly connect the effects of the 
621 deletion on neuropsychiatric phenotypes to genes and pathways implicated in NDD, ASD and

622 schizophrenia through prior large-scale exome sequencing and GWAS studies $27,28,32,45-47,63,64,74$.

623 Thus, rather than working through independent mechanisms, our studies suggest the deletion

624 confers risk for these various conditions at least in part by converging on the same gene products

625 and pathways that are more widely disturbed in other patients.

626 We used a new tool that we developed and report here to ask which minimal PPI

627 networks best explain the changes in gene expression we observed. This analysis revealed that a

628 surprising number of deletion components likely play a role in the transcriptional signals. We

629 therefore propose a model in which reduced abundance of multiple factors within the deletion

630 region leads to highly distributed effects on many genes outside the deletion. Through the course

631 of development, the deletion affects distinct sets of genes. In stem cells and neuronal progenitor

632 cells the deletion impacts pathways linked to proliferation, NOGO signaling and RNA

633 metabolism. In neurons, the deletion alters activity-dependent gene expression, protein

634 homeostasis and ultimately, presynaptic biology. Overall, it was notable that $M E F 2 C$, an

635 activity dependent transcription factor and negative regulator of excitatory synaptic density ${ }^{66,67}$ is

636 overexpressed in NPCs with 22q11.2 deletion, likely due to the loss of one copy of $T B X 1$, a

637 known $M E F 2 C$ inhibitor located in the $22 \mathrm{q} 11.2$ interval $^{49,50}$. Increased expression of $M E F 2 C$,

638 could, in turn, lead to premature activation of the JUN and FOS pathway, which would be

639 predicted to result in reduced network activity and synaptic connectivity.

640 To directly test this idea, we examined whether neurons from 22q11.2 deletion carriers

641 displayed reduced synaptic functionality. Using a network activity assay in these cells, which we

642 have previously shown was largely driven by a mixture of AMPA and NMDA receptor mediated

643 transmission ${ }^{34}$, we indeed found this to be the case. Many of the patients' neurons showed a 
644 significant overall reduction in network activity relative to controls. Thus, the deletion was not

645 only associated with induction of activity dependent gene expression, but also associated with

646 aligned changes in neuronal function. Based on these findings, we would thus expect a decreased

647 expression of synaptic proteins, which we do, indeed, detect.

Our proteomic examination of 22q11.2 deletion neurons afforded an orthogonal

649 examination of synaptic components in these cells and independently identified significant

650 presynaptic alterations, including alterations in components that we could not ascertain by RNA

651 sequencing such as the schizophrenia associated gene SV2A, a key mediator of pre-synaptic

652 function. This last result is of translational and therapeutic importance given the existence of a

653 positron emission tomography (PET) radiotracer specific for SV2A based on the drug

654 Levetiracetam which now enables the in vivo investigation of presynaptic protein levels in the

655 patient brain $^{75}$. Interestingly, a recent PET-imaging study utilizing this SV2A radiotracer found a

656 significant reduction in the abundance of this presynaptic component in the cortex of

657 schizophrenia patients relative to controls ${ }^{76}$. Careful genotyping of this schizophrenia patient

658 population was not carried out prior to imaging and our results suggest that a more specific study

659 examining SV2A levels in 22q11.2 deletion carriers of varying diagnoses would be warranted.

660 Early during neuronal differentiation, we found that a significant number of the genes

661 differentially expressed in deletion carriers had been previously linked to damaging or LoF

662 sequence variants more widely identified in NDD and ASD. This enrichment for overlap

663 between broader genetic signals in ASD and the effects of the 22q11.2 deletion was very

664 significant when we considered the known biochemical interaction partners of gene products

665 implicated in ASD. These findings are consistent with smaller scale studies investigating 
666 transcriptional effects of individual genes, such as FOXP1 or CHD8, linked with autism, and

667 found to regulate the expression of ASD-relevant pathways ${ }^{77,78}$.

668 Interestingly, as differentiation proceeded and cells took on a post-mitotic, excitatory

669 neuronal identity, the effects of the 22q11.2 CNV on expression of genes outside of the deletion

670 lost enrichment for genes implicated in NDD/ASD and acquired an enrichment for genes

671 harboring rare inactivating exome variants preferentially associated with schizophrenia. The

672 influence of the 22q11.2 deletion on expression of neuronal genes associated with schizophrenia

673 was not limited to those impacted by rare schizophrenia mutations acting with large effect. We

674 also found that the deletion affected neuronal genes that were in linkage disequilibrium with

675 common genetic variants associated with schizophrenia, a result replicated using genotypic data

676 from two independent GWAS studies. Just as signal from ASD/NDD associated genes was

677 absent in the neuronal stage of differentiation, the enrichment for effects on schizophrenia

678 associated genes was absent in stem cells and NPCs. This surprisingly selective signal is likely to

679 reflect stage-specific cellular programs, such as synaptic processes (for example those listed in

680 Tables S9, S19 and S20) being specific to neurons.

681 We found these transcriptional results striking as NDD and ASD are linked to biological

682 processes acting early in brain development ${ }^{79}$, while sequence variants associated with

683 schizophrenia have been previously shown to be enriched for genes expressed in excitatory

684 neurons and more recently for genes functioning in excitatory synaptic transmission ${ }^{80}$. It is

685 important to note that our findings were not merely the result of looking at a chance list of genes

686 in cell types clearly impacted in these diseases. While we did find that the overall gene

687 expression profile of our excitatory neurons was enriched for expression of genes implicated in

688 schizophrenia, the specific transcripts induced by the 22q11.2 deletion showed significantly 
greater enrichment in all tests we performed. Thus, we hypothesize that by looking in a human cell type with disease relevant biology, we were able to identify previously unappreciated effects

691 of the $22 \mathrm{q} 11.2$ deletion.

693 CNVs such as 22q11.2 deletion likely interact with risk variants in the genetic background ${ }^{23-25}$.

694 Transgenic mice carrying syntenic deletions that model the human 22q11.2 deletion have

695 produced a wealth of datasets around neurodevelopmental abnormalities linked to the deletion or

696 to individual genes within the region ${ }^{13,20,81}$. It is, however, important to keep in mind that such

697 transgenic mice do not have genetic backgrounds harboring human polygenic risk alleles, which

698 explain the majority of heritable variation in schizophrenia and other psychiatric phenotypes ${ }^{47}$.

699 Therefore, while non-human model systems offer invaluable biological insight, they fall short of

700 reproducing human specific gene regulatory effects underlying complex human disorders.

$701 \quad$ Individual genes within the 22q11.2 region have been at the center of several studies

702 aiming to identify causal genes underlying the $22 q 11.2$ deletion syndrome. Several of these

703 studies, using rodent, and more recently, human ${ }^{41}$ models, have reported defects in synaptic

704 processes and brain connectivity ${ }^{82-84}$, many with a focus on $\operatorname{Dgcr} 8$, which encodes a subunit of

705 the microprocessor complex which mediates microRNA biogenesis ${ }^{13}$. Khan et $\mathrm{al}^{41}$ identified a

706 calcium signaling defect in organoids containing mixed cell types derived from 22q11.2 deletion

707 and controls individuals, which could then be rescued by DGCR8 overexpression. Whether these

708 phenotypes can be recapitulated with a scaled sample set and defined cell types remains to be

709 seen. At face value, alterations in DGCR8 might seem like a promising candidate for the

710 distributed effects on gene expression we observed across many transcripts. However, reduced

711 microRNA function from lower $D G C R 8$ copy number would predict an increased rather than 
712 decreased abundance of the synaptic proteins we found. Another candidate, DGCR5, which

713 encodes a long non-coding RNA within the 22q11.2 interval, has previously been shown to

714 regulate several transcripts encoding genes associated with schizophrenia ${ }^{85}$. However, that study

715 found that reducing the function of DGCR5 lead to a reduction in the expression of its targets,

716 again the inverse of our finding.

717 A challenge in studying psychiatric conditions has been that it is difficult to establish

718 causal relationships between genetic variants of interest and their effects. In this study we

719 utilized CRISPR/Cas9 to generate the 22q11.2 deletion in a control human stem cell line by

720 inducing double strand breaks within the same repetitive elements that are normally important

721 mediators of the deletion. While the process was relatively inefficient, we were able to obtain

722 two independent clones that carried this large structural variant on one of the two alleles. Using

723 these edited cells, we could then ask, without confounding by inherited variation elsewhere in the

724 genome, which associations we had previously observed was the deletion sufficient to cause. We

725 found that the deletion in this isogenic setting was sufficient to induce significant and aligned

726 alterations in the expression of genes contributing to the minimal PPI network at each of the

727 three differentiation stages, including changes, in neurons, in the activity-dependent, presynaptic,

728 and ubiquitin/proteasome pathways as well as the heritability enrichment for schizophrenia.

729 When combined with genetic findings from $22 \mathrm{q} 11.2$ patients $^{23-25}$, our observations lead

730 us to a model in which the 22q11.2 deletion exerts a strong effect on genetic risk factors for

731 NDD and ASD genes early in differentiation, while in more differentiated neurons the gene

732 regulatory influence of the deletion shifts to risk factors for schizophrenia. Our gene editing

733 experiments suggest that these distinct "pushes" on NDD/ASD and schizophrenia risk occur

734 regardless of one's genotype. 
How exactly the 22q11.2 deletion might regulate the expression of genes outside of the deletion region remains a matter of great interest. Many studies have highlighted the role of

737 miRNAs as possible mediators of some of the phenotypes, particularly given that $D G C R 8$ is

738 located within the region. However, as discussed earlier, reduced levels of DCGR8 would not

739 explain our finding of reduced synaptic proteins. One intriguing possibility is that $22 \mathrm{q} 11.2$

740 deletion might impact chromatin architecture, thereby regulating the expression of genes outside

741 of the deletion region. Spatial organization of the genome has been shown to play a critical role

742 in cell type-specific regulation of transcription ${ }^{86}$, and structural variants, such as CNVs, have

743 been shown to alter chromatin architecture, leading to disease ${ }^{87}$. The $22 \mathrm{q} 11.2$ deletion lacks a

744 large portion of chromosome $22^{43}$, which might impact chromatin organization. Indeed, a recent

745 study using lymphoblastoid cell lines with 22q11.2 deletion revealed changes in their genome

746 architecture ${ }^{88}$. It is thus possible that the $22 \mathrm{q} 11.2$ deletion spatially rearranges the genome of

747 neuronal cells, resulting in mis-regulation of genes linked to neuropsychiatric disorders.

748 The current study is not without its limitations. Even though it is, to our knowledge, one

749 of the largest of the effect of 22q11.2 deletion on human neuronal cells, our current sample size

750 still falls shorts of enabling us to stratify the cohort by diagnosis, age, sex, or deletion size.

751 Future studies with even larger sample sets could be sufficiently powered to enable the

752 comparison of cells from 22q11.2 deletion patients with or without schizophrenia, or with or

753 without intellectual disability or ASD, for example, to more comprehensively delineate the

754 cellular and transcriptional changes associated with each diagnosis. It would also be interesting

755 to stratify the cohort with respect to deletion size: while the $3 \mathrm{Mb}$ deletion is by far the most

756 common, accounting for around $90 \%$ of cases, smaller nested deletions within the region still

757 result in similar symptoms and diagnoses $3,7,38,39$. While the current study only includes two such 
758 shorter deletions, larger studies could be better poised to identify common and distinct signatures

759 of the distinct deletions. Other interesting co-variates to examine include donor age and sex,

760 which do not appear to drive any of the transcriptional differences and signatures we report here

761 but might result in subtle differences that could be detected with a larger sample set.

762 Collectively, the novel iPSC lines, CRISPR edited cell lines, RNA sequencing data and

763 functional phenotypes we report here will provide a framework for evaluating future therapeutic

764 targets and candidates for 22q11.2 carriers. These $22 \mathrm{q} 11.2$ carriers represent an interesting

765 population for drug discovery as they are a group of individuals with more homogenous, yet still

766 textured risk of these psychiatric illnesses. For instance, with the tools we report here, it should

767 be possible to quantitatively address which combinations of the immediate consequences of the

768 deletion most contribute to various components of the gene expression effects we have observed,

769 including deficits in expression of presynaptic proteins. While these efforts are beyond the scope

770 of our current study, we suggest that as aspects of the gene expression signal we observed are

771 rescued, the functional relevance of such findings could be tested in the context of whether

772 neuronal network activity is also restored in patient neurons. Through this approach, the likely

773 multifaceted contributors to psychiatric illness that the 22q11.2 deletion confers could be

774 quantitatively deciphered and the best approaches for alleviating its effects identified.

776 Acknowledgements

777 We thank the many donors, institutions and investigators world-wide that provided their cell

778 lines and supported the publication of the results. We are indebted to Maura Charlton, Genevieve

779 Saphier and Kristen Elwell for their assistance with the regulatory and logistical efforts required

780 to acquire and sequence hiPSC lines. We regret the omission of any relevant references or 
781 discussion due to space limitations. The Genomics Platform at the Broad Institute performed

782 sample preparation, sequencing, and data storage. This work was funded predominantly by

783 U01MH105669 (NIH/NIMH), with additional support from the Stanley Center for Psychiatric

784 Research at the Broad Institute, R37NS083524 and U01MH115727. RN was also supported by a

785 NARSAD young investigator award (Brain and Behavior Research Foundation) and a Bn10

786 grant (Broad Institute), and OP was also supported by the Sigrid Juselius Foundation, Orion

787 Research Foundation, Instrumentarium Science Foundation, and Päivikki and Sakari Sohlberg

788 Foundation.

\section{Data Availability Statement}

791 The raw sequence datasets generated during the current study are not currently publicly available

792 due to patient confidentiality and multiple different consents of population cohorts used but

793 subsets of the data are available from the corresponding authors on reasonable request. Computer

794 code relevant to the PPI analysis has been deposited in GitHub

795 (https://github.com/alexloboda/PPItools). Other computer code and data analysis will be made

796 available upon request.

\section{Author contributions}

799 R.N., O.P. and K.E. conceived the work, designed the experiments, analyzed the data and wrote

800 the manuscript. R.N. supervised and performed the experiments, with help from A.T., C.B.,

801 M.T., R.M., E.J.G., V.V., D.H., E.P., and E.Z. O.P. performed the computational analysis, with

802 help from M.T. and G.G. M.A. performed the PPI analysis, with help from A.L. and supervision

803 from M.D. C.B. performed the proteomics experiments with help from J.A.P. and supervision 
804 from J.W.H. A.G. carried out the SNP heritability analysis, with oversight from B.N. T.S. carried

805 out the rare variant analysis. J.S. performed the MEA analysis. D.M., A.B., A.M.B. and D.Z.H.

806 carried out the CRISPR editing, supervised by L.E.B. A.N. and C.L. assisted with stem cell

807 compliance and data deposition. O.K., E.H., and M.K. provided the NFID cell lines, with

808 oversight from A.P. C.M.H. and A.K.K. contributed the KI cell lines. B.C. and D.M. provided

809 cell lines from Mclean Hospital. J.M., R.A. provided the Umea samples, R.D. provided the

810 Stanford cell lines, and R.P. provided the MGH cell line. S.M. and S.H. provided guidance

811 throughout the project.

812

813 Competing interests

814 K.E. is Group Vice President, Head of Research and Early Development at Biomarin

815 Pharmaceuticals and a founder of Q-state Biosciences, Quralis and Enclear. J.W.H. is a founder

816 and advisor of Caraway Therapeutics. 
bioRxiv preprint doi: https://doi.org/10.1101/2021.09.22.461360; this version posted September 22, 2021. The copyright holder for this preprint (which was not certified by peer review) is the author/funder, who has granted bioRxiv a license to display the preprint in perpetuity. It is made available under aCC-BY 4.0 International license.

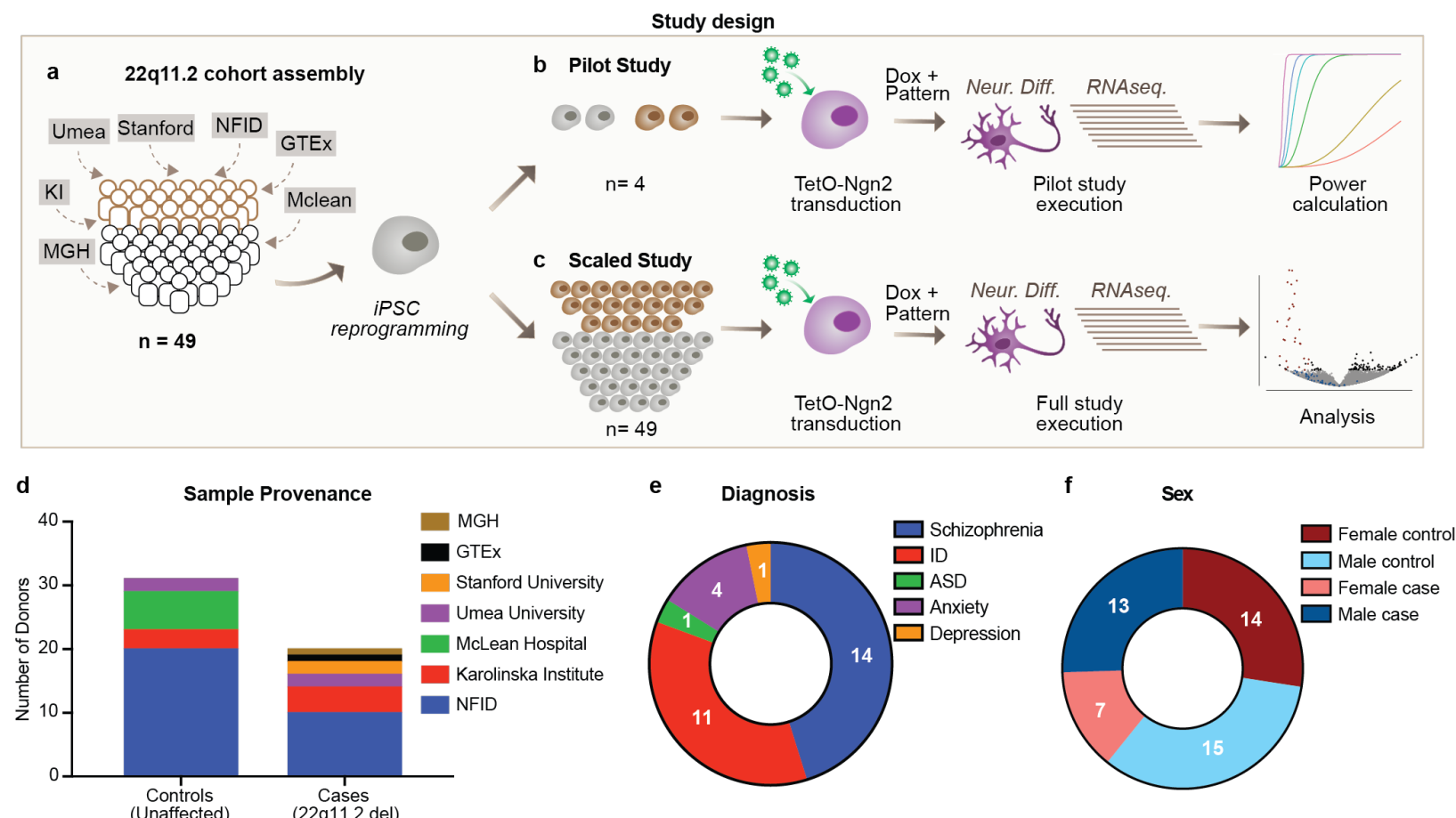

g

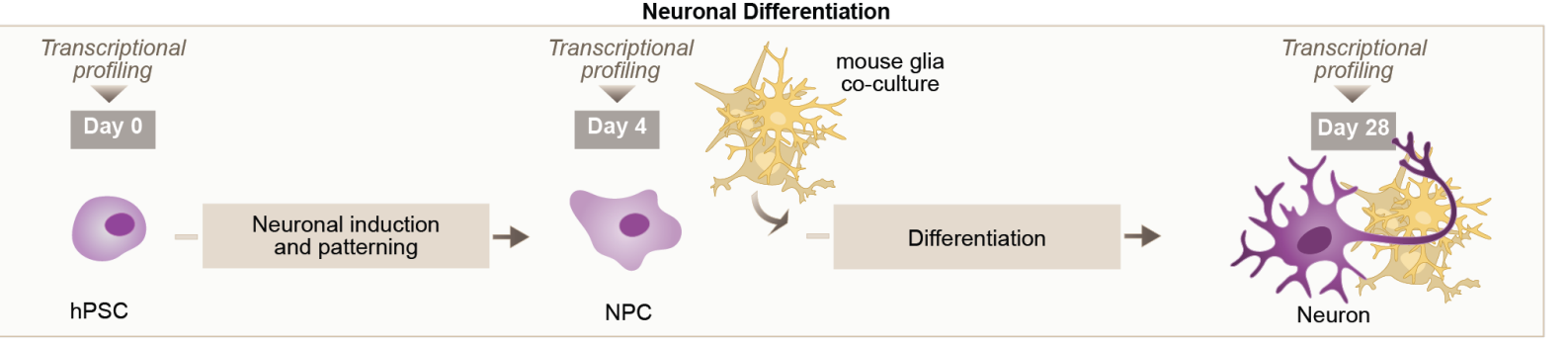

$\mathbf{h}$
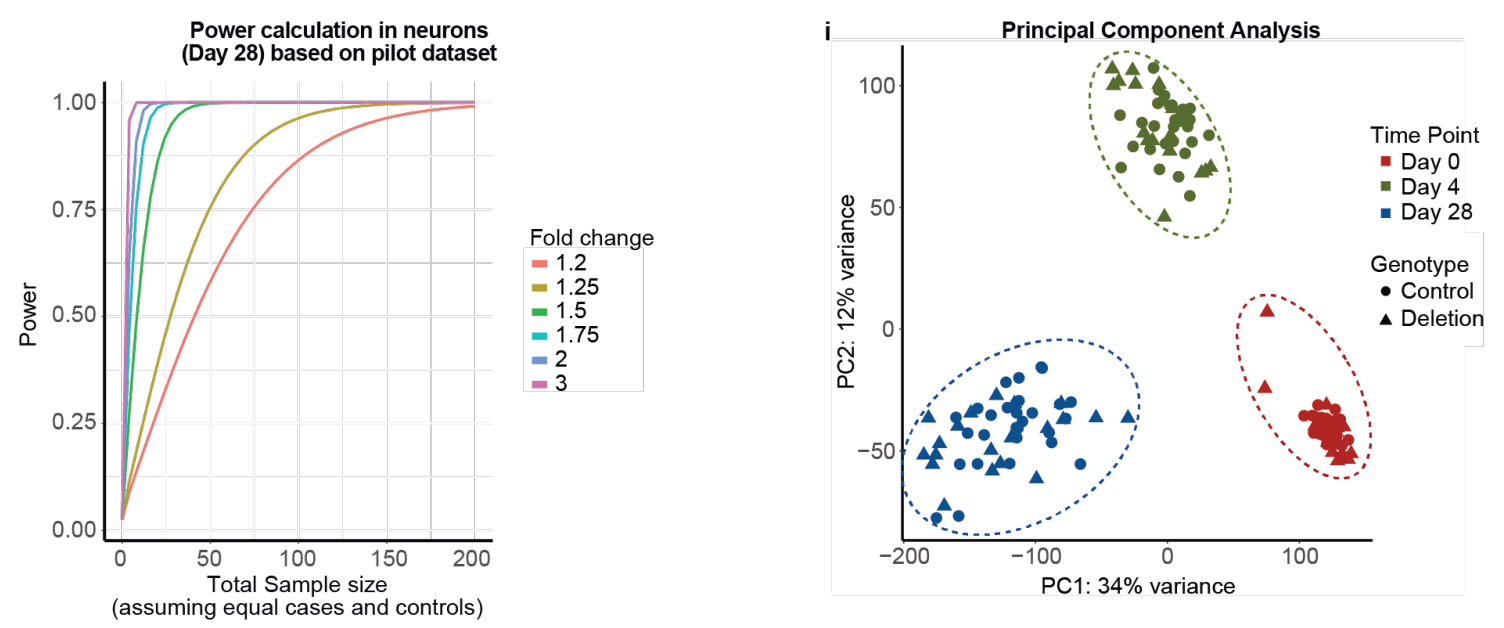

Fig. 1. Design of a statistically powered study to determine the impact of 22q11.2 deletion on gene expression. a, Final sample set composed of 20 cell lines with 22q11.2 deletion (brown) and 29 controls (grey), collected at seven locations (MGH: Massachusetts General Hospital, KI: Karolinska Institute, Umea: Umeå University, NFID: Northern Finnish Intellectual Disability Cohort (Institute for Molecular Medicine Finland), GTEx: Genotype-Tissue Expression Project, Mclean: Mclean Hospital) b, Pilot study using four hiPSC lines differentiated into neurons through transduction with TetO-Ngn2, Ub-rtTA and TetO-GFP lentivirus and subjected to RNA sequencing. RNA abundances were then used to estimate the appropriate sample size for differential gene expression for the final study. c, The final dataset consisted of 49 cell lines that were differentiated and subjected to RNA sequencing. d, Provenance e, Diagnosis and $\mathbf{f}$, Sex of the samples in the final cohort. g, Neuronal differentiation protocol, previously published and characterized ${ }^{34,37}$ consisting of the combination of Ngn 2 overexpression with 
bioRxiv preprint doi: https://doi.org/10.1101/2021.09.22.461360; this version posted September 22, 2021. The copyright holder for this preprint (which was not certified by peer review) is the author/funder, who has granted bioRxiv a license to display the preprint in perpetuity. It is made available under aCC-BY 4.0 International license.

forebrain patterning using small molecules (SB431542, LDN193189 and XAV939). Samples were harvested for RNA sequencing at the stem cell (day 0), neuronal progenitor cell (NPCs) (day 4) and neuronal (day 28) stages. h, Power estimation in the pilot dataset for median expressed genes (24 read counts) for different fold-changes and sample sizes in neurons. i, Principal component analysis (PCA) of RNA sequencing data from the full study.

a

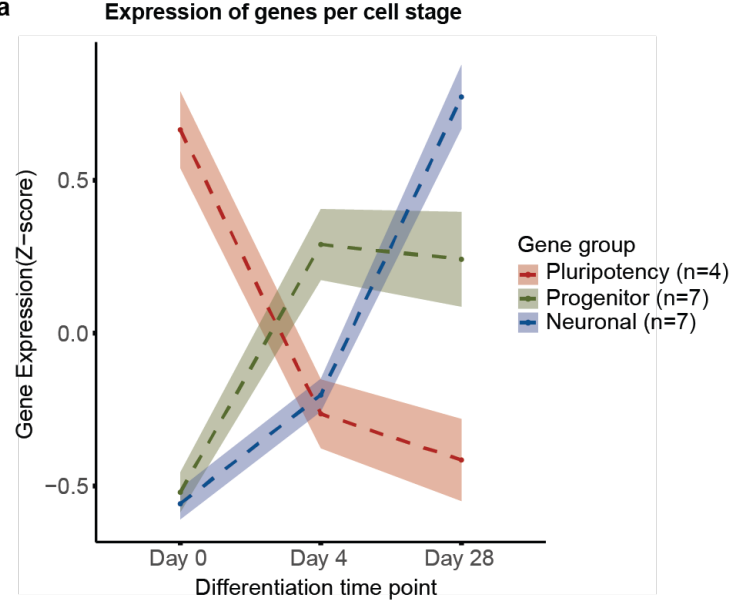

b Influence of time on differentially expressed genes

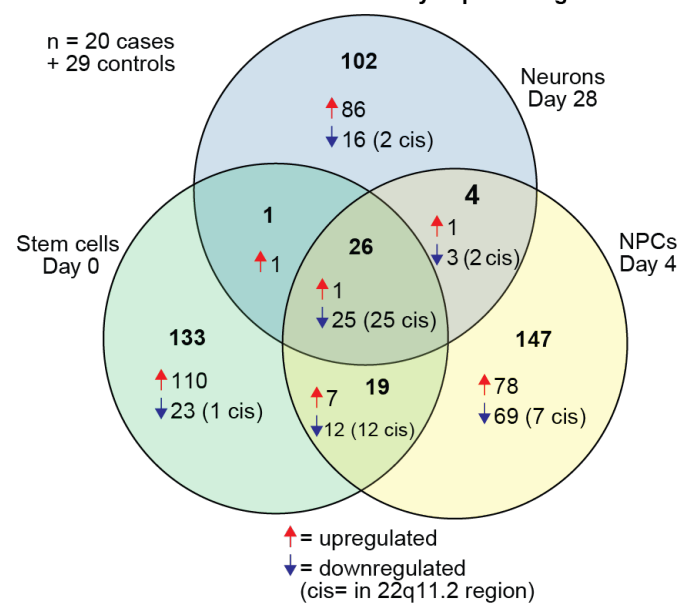

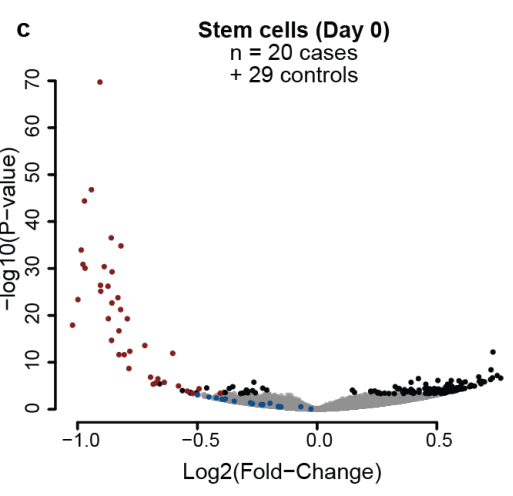

- significant 22q11.2 cis genes d

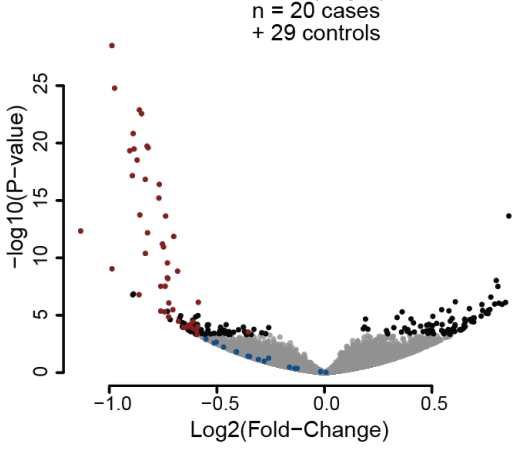

significant trans genes

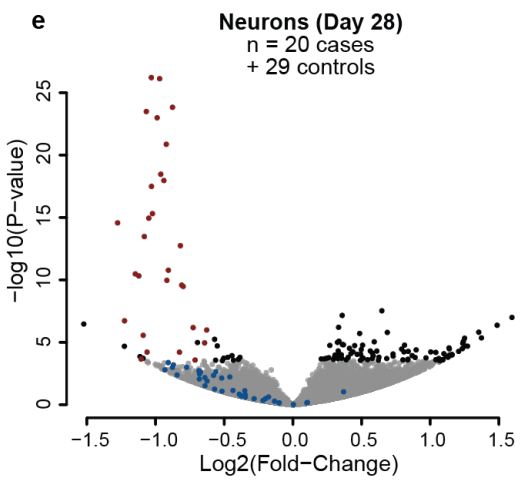

- non-significant trans genes

Fig. 2. Cell-type specific effects of the 22q11.2 deletion. a, Expression of selected marker genes for defined specific cell stages by suppression of genes related to pluripotency $(S O X 2, O C T 4, N A N O G, M K I 67)$ and up-regulation of genes characteristic for neural progenitor cells (NEUROD1, SOX2, EMX2, OTX2, HES1, MSI1, MKI67) and mature neurons (NEUN, SYN1, DCX, MAP2, $T U J 1, N C A M, M A P T$ ) as the differentiation progresses (gene lists also provided in Extended Data Fig. 2c). b, Venn Diagramm highlighting the number and directionality of shared and unique differentially expressed genes between deletion carriers and controls at each cell stage. Genes within the deletion region (cis) are mostly shared across development stages, whereas genes outside the deletion region (trans) are cell-stage specific. c-e, Volcano plots showing differential gene expression in stem cells (c), NPCs (d) and neurons (e) Significantly differentially expressed genes (FDR $<5 \%$ ) within the deletion region are presented in red and outside deletion in black. Non-significant genes in deletion region are presented in blue. 
bioRxiv preprint doi: https://doi.org/10.1101/2021.09.22.461360; this version posted September 22, 2021. The copyright holder for this preprint (which was not certified by peer review) is the author/funder, who has granted bioRxiv a license to display the preprint in perpetuity. It is made available under aCC-BY 4.0 International license.

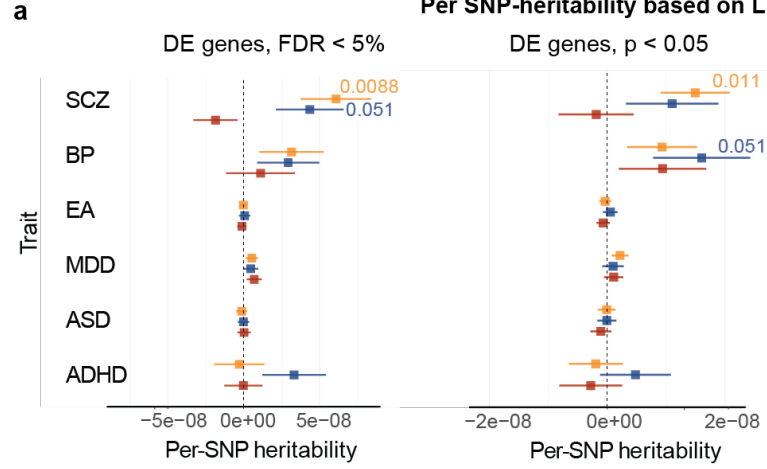

b 25 . DE genes in schizophrenia polygenic risk

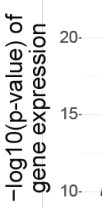

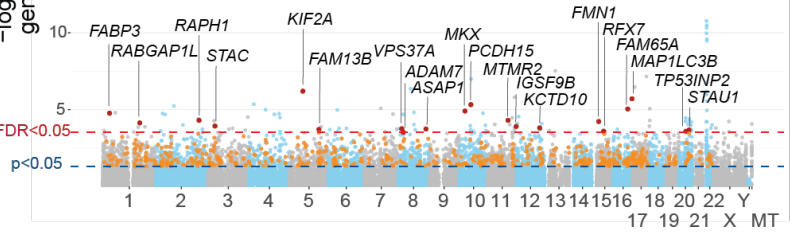

Gene position (chromosome)

d Enrichment of genes with rare variants in SCZ in neurons

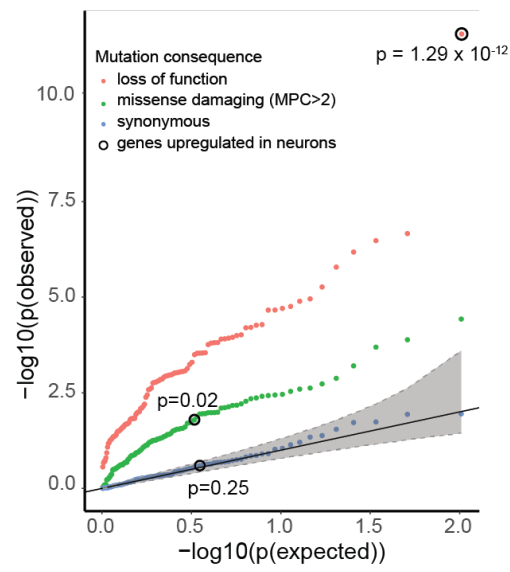

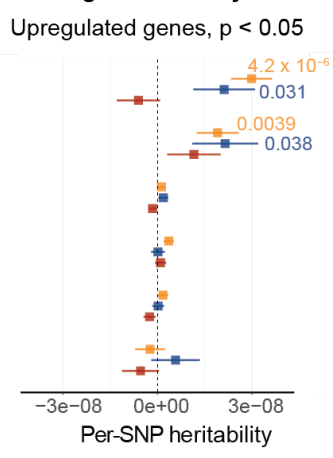

Downregulated genes, $\mathrm{p}<0.05$

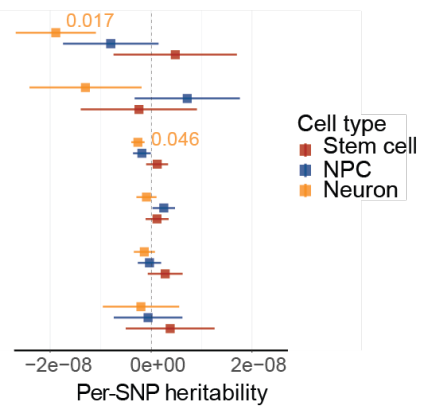

c Heritability enrichment for DE genes in neurons in the UK Biobank

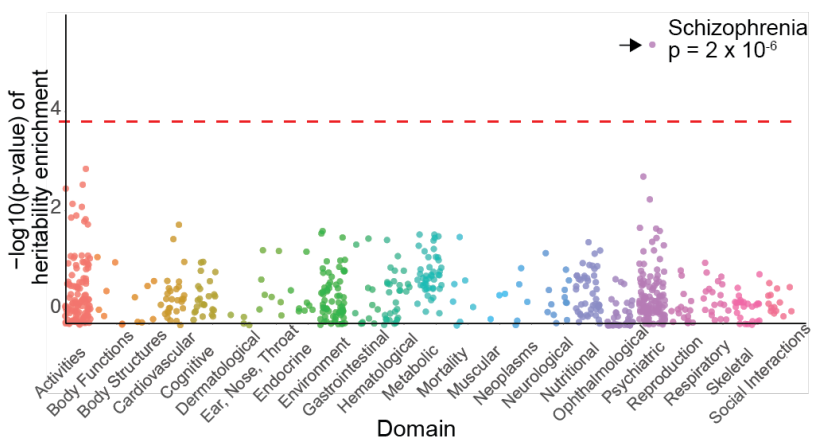

Fig. 3. Heritability enrichment for schizophrenia risk genes 22q11.2 deletion neurons. a, Marginal enrichment in per-SNP heritability explained by common (MAF $>5 \%$ ) variants within $100 \mathrm{~kb}$ of genes differentially expressed, estimated by LD Score regression. Six traits were analyzed: $\mathrm{SCZ}=$ schizophrenia, $\mathrm{BP}=$ bipolar disorder, $\mathrm{EA}=$ educational attainment, $\mathrm{MDD}=$ major depressive disorder, $\mathrm{ASD}=$ autism spectrum disorder, $\mathrm{ADHD}=$ attention deficit hyperactivity disorder, at all three cell stages, showing enrichment for schizophrenia most prominently in genes upregulated in 22q11.2 deletion neurons. $D E=$ differentially expressed. Four groups of DE genes were analyzed. Right, all DE genes with an FDR $<5 \%$. Middle right, all nominally significant DE genes $(p<0.05)$. Middle left, all nominally significant upregulated DE genes $(p<0.05)$. Left, all nominally significant downregulated DE genes $(p<0.05)$. $\mathbf{b}$, DE genes in $22 \mathrm{q} 11.2$ neurons with nominally significant gene-wise association to schizophrenia from MAGMA $\left(\mathrm{p}_{\mathrm{g}}<0.05\right)$. c, GWAS summary statistics for 650 traits from the UK-biobank showing significant enrichment for heritability only for schizophrenia $\left(\mathrm{p}=2 \times 10^{-6}\right)$ in genes upregulated in deletion neurons. d, qq plot of $\mathrm{p}$-values for the enrichment of rare coding LoF, missense damaging or synonymous variants in schizophrenia patients in genes upregulated in 863 deletion neurons (circled in black) and 100 random gene sets matched by expression level to the upregulated genes. 
bioRxiv preprint doi: https://doi.org/10.1101/2021.09.22.461360; this version posted September 22, 2021. The copyright holder for this preprint (which was not certified by peer review) is the author/funder, who has granted bioRxiv a license to display the preprint in perpetuity. It is made available under aCC-BY 4.0 International license.
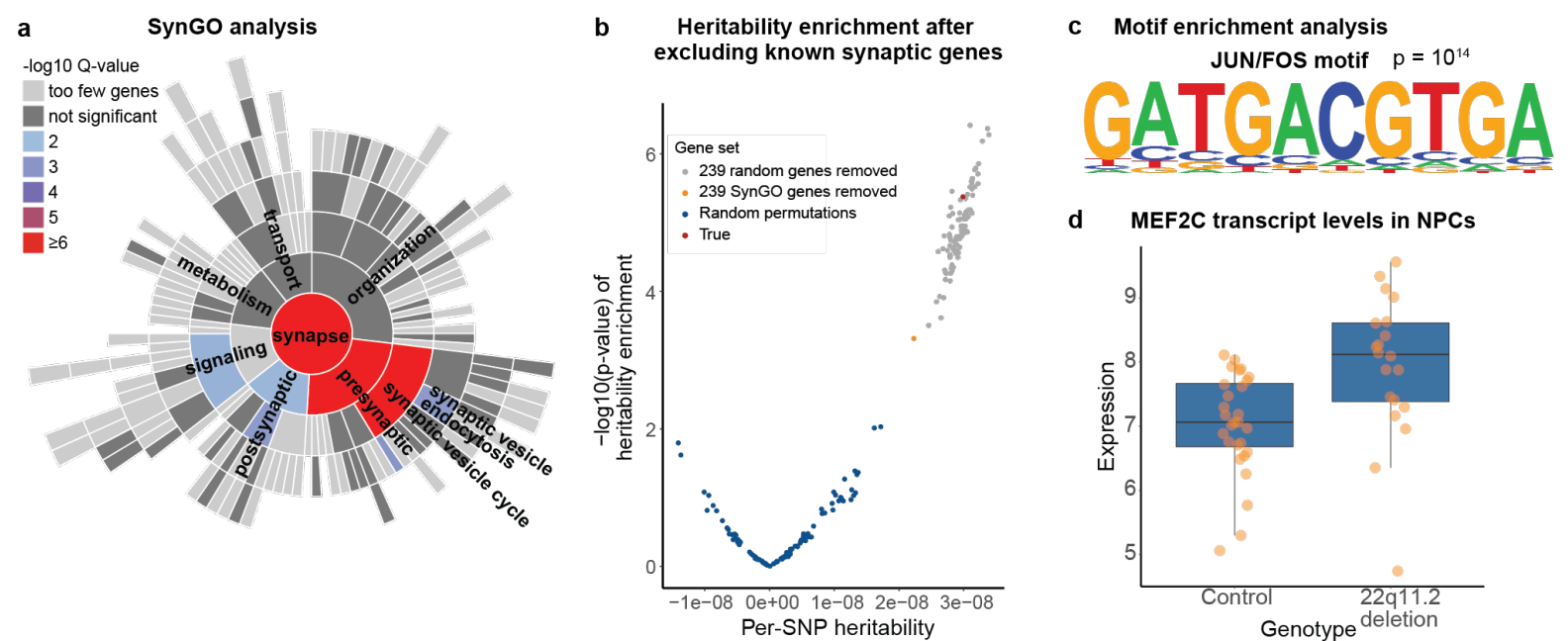

MEA analysis of neurons from case-control cohort

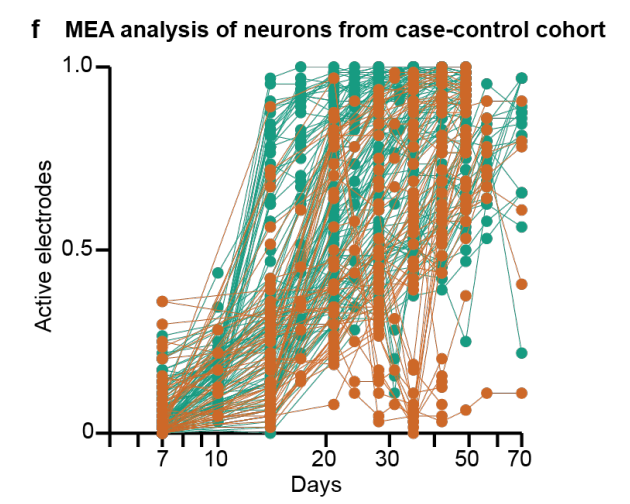

g PPI network in Neurons (Day 28)
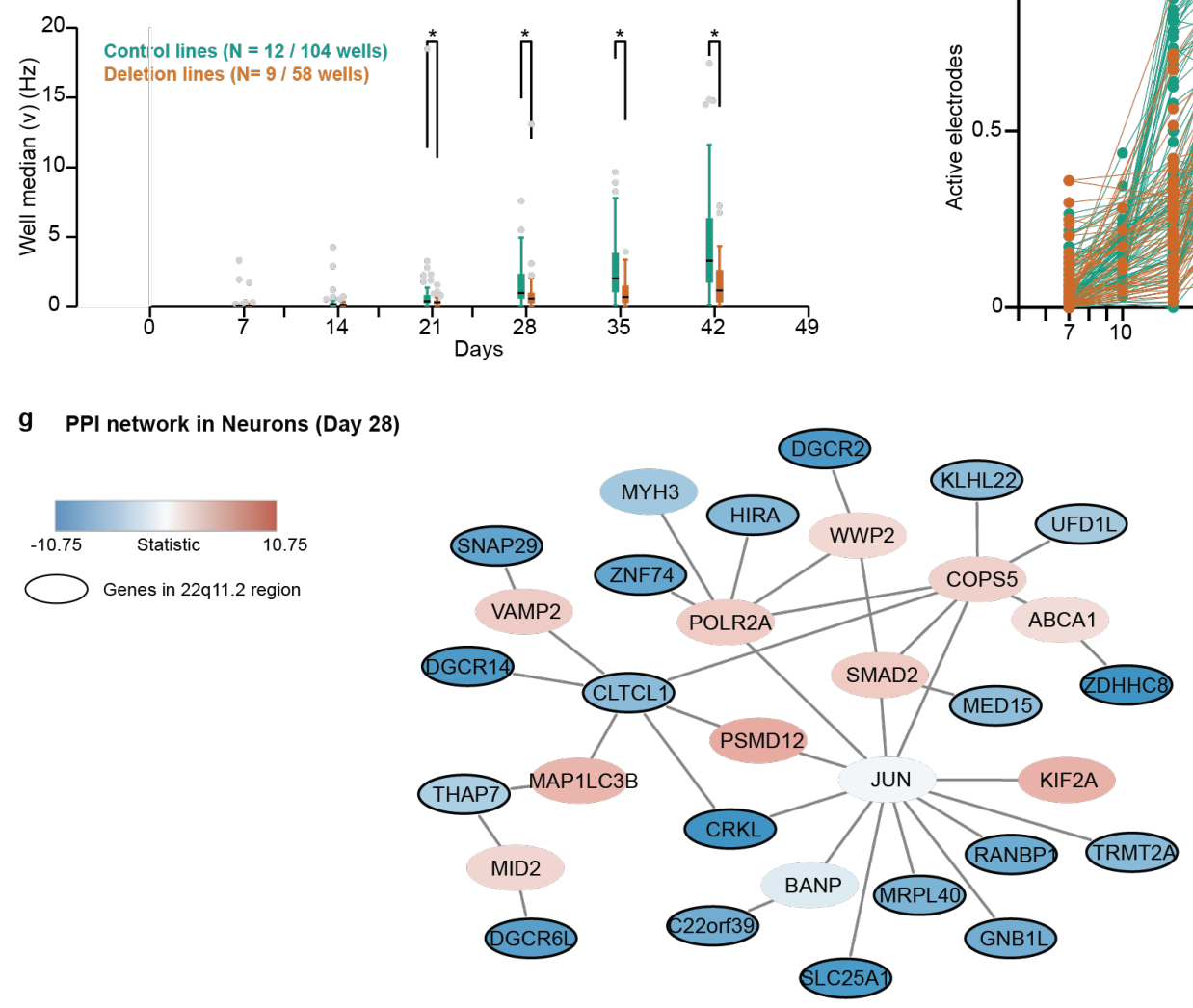

Fig. 4. Impact of the 22q11.2 deletion on synaptic gene expression and network activity. a, SynGO annotation for genes upregulated in neurons showing enrichment for synaptic processes. b. Heritability enrichment for schizophrenia after excluding the 239 genes with SynGO annotation. c, Motif Enrichment analysis in upregulated genes $(p<0.05)$, showing enrichment of JUN / FOS targets. d, $M E F 2 C$ is upregulated in NPC of 22q11.2 deletion carriers. e, Spike count (mean number of spikes in a 10 second period). The activity of neurons derived from control (green, $\mathrm{N}=12$ lines, 104 wells) is compared to neurons from cases with 22q11.2 deletion ( $\mathrm{N}=9$ lines, 54 wells). f, Proportion of electrodes detecting spontaneous activity, against the number of days post-induction. $\mathbf{g}$, The most weighted sub-cluster graph for protein-protein interactions (PPI) for differentially expressed genes in neurons. 
bioRxiv preprint doi: https://doi.org/10.1101/2021.09.22.461360; this version posted September 22, 2021. The copyright holder for this preprint (which was not certified by peer review) is the author/funder, who has granted bioRxiv a license to display the preprint in perpetuity. It is made available under aCC-BY 4.0 International license.

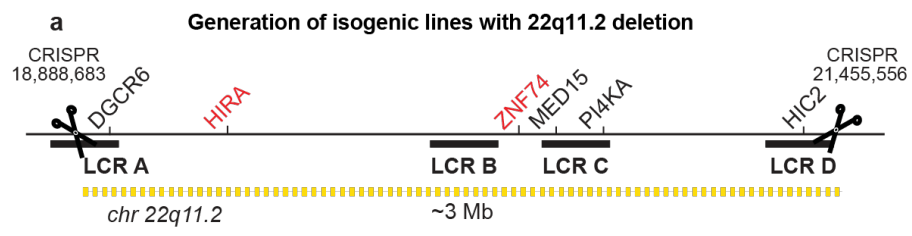

b Detection of 22q11.2 deletion by DNA FISH
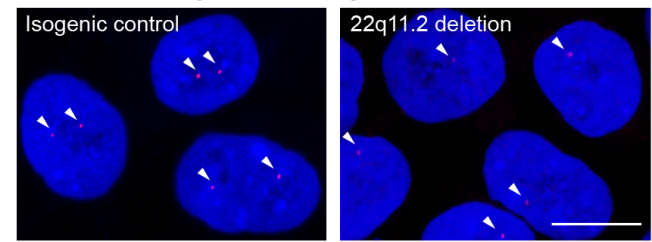

C 3 Cas9 nuclease mediated deletion detected by ddPCR
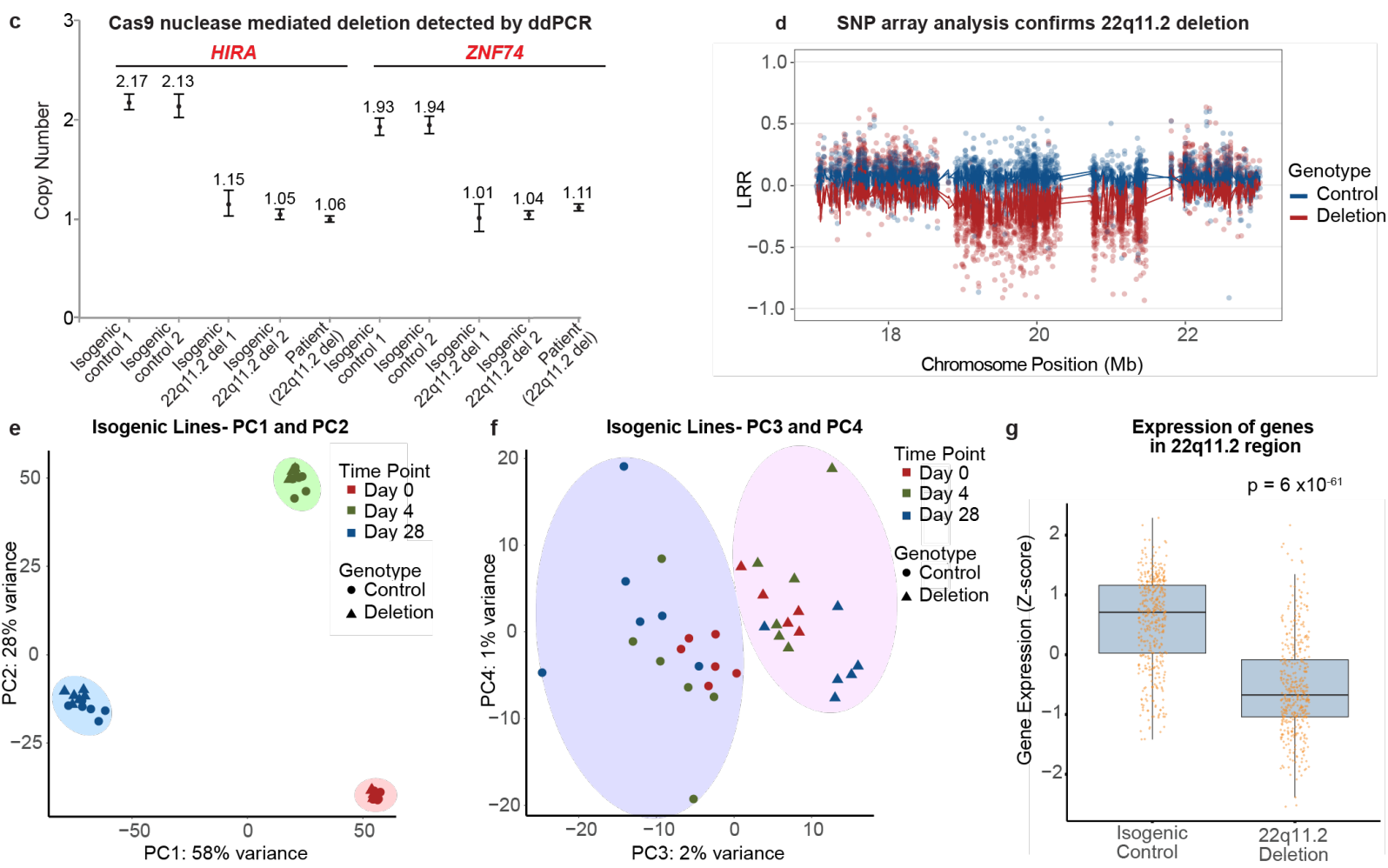

g Expression of genes

$h$ Correlation of DE genes in neurons (day 28), discovery and isogenic sets

$76 \%$ in same direction

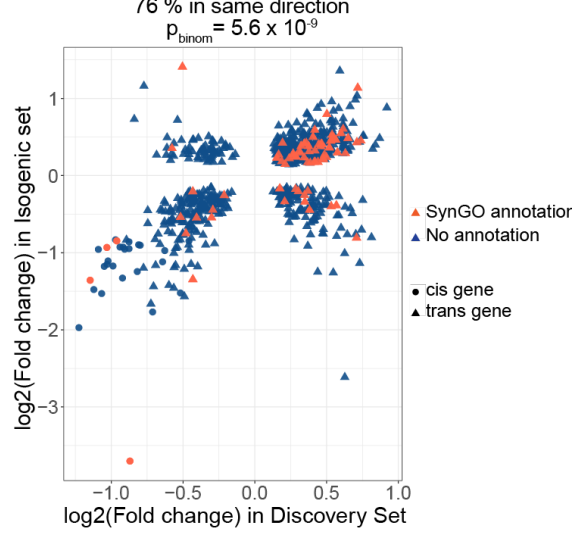

i MEF2C expression in isogenic NPCs

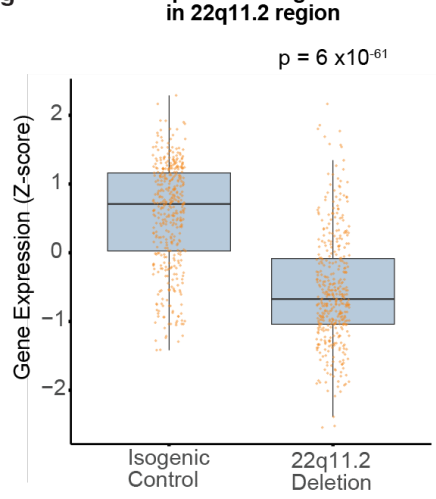

Genotype

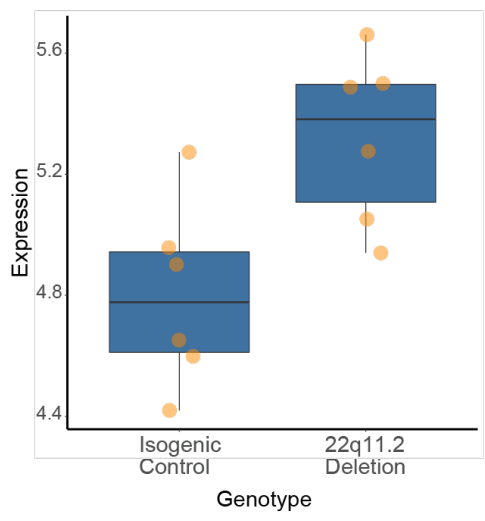

j Synaptic Ontologies (SynGo)

Fig. 5. Validation of causality between the differentially expressed genes and the deletion genotype in an isogenic setting. a, Generation of isogenic lines with 22q11.2 deletion using CRISPR Cas9 guide RNAs that cut within the low copy repeats (LCRs) flanking the $3 \mathrm{Mb} 22 \mathrm{q} 11.2$ deletion. The coordinates for the genomic position of the CRISPR guides on chromosome 22 are indicated $(\mathrm{Hg} 19)$. b. Detection of isogenic 22q11.2 deletion using DNA FISH analysis and a probe generated probe using CTD-2300P14 (Thermo Fisher Scientific, Supplier Item: 96012). Blue = DAPI (DNA), Red=22q11.2 region. Scale bar: 10um. c, ddPCR assay to determine the copy numbers of the HIRA and ZNF74 genes, located in the 22q11.2 region, to validate isogenic deletion of 22q11.2. d, SNP array marker intensity (LRR) for SNPs overlapping the deletion locus confirms isogenic $22 \mathrm{q} 11.2$ 
bioRxiv preprint doi: https://doi.org/10.1101/2021.09.22.461360; this version posted September 22, 2021. The copyright holder for this preprint (which was not certified by peer review) is the author/funder, who has granted bioRxiv a license to display the preprint in perpetuity. It is made available under aCC-BY 4.0 International license.

884 genes within the 22q11.2 interval (cis). Triangles = genes outside 22q11.2 (trans). e, PC1 and PC2 separate cells by developmental stage. f, PC3 and PC4 separate cells by deletion genotype. g, Significant downregulation of genes in 22q11.2 region in lines with isogenic 22q11.2 deletion. $\mathbf{h}$, Correlation of fold changes in differentially expressed genes in discovery and isogenic datasets in neurons. 32 genes were detected and significantly changed in transcript levels in the discovery cohort and the isogenic lines (adjusted p-value $<0.05$ in both experiments), of which nine were located outside the deletion region (FAM13B, KMT2C, HYAL2, DNPH1, ZMYM2, VAPB, SMG1, CPSF4, MAP3K2) and the rest were in cis. All 32 genes were changed in the same direction both in the discovery and isogenic cohorts $(\mathrm{p}=0.004$, binomial test $)$. Genes with a SynGO annotation are shown in red, genes with no SynGO annotation are shown in blue. Circles = cis genes. Triangles = trans genes. $\mathbf{i}, M E F 2 C$ is upregulated in NPCs of deletion carriers compared to isogenic controls, similar to the discovery dataset. $\mathbf{j}$, SynGo annotation of genes induced in isogenic neurons with 22q11.2 deletion showing enrichment for synaptic vesicle cycle and endocytosis.
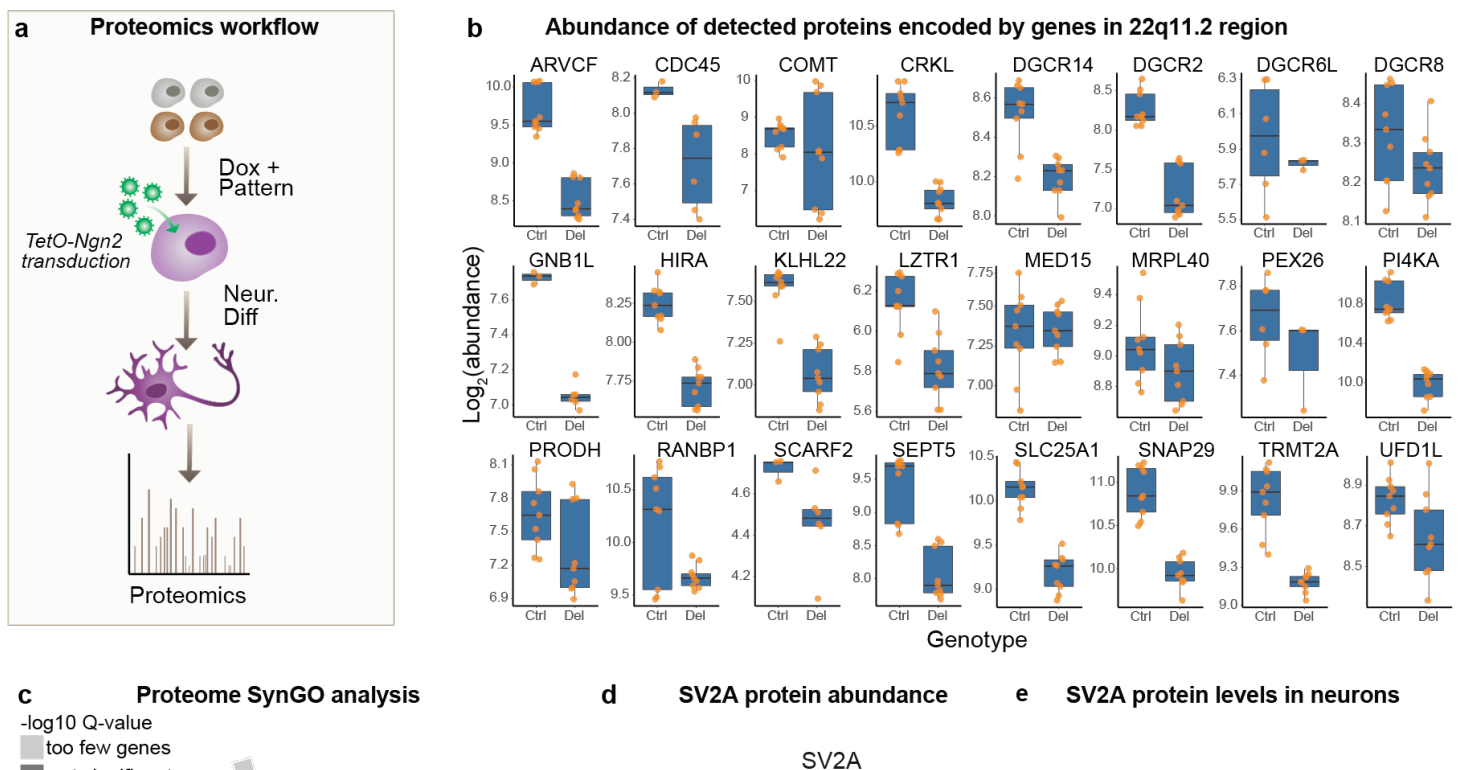

d SV2A protein abundance

e SV2A protein levels in neurons

SV2A

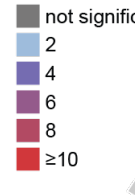

nt
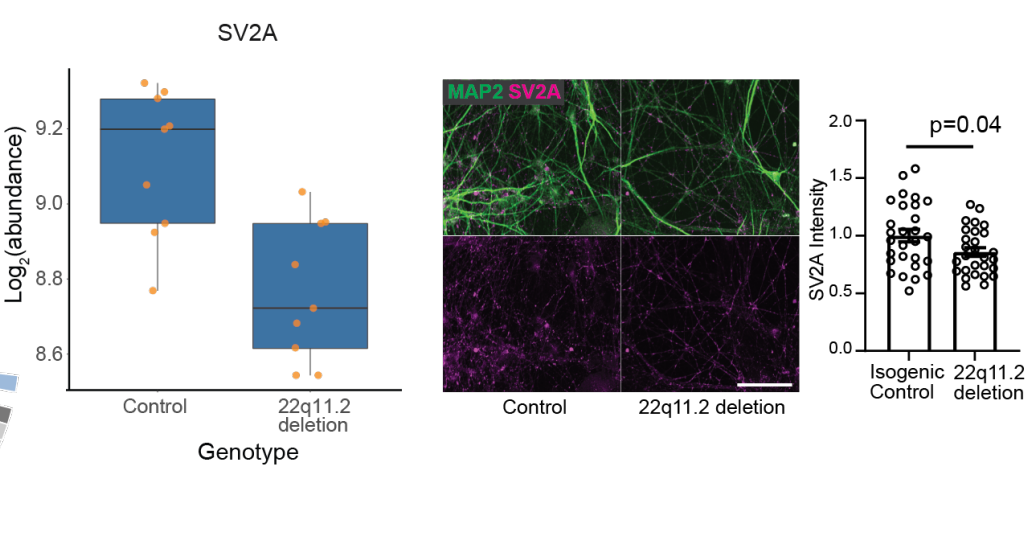

Fig. 6. Whole cell proteomics on $22 q 11.2$ deletion neurons. a, Workflow schematic. Neurons from deletion carriers and controls were harvested 28 days post neuronal induction. $\mathbf{b}$, Abundance of proteins encoded by genes in the 22q11.2 region detected by proteomics in neurons. $\mathrm{Del}=22 \mathrm{q} 11.2$ deletion. $\mathrm{Ctrl}=$ control. c, Synaptic gene ontologies (SynGO) in proteins downregulated in deletion carrier neurons. d, SV2A protein levels detected by proteomics are decreased in deletion carrier neurons. e, SV2A protein levels detected by antibody staining are decreased in day 28 neurons derived from isogenic lines with 22q11.2 heterozygous deletion compared to controls. (Left) Representative confocal images of control and 22q11.2 deletion neurons stained with antibodies against SV2A (magenta) and MAP2 (green). Scale bar is $100 \mu \mathrm{m}$. (Right) Quantification of total SV2A fluorescence within MAP2-positive neurites normalized to isogenic controls. Data are means \pm SEM. Individual points are analyzed fields of view from 4 independent inductions per condition. Statistical analysis by Student's t test reveals statistically significant $(\mathrm{p}=0.037)$ decrease in SV2A levels in deletion neurons. 
bioRxiv preprint doi: https://doi.org/10.1101/2021.09.22.461360; this version posted September 22, 2021. The copyright holder for this preprint (which was not certified by peer review) is the author/funder, who has granted bioRxiv a license to display the preprint in perpetuity. It is made available under aCC-BY 4.0 International license.
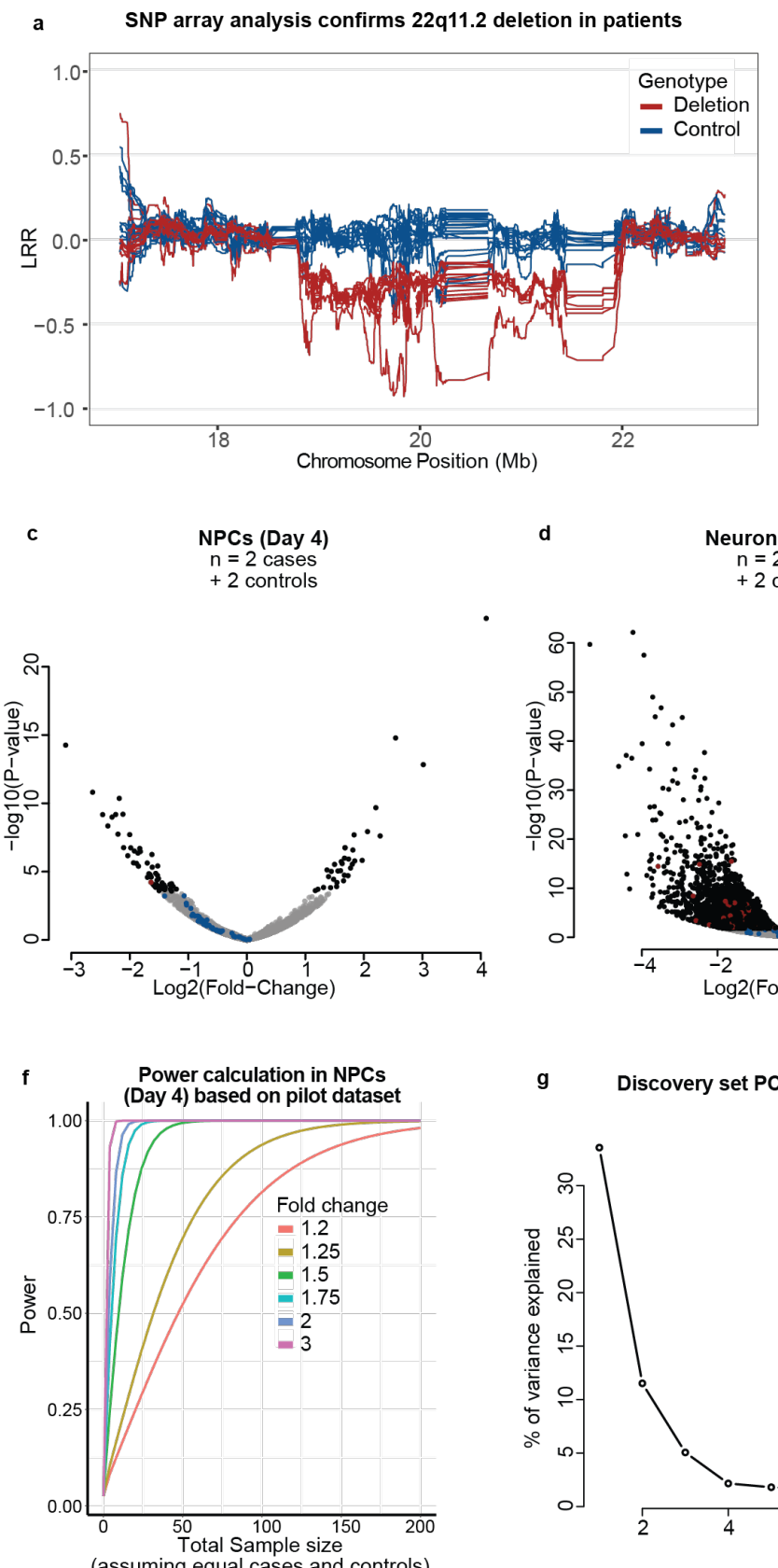

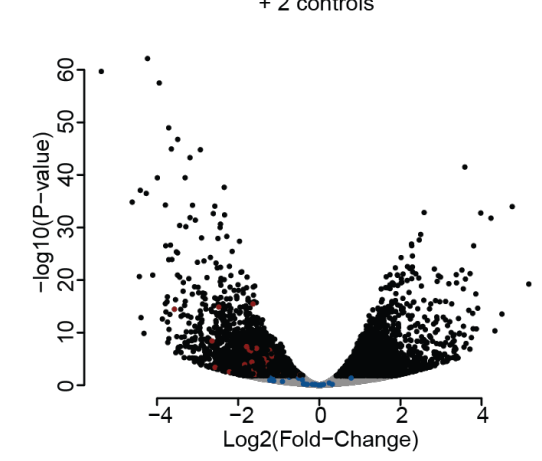

g

Discovery set PCA variance

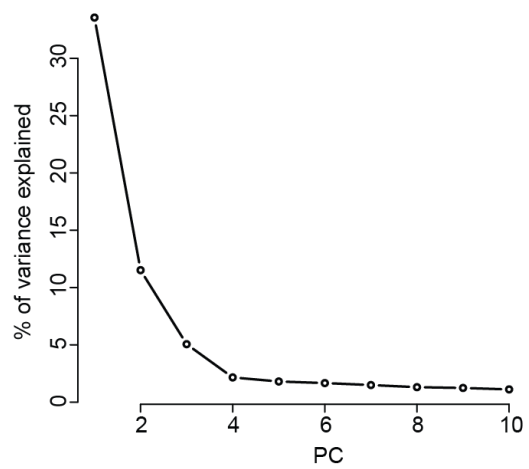

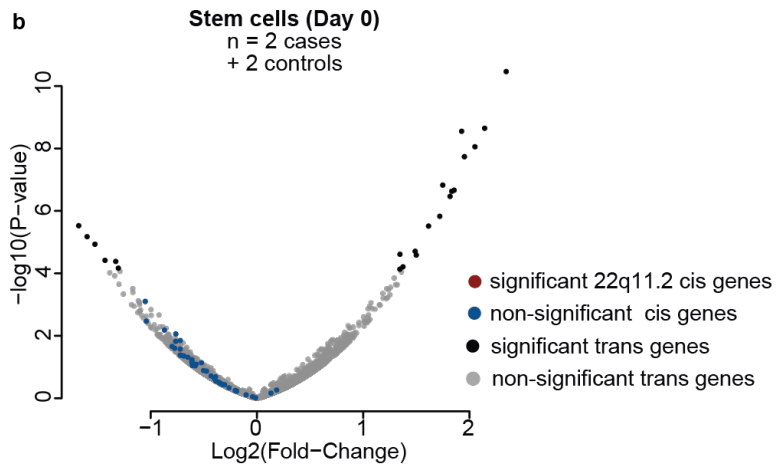

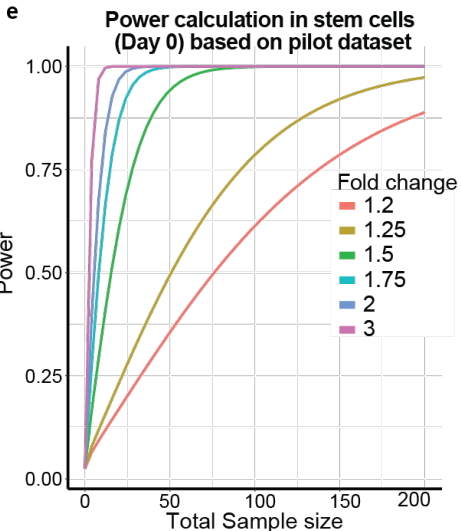

(assuming equal cases and controls)

h

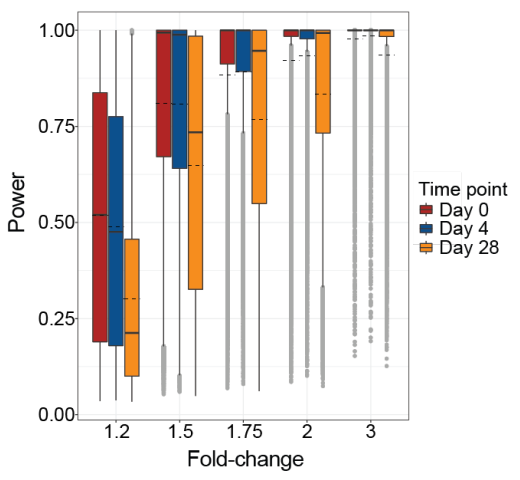

Extended Data Fig. 1. Discovery and pilot datasets. a, Validation of the full-size deletion in 22q11.2 lines used in the current study by sliding-window average of SNP marker intensity (LRR) in the deletion locus. b-d, Volcano plots showing differentially expressed genes in the pilot dataset. e, Power estimation in the pilot dataset for median expressed genes for different fold-changes and sample sizes in stem cells. f, Power estimation in the pilot data set for median expressed genes for different fold-changes and sample sizes in neuronal progenitor cells (NPCs). g, Variance explained by the first 10 principal components in the discovery sample. $\mathbf{h}$, Estimated power in the final (discovery) dataset, at each time point. 
bioRxiv preprint doi: https://doi.org/10.1101/2021.09.22.461360; this version posted September 22, 2021. The copyright holder for this preprint (which was not certified by peer review) is the author/funder, who has granted bioRxiv a license to display the preprint in perpetuity. It is made available under aCC-BY 4.0 International license.

a
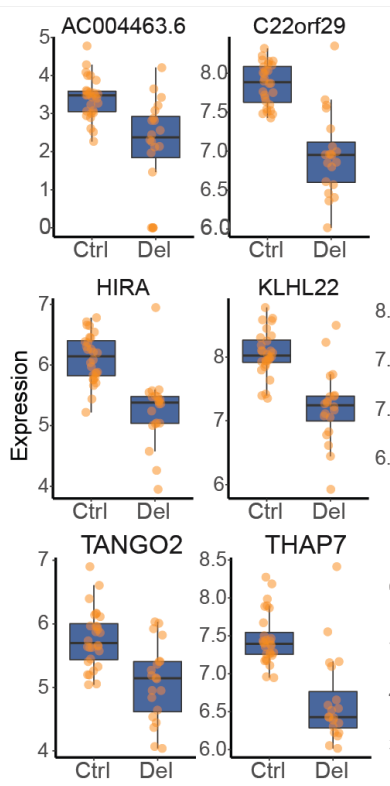

Expression of 22q11.2 region genes downregulated at all stages
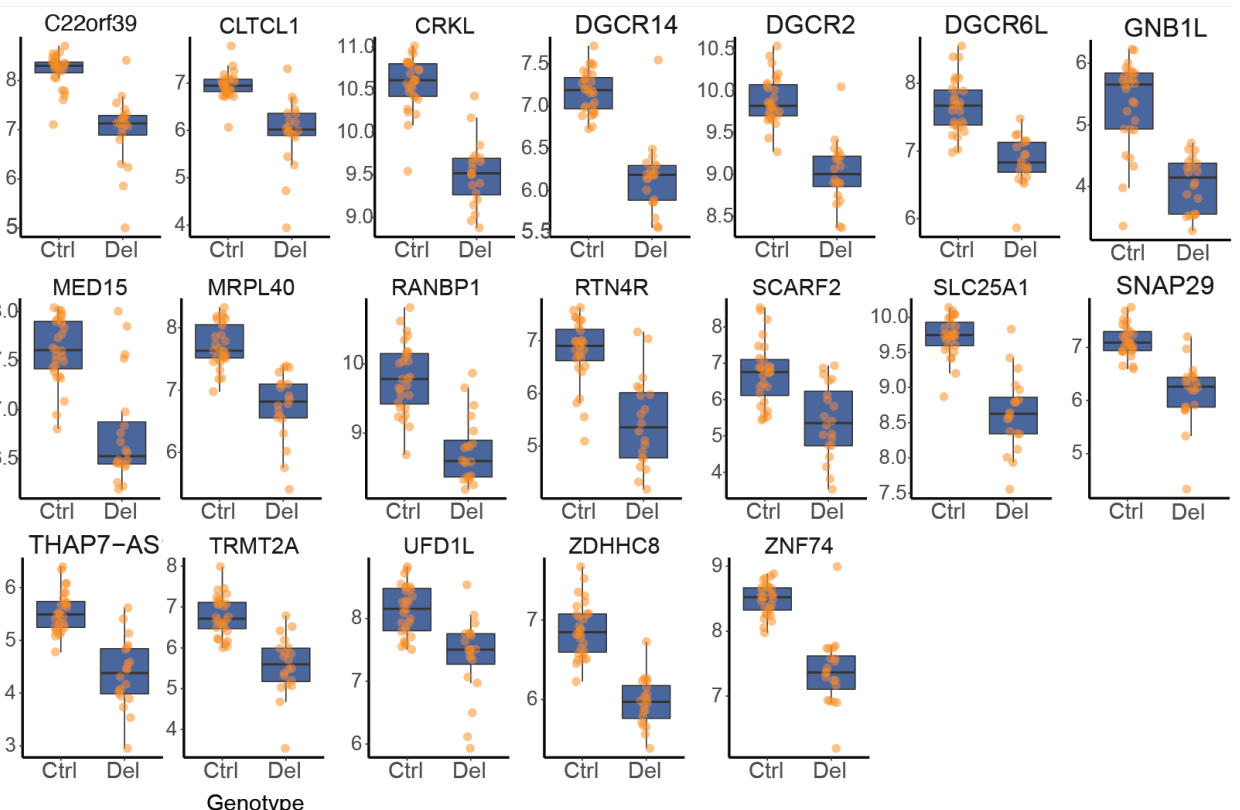

d TBX1 transcript levels in NPCs

b One gene upregulated at all stages C Categories and genes for line plot in Fig. 1h

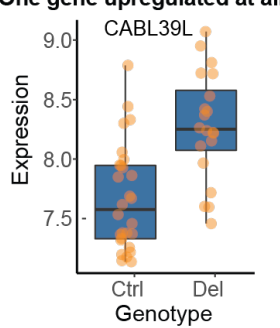

\begin{tabular}{lll}
\hline Pluripotency & Progenitors (Forebrain) & Pan Neuronal \\
\hline SOX2 & NEUROD1 & NEUN \\
OCT4 & SOX2 & SYNAPSIN1 \\
NANOG & EMX2 & DCX \\
MKI67 & OTX2 & MAP2 \\
& HES1 & TUJ1 \\
& MSI1 & NCAM \\
& MKI67 & MAPT \\
\hline
\end{tabular}

e

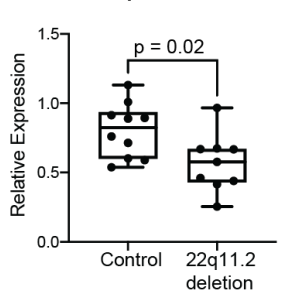

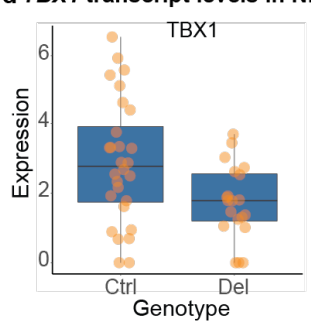

g Western Blot for MEF2C in NPCs
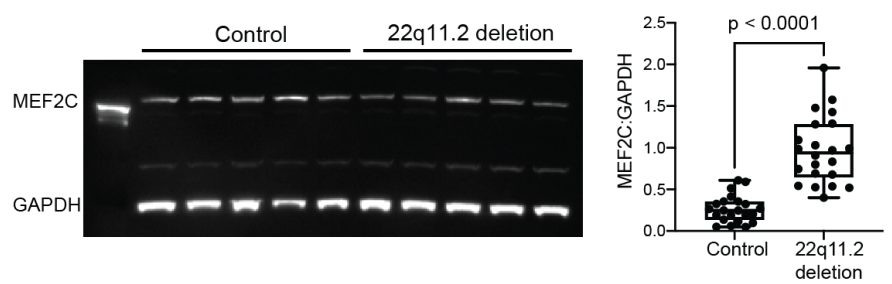

Extended Data Fig. 2. Expression of differentially regulated genes. a, Expression of significant cis genes shared across all three developmental stages. $\mathbf{b}, C A B 39 \mathrm{~L}$ is the only trans gene upregulated in all developmental stages. $\mathbf{c}$, List of categories and genes used in Fig. 2a. d, TBXI is downregulated in NPC of 22q11.2 deletion carriers. e, Relative expression of $T B X 1$ via qPCR in Day 4 NPCs from control and 22q11.2 deletion patients (Samples: 3/3, 2BR/2TR, $p<0.05$ ). f, Relative expression of $M E F 2 C$ via qPCR in NPCs from control and patients (Samples:3/3, 2BR/2TR, p $<0.01$ ). g, Expression of MEF2C in total protein lysates from control and 22q11.2 deletion NPCs. (Left) Total protein lysates from control (left five lanes) and deletion lines (right five lanes) probed for MEF2C (top) and GAPDH (bottom). (Right) Statistical analysis by Student's t test reveals statistically significant decrease in MEF2C expression in the deletion lines. (Samples: 5/5, 1BR/3TR, $\mathrm{p}<0.0001$ ). $\mathrm{BR}=$ biological replicate (independent differentiations); $\mathrm{TR}=$ technical replicate (independent wells). 
bioRxiv preprint doi: https://doi.org/10.1101/2021.09.22.461360; this version posted September 22, 2021. The copyright holder for this preprint (which was not certified by peer review) is the author/funder, who has granted bioRxiv a license to display the preprint in perpetuity. It is made available under aCC-BY 4.0 International license.
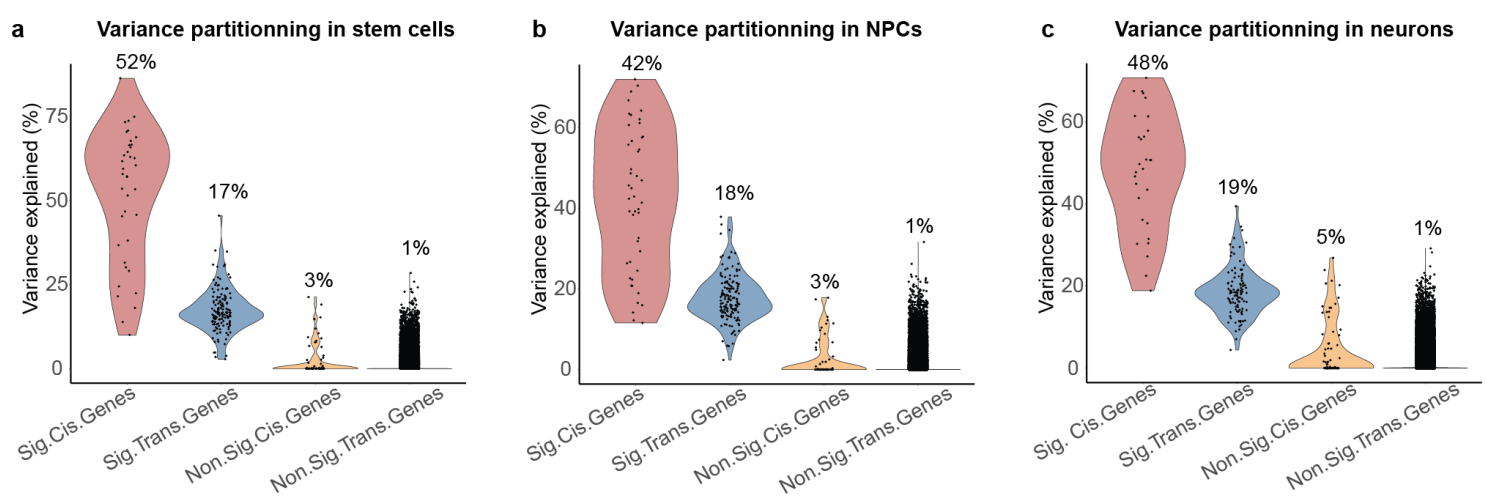

d Differentially Expressed (DE) genes in neurons (day 28), FDR $<0.05$

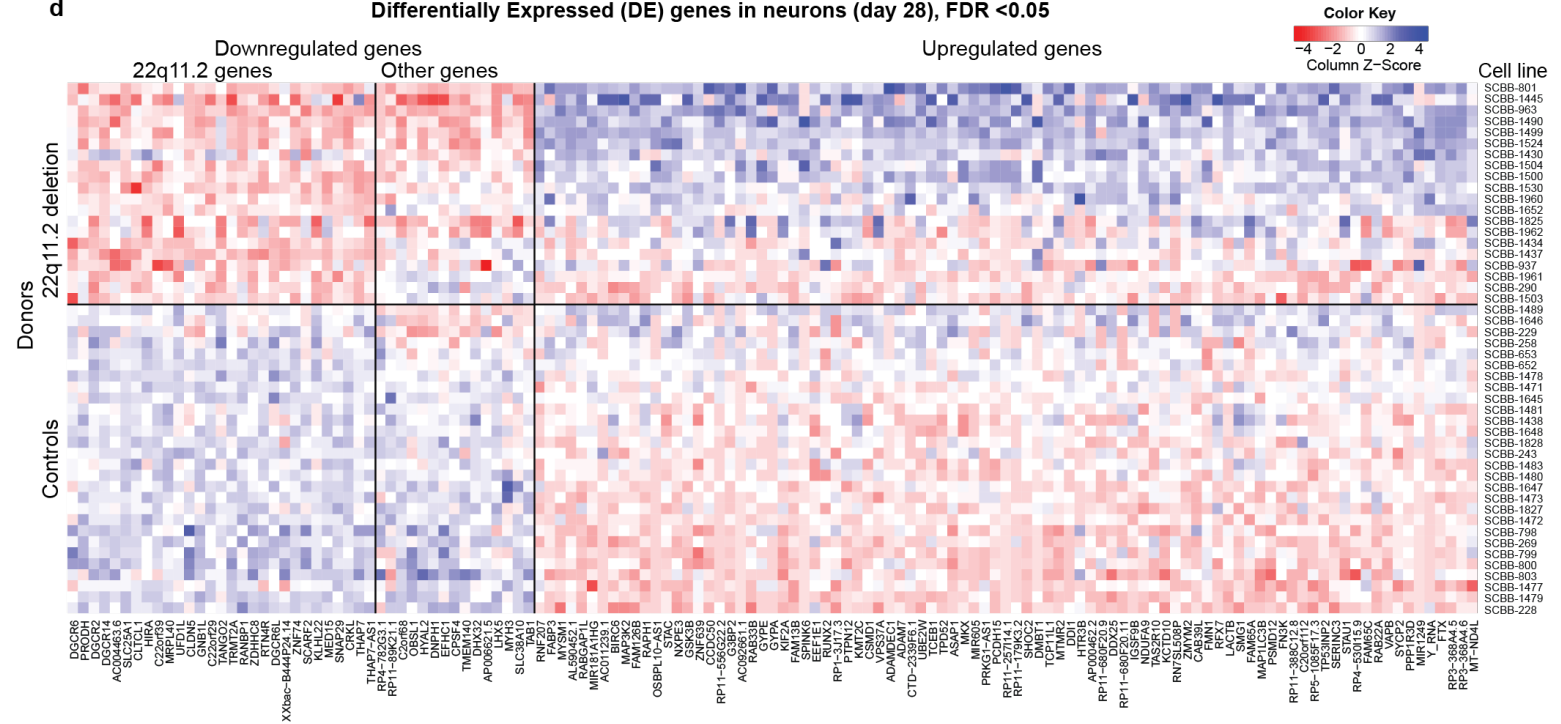

e

Genome position of DE genes in neurons

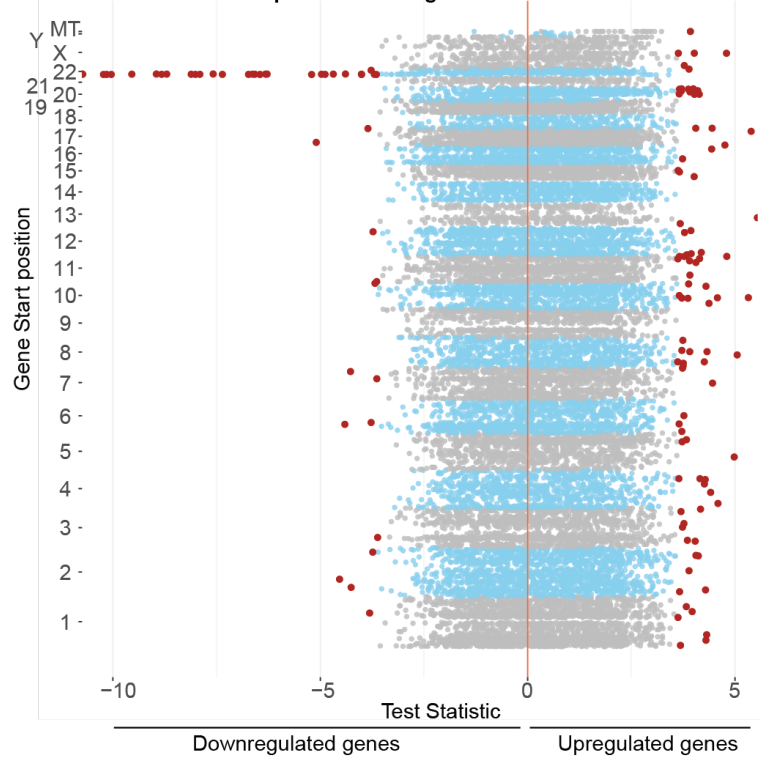

Extended Data Fig. 3. Variance partitioning and expression of differentially regulated genes a-c, Variance in gene expression explained by the deletion genotype in different gene categories in the final dataset in $\mathbf{a}$, Stem cells, $\mathbf{b}$, Neuronal progenitor cells and $\mathbf{c}$, Neurons. d, Heatmap of 133 genes differentially expressed in neurons showing the range of expression, in all donor lines, of genes down or upregulated. e, Test statistic for differential expression plotted by chromosomal position of differentially expressed genes in cells with 22q11.2 deletion. Differentially expressed genes (FDR $<5 \%)$ are colored in red. 
bioRxiv preprint doi: https://doi.org/10.1101/2021.09.22.461360; this version posted September 22, 2021. The copyright holder for this preprint (which was not certified by peer review) is the author/funder, who has granted bioRxiv a license to display the preprint in perpetuity. It is made available under aCC-BY 4.0 International license.

a

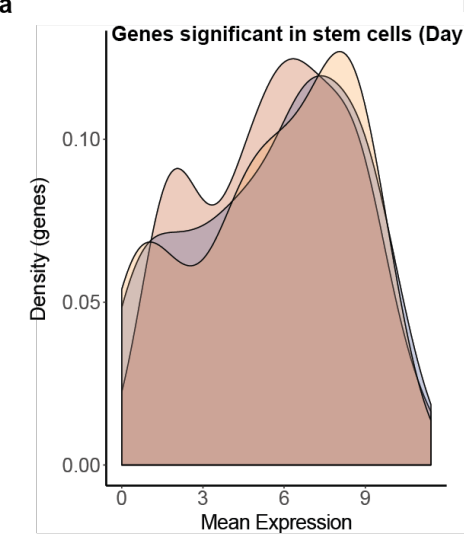

Expression of differentially regulated genes during development

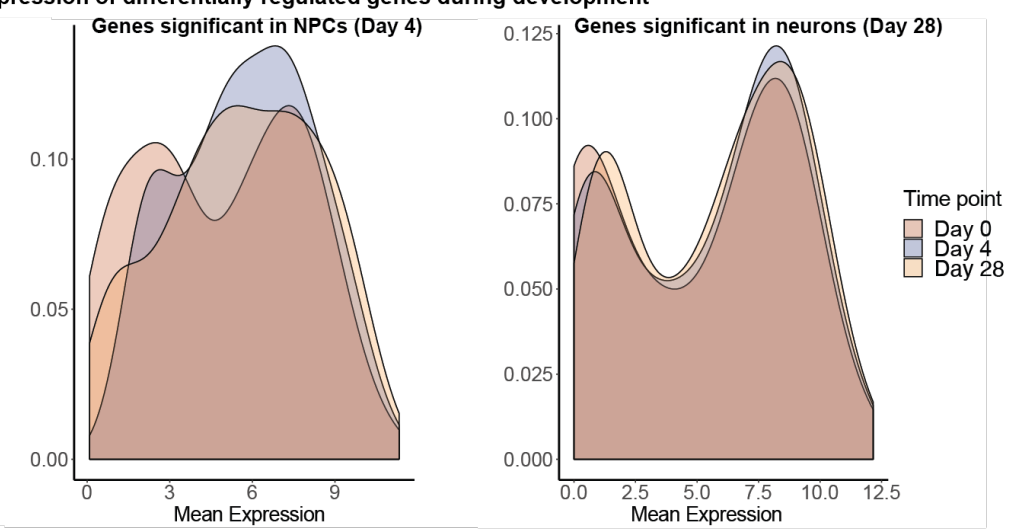

b

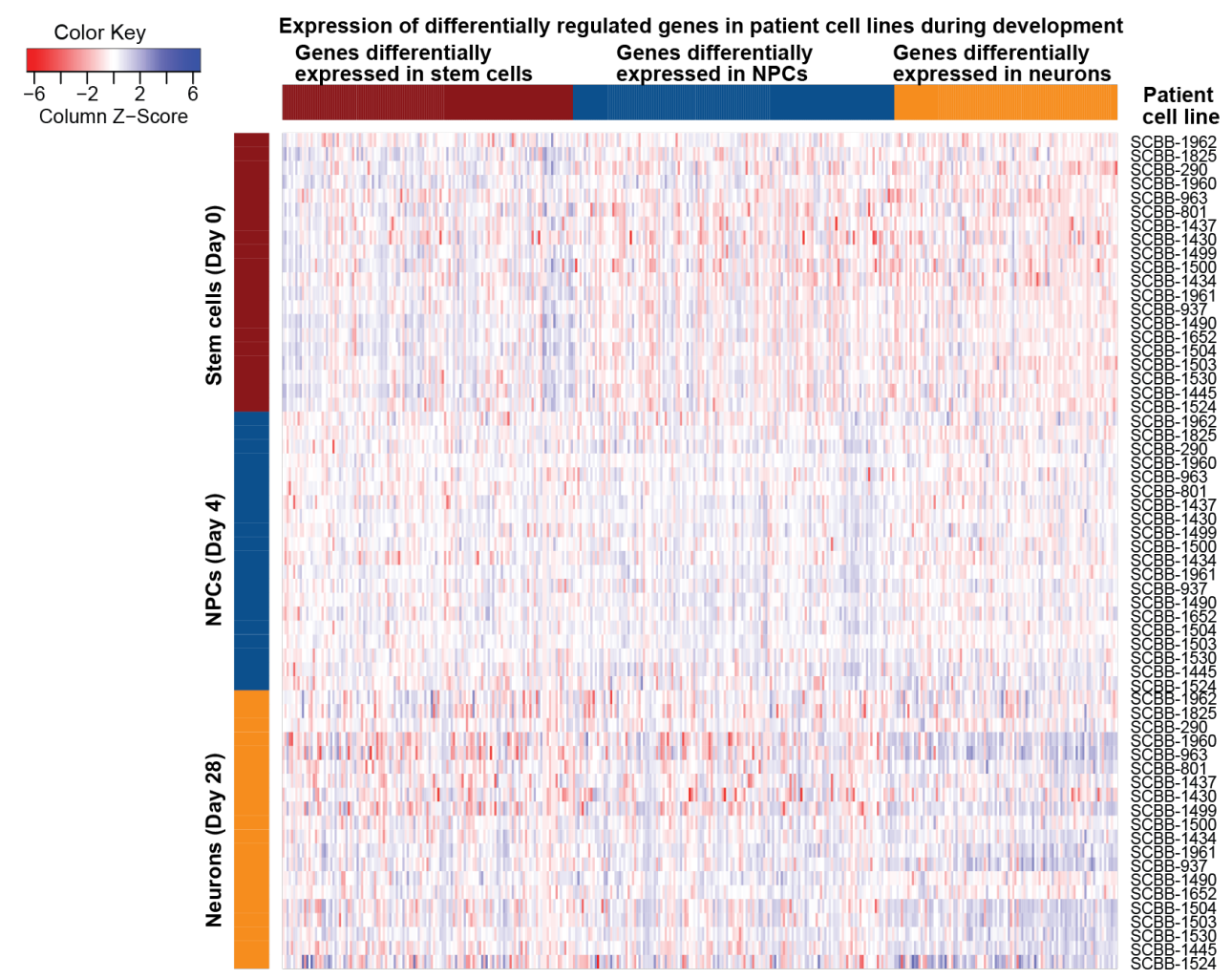

C

Enrichment of connectivity between neurodevelopmental genes and differentially expressed genes (FDR<5\%)
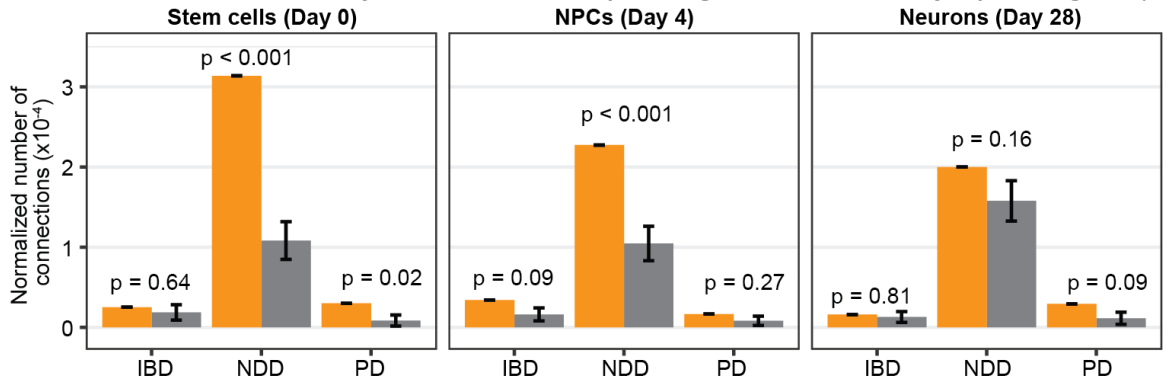

Disease genes

Random genes matched

by expression level

Extended Data Fig. 4. Expression of genes differentially regulated at specific cell stages in $22 q 11.2$ deletion cells across developmental stages. a, density plots and $\mathbf{b}$, heatmap showing that the differentially regulated genes are expressed at similar levels across all three cell stages. c, Connectivity enrichment analysis. Enrichment of interactors of proteins encoded by genes associated with intellectual disability and autism (NDD) and differentially expressed genes (FDR $<5 \%$ ) in the early developmental stages after 1000 random permutations. Gene products encoded by genes linked to inflammatory bowel disease (IBD) yielded no enrichment for protein-protein interactions between the differentially expressed genes at any cell stage, and genes linked to Parkinson's disease (PD) yielded no enrichment in NPCs or neurons. 
bioRxiv preprint doi: https://doi.org/10.1101/2021.09.22.461360; this version posted September 22, 2021. The copyright holder for this preprint (which was not certified by peer review) is the author/funder, who has granted bioRxiv a license to display the preprint in perpetuity. It is made available under aCC-BY 4.0 International license.

a

Gene bin size for permutation of upregulated genes in neurons (Day 28)

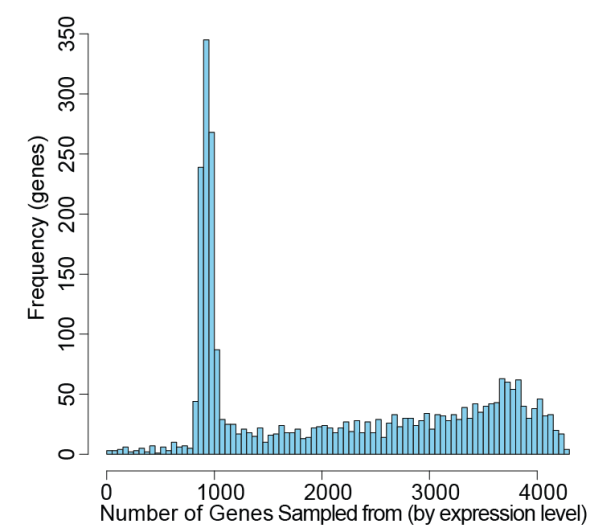

b

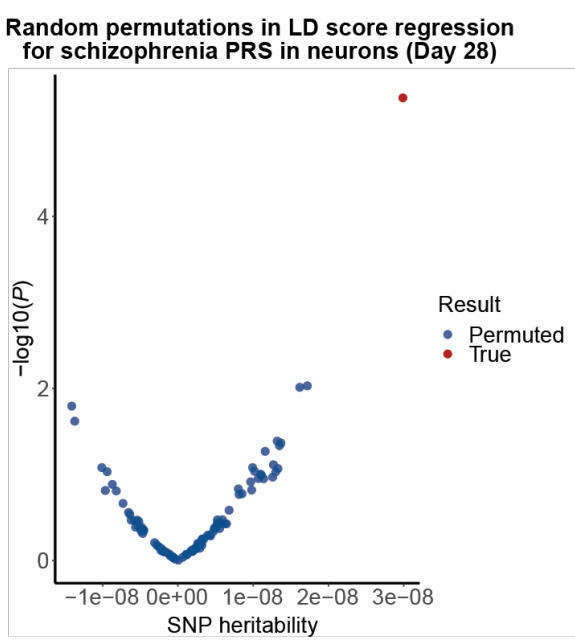

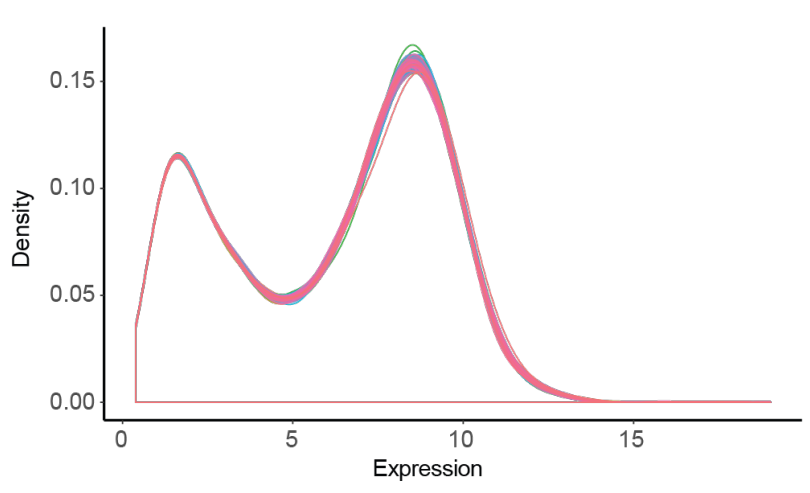

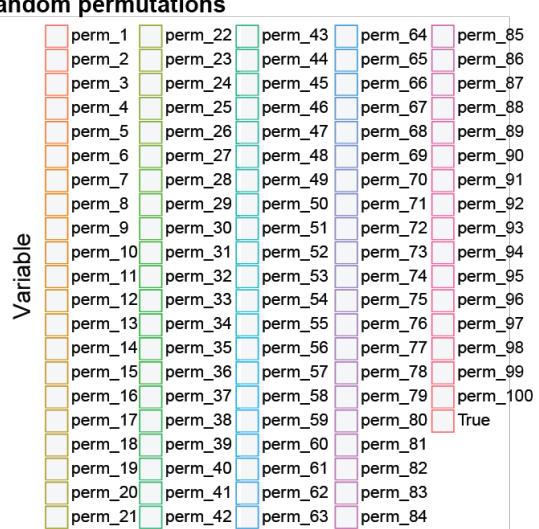

d

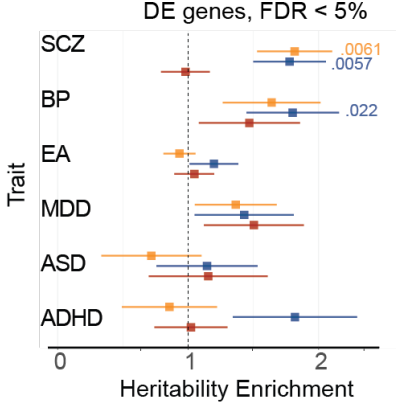

Heritability enrichment based on LD score regression analysis

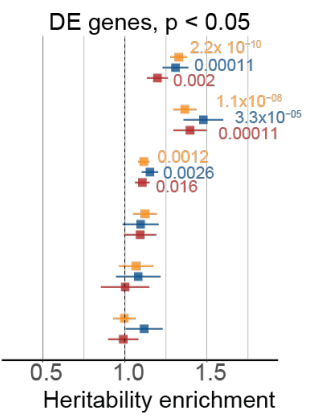

Upregulated genes, $p<0.05$

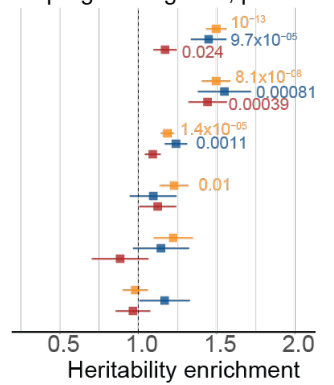

Downregulated genes, $\mathrm{p}<0.05$

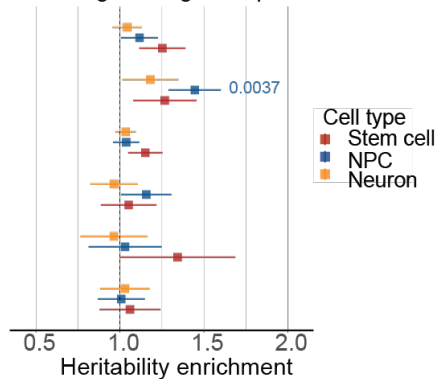

e Random permutations in heritablitiy enrichment

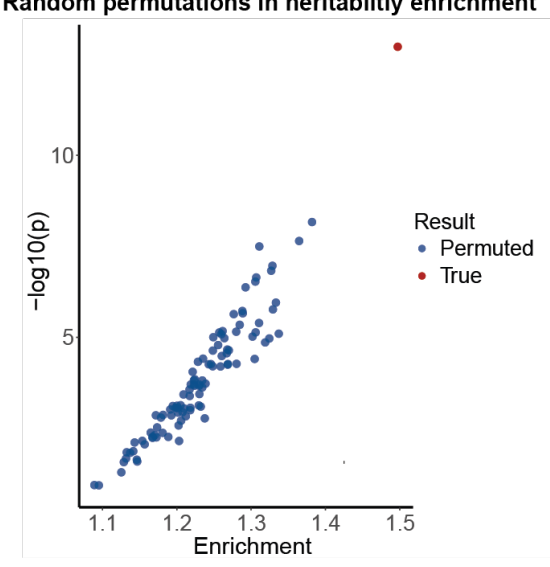


bioRxiv preprint doi: https://doi.org/10.1101/2021.09.22.461360; this version posted September 22, 2021. The copyright holder for this preprint (which was not certified by peer review) is the author/funder, who has granted bioRxiv a license to display the preprint in perpetuity. It is made available under aCC-BY 4.0 International license.

Extended Data Fig. 5. LD-score regression analysis. a, Gene bin size for permutation of upregulated genes in neurons. b, PerSNP heritability enrichment in LD score regression for random permutations (in blue) and the upregulated genes (in red) in neurons c, Distribution of gene expression in random generated gene sets in the 100 permutations for per-SNP heritability. d, Heritability enrichment analysis of six traits across the three developmental cell stages. SCZ $=$ schizophrenia, BP=bipolar disorder, $\mathrm{EA}=$ educational attainment, $\mathrm{MDD}=$ major depressive disorder, $\mathrm{ASD}=$ autism spectrum disorder, $\mathrm{ADHD}=\mathrm{attention}$ deficit hyperactivity disorder. e, LD score regression heritability enrichment in random expression matched gene lists from 100 permutations (in blue) compared to the up-regulated genes in neurons (in red).

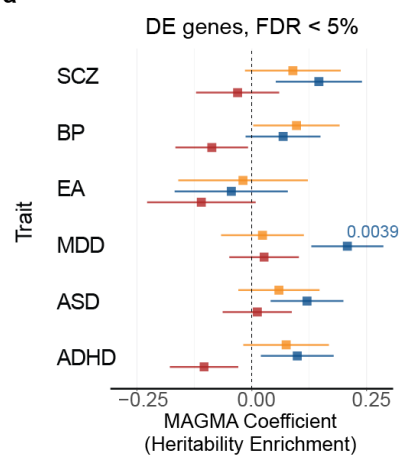

MAGMA analysis in neurons (day 28)

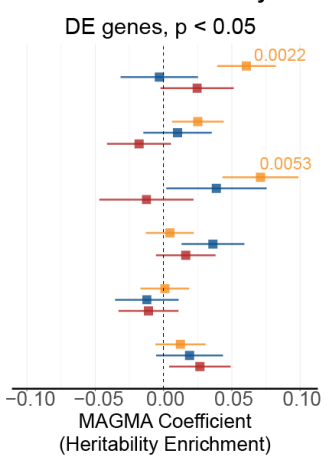

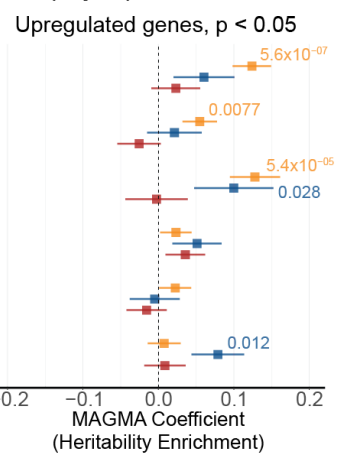

Downregulated genes, $\mathrm{p}<0.05$

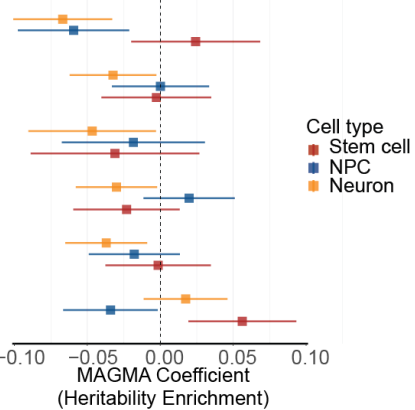

b Random permutations in MAGMA analysis

C

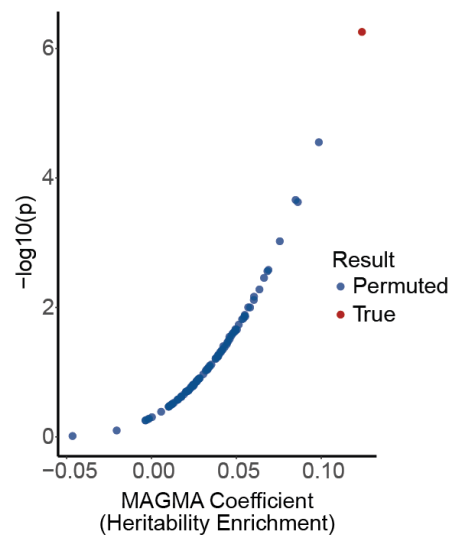

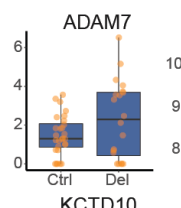

DE genes in schizophrenia polygenic risk
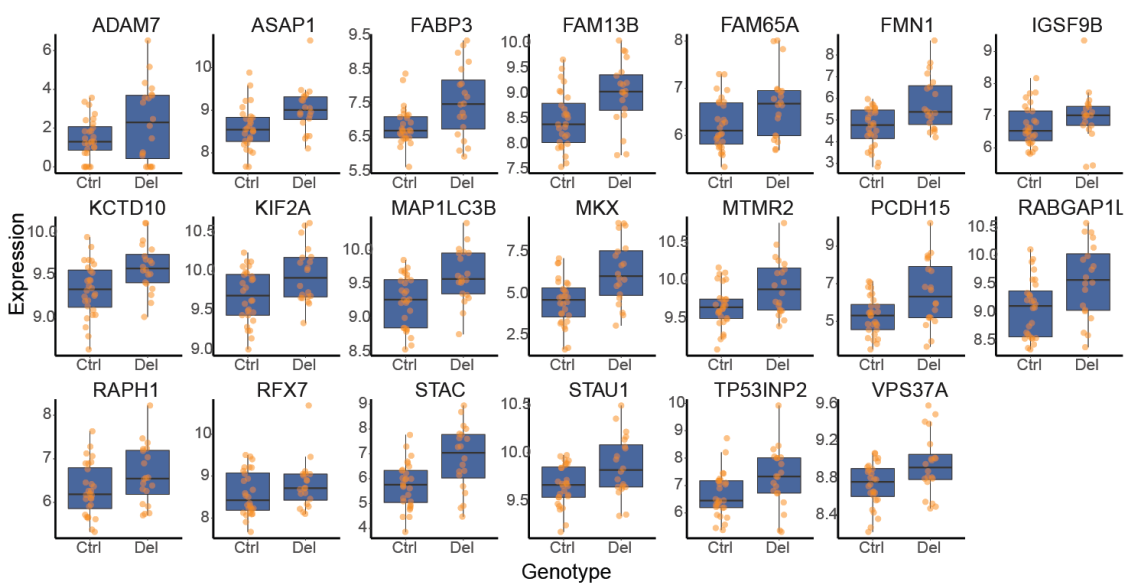

Extended Data Fig. 6. MAGMA (Multi-marker Analysis of GenoMic Annotation) analysis in neurons. a, MAGMA

heritability enrichment analysis of six traits across the three developmental cell stages. $\mathrm{SCZ}=$ schizophrenia, $\mathrm{BP}=$ bipolar disorder, $\mathrm{EA}=$ educational attainment, $\mathrm{MDD}=$ major depressive disorder, $\mathrm{ASD}=$ autism spectrum disorder, $\mathrm{ADHD}=$ attention deficit hyperactivity disorder. b, Magma heritability enrichment in random expression matched gene lists from 100 permutations (in blue) compared to the up-regulated genes in neurons (in red).c, Expression of the differentially expressed genes contributing to the MAGMA schizophrenia signal (FDR $<5 \%$ ). 
bioRxiv preprint doi: https://doi.org/10.1101/2021.09.22.461360; this version posted September 22, 2021. The copyright holder for this preprint (which was not certified by peer review) is the author/funder, who has granted bioRxiv a license to display the preprint in perpetuity. It is made available under aCC-BY 4.0 International license.

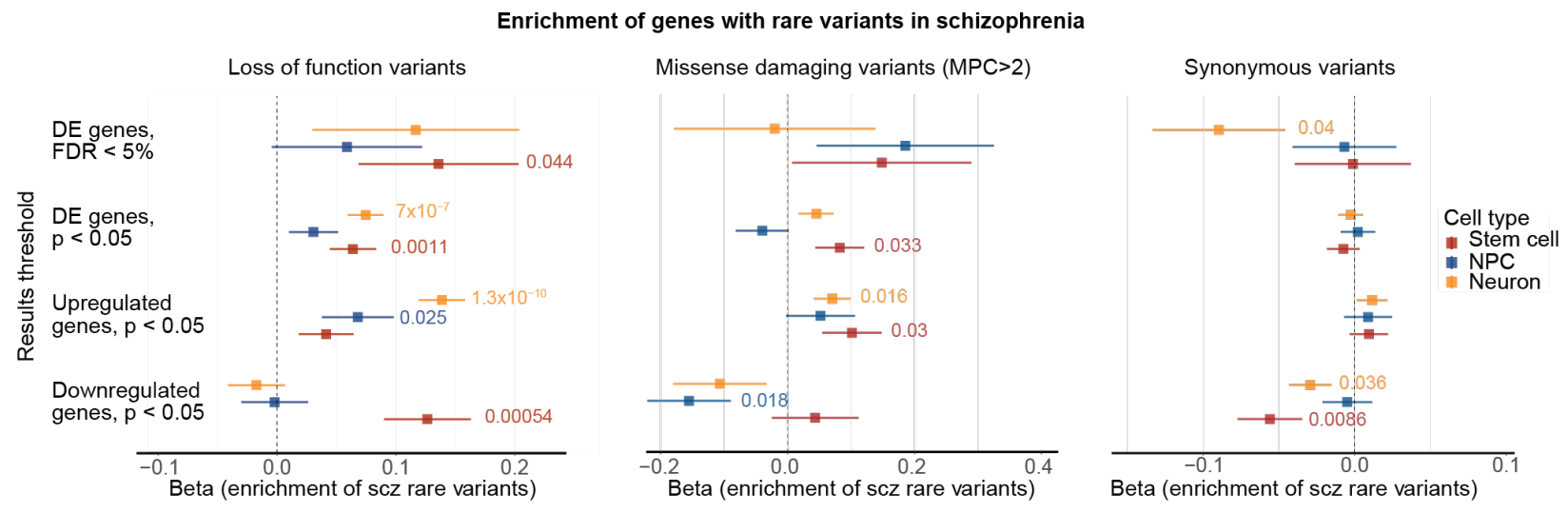

965 Extended Data Fig. 7. Enrichment analysis of genes with rare variants in schizophrenia. Forest plots for the difference in number of rare coding variants (beta) between schizophrenia patients and controls for loss of function, missense damaging and synonymous variants in genes at different significance cutoffs: $F D R<5 \%, p<0.05$ (all genes), upregulated genes with $\mathrm{p}<0.05$ and downregulated genes with $\mathrm{p}<0.05$ at all developmental stages. 
bioRxiv preprint doi: https://doi.org/10.1101/2021.09.22.461360; this version posted September 22, 2021. The copyright holder for this preprint (which was not certified by peer review) is the author/funder, who has granted bioRxiv a license to display the preprint in perpetuity. It is made available under aCC-BY 4.0 International license.

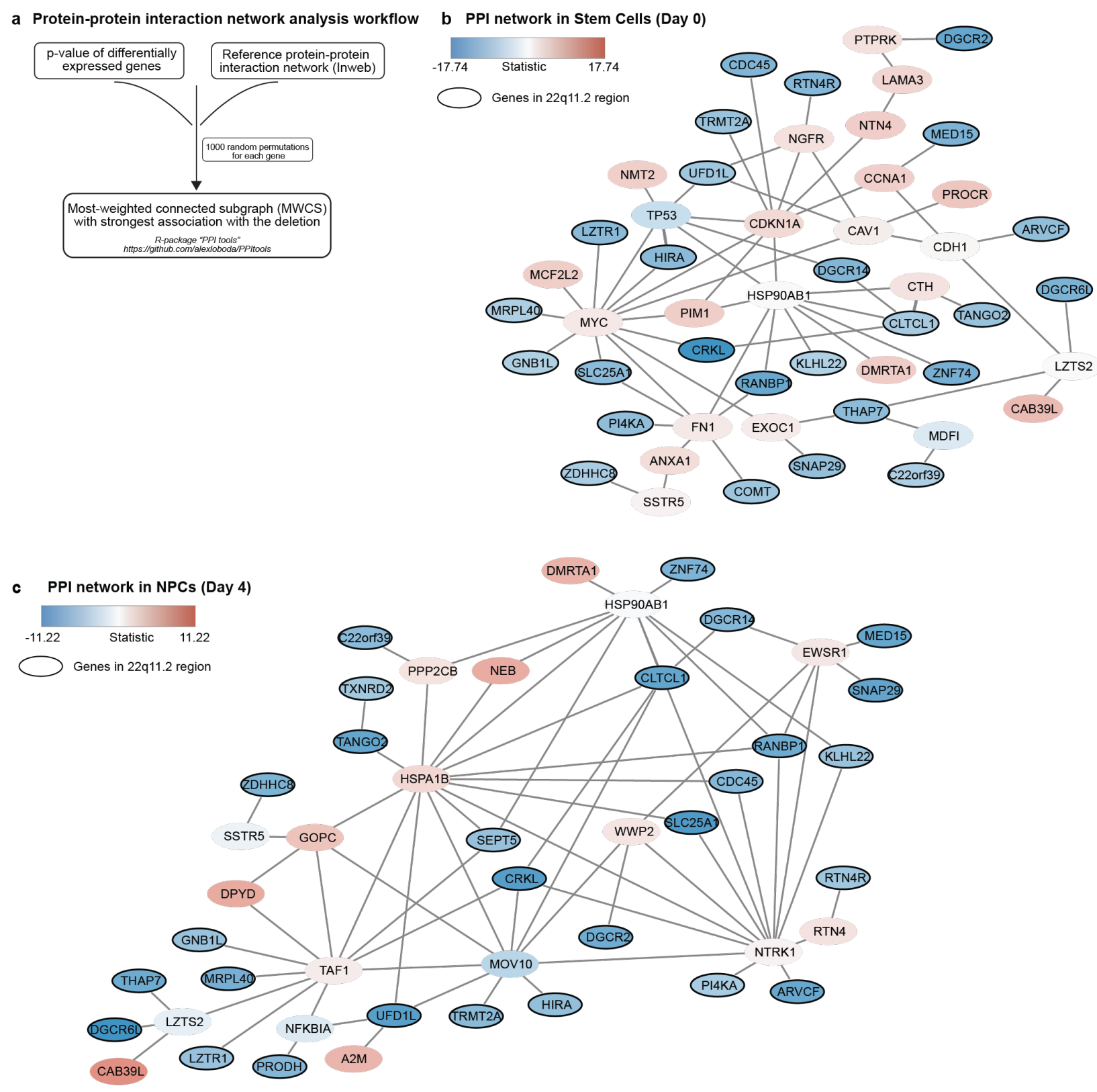

Protein-protein interaction network analysis workflow

b PPI network in Stem Cells (Day 0)

ost-weighted connected subgraph (MWCS) https:/lgithub.com/alexloboda/PPItools

Extended Data Fig. 8. The most weighted sub-cluster graph for protein-protein interactions (PPI) for differentially

972 expressed genes. a, Workflow. b, Network in Stem cells. c, Network in neuronal progenitor cells. 
bioRxiv preprint doi: https://doi.org/10.1101/2021.09.22.461360; this version posted September 22, 2021. The copyright holder for this preprint (which was not certified by peer review) is the author/funder, who has granted bioRxiv a license to display the preprint in perpetuity. It is made available under aCC-BY 4.0 International license.

a

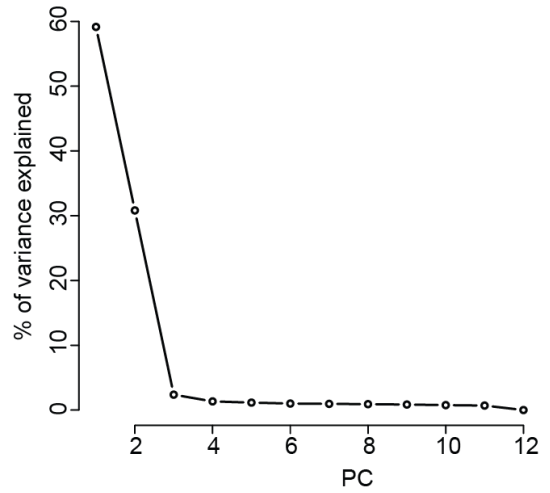

b

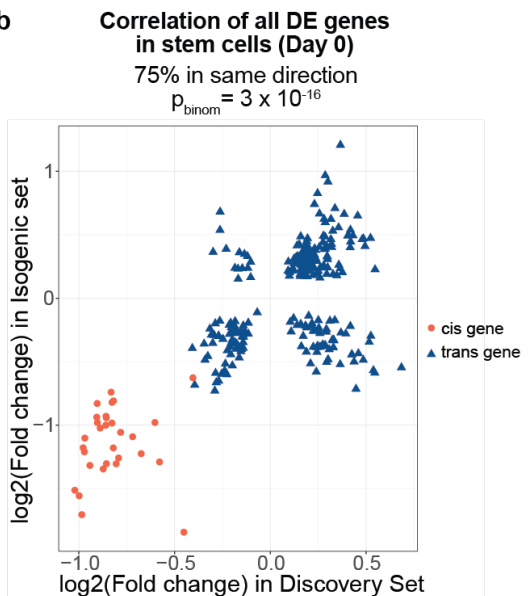

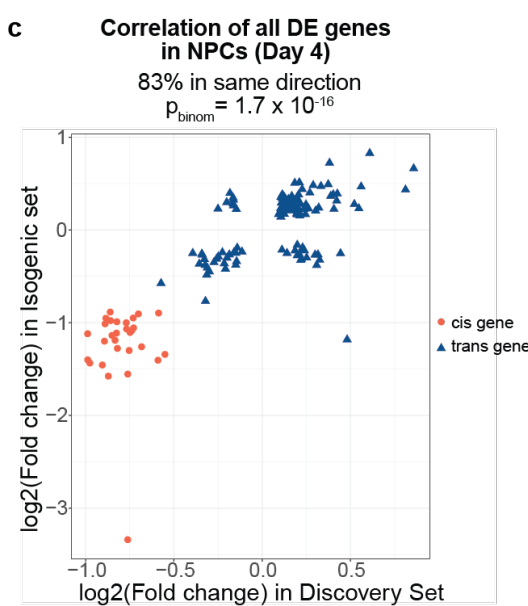

d

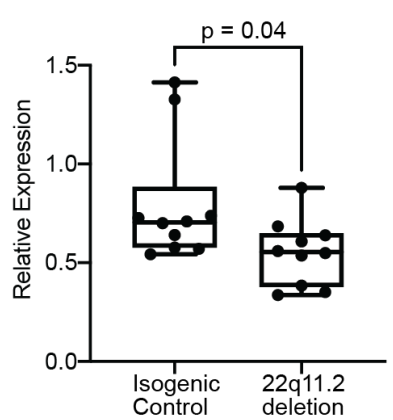

g

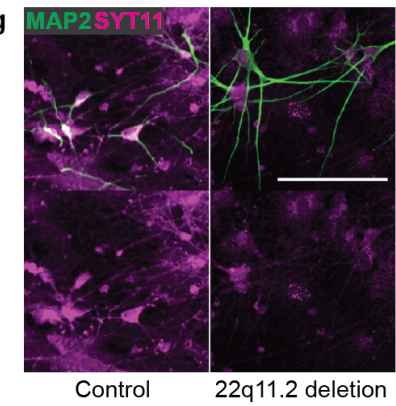

e MEF2C qPCR in NPCs

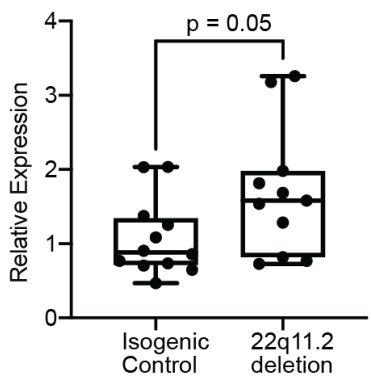

f Protein versus transcript levels

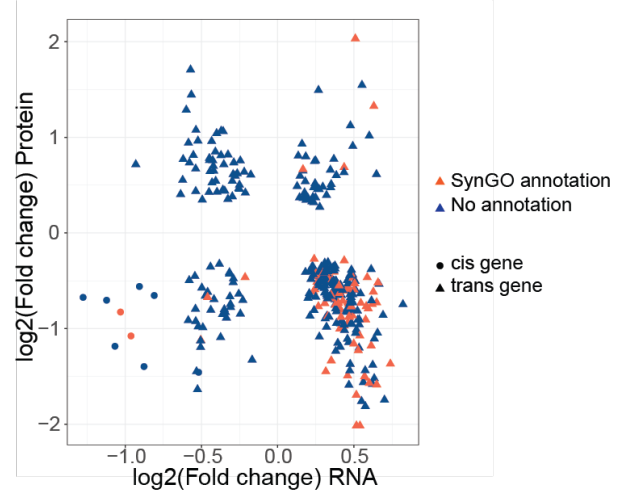

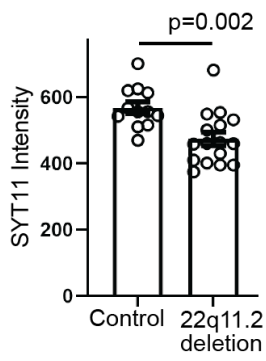

h

Western Blot for NRXN1 in neurons
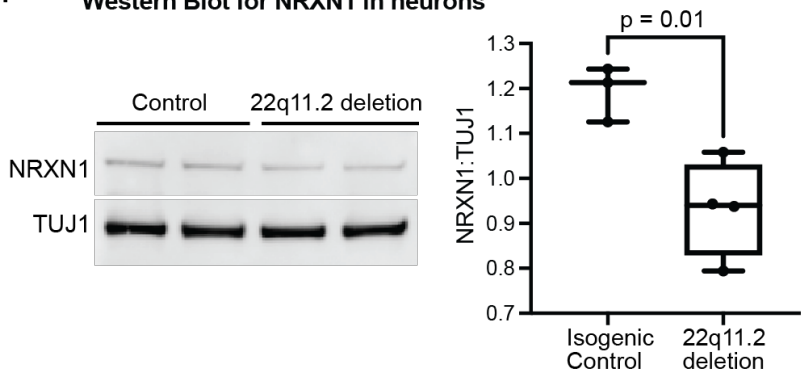

975

Extended Data Fig. 9. Isogenic line and protein analysis. a, Variance explained by each principal component from RNA sequence data in the isogenic lines. b-c, Correlation of fold-changes of differentially expressed genes in discovery and isogenic datasets in stem cells $(\mathbf{b})$ and neuronal progenitors $(\mathbf{c})$. Red circles $=$ cis genes. Blue triangles $=$ trans genes. d, Relative expression of TBX1 via qPCR in Day 4 NPCs from isogenic control and 22q11.2 deletion lines (Samples: 2/2, 3BR/2TR, $\mathrm{p}=0.04$ ). e, Relative expression of MEF2C via qPCR in Day 4 NPCs from isogenic control and 22q11.2 deletion lines (Samples: $2 / 2,3 \mathrm{BR} / 2 \mathrm{TR}, \mathrm{p}=0.05)$. f, Protein versus RNA levels of genes differentially expressed in $22 \mathrm{q} 11.2$ deletion carrier patient neurons. Genes with a SynGO annotation are shown in red, genes with no SynGO annotation are shown in blue. Circles $=$ cis genes. Triangles $=$ trans genes. g, Synaptotagmin-11 (SYT11) protein levels are decreased in Day 28 22q11.2 deletion neurons. (Left) Representative confocal images of control and 22q11.2 deletion patient neurons stained with antibodies against SYT11 (magenta) and MAP2 (green). Scale bar is $100 \mu \mathrm{m}$. (Right) Quantification of total SYT11 fluorescence within MAP2-positive area normalized to controls. Data are represented as means \pm SEM. Individual points are analyzed fields of view from 3 independent control lines and 4 patient-derived lines. Statistical analysis by Student's t test reveals statistically significant $(\mathrm{p}=0.0022)$ decrease in SYT11 levels in patient-derived neurons. h, Expression of Neurexin-1 (NRXN1) in total protein lysates from isogenic control and 22q11.2 deletion neurons. (Left) Total protein lysates from isogenic control (left two lanes) and deletion lines (right two lanes) stained for NRXN1 (top) and TUJ1 (bottom). (Right) Statistical analysis by Student's t test reveals statistically significant decrease in Neurexin-1 expression in the deletion lines. (Samples: 5/5, 2BR/2TR, $\mathrm{p}=0.01$ ). BR = biological replicate (independent differentiations); $\mathrm{TR}=$ technical replicate (independent wells). 


\section{Methods}

\section{Human pluripotent stem cell (hPSC) lines cohort and derivation}

995 We assembled a scaled discovery sample set through highly collaborative, multi-

996 institutional efforts with the Stanley Center Biobank (Broad Institute), the Swedish

997 Schizophrenia Cohort (Karolinska Institute), the Northern Finnish Intellectual Disability Cohort

998 (NFID), Umea University, Massachusetts General Hospital (MGH), McLean Hospital, and

999 GTEx. Human induced pluripotent stem cell (hiPSC) lines were generated from either fibroblasts

1000 or lymphoblasts, and either reprogrammed in house (as previously described ${ }^{34}$ ), at the New York

1001 Stem Cell Foundation (NYSCF) or at the Harvard Stem Cell Institute (HSCI) iPS core as listed

1002 in Extended Data Table 1. The human embryonic stem cell (hESC) line H1 was obtained from

1003 the Human Embryonic Stem Cell Facility of the Harvard Stem Cell Institute.

1005 hPSC culture

1006

Human ESCs and iPSCs were maintained on plates coated with geltrex (life technologies,

1007 A1413301) in StemFlex media (Gibco, A3349401) and passaged with accutase (Gibco, A11105).

1008 All cell cultures were maintained at $37^{\circ} \mathrm{C}, 5 \% \mathrm{CO} 2$.

1009

1010 Infection of hPSCs with lentiviruses

1011 Lentivirus particles were produced by Alstem (http://www.alstembio.com/). hPSCs were

1012 seeded in a geltrex coated 12 well plate at a density of 100,000 cells $/ \mathrm{cm}^{2}$ in StemFlex medium

1013 supplemented with rock inhibitor (Y27632, Stemgent 04-0012) and lentiviruses, at a MOI

1014 (multiplicity of infection) of 2. 24 hours later, the medium was changed to StemFlex. The cells 
1015 were grown until confluency, and then either maintained as stem cells, passaged, banked, or

1016 induced with Doxycycline for neuronal differentiation.

1018 Neuronal differentiation

hPSCs were differentiated into cortical glutamatergic neurons as previously described ${ }^{34}$.

1020 Our protocol differs from previous Ngn2-driven protocols ${ }^{33,89}$ through inclusion of

1021 developmental patterning alongside Ngn2 programming ${ }^{34}$ (Fig. 1b,c,f). This paradigm generates

1022 post-mitotic excitatory cortical neurons that are highly homogeneous in terms of cell type $\mathrm{e}^{34}$

1023 compared to most differentiation paradigms which yield heterogeneous cell types ${ }^{90}$. At 4 days

1024 post induction, cells are co-cultured with mouse glia to promote neuronal maturation and

1025 synaptic connectivity ${ }^{91,92}$.

1027 RNA sequencing and alignment

We used triplicate wells of each line at each time point to reduce experimental variation.

1029 Cells were harvested in RTLplus Lysis buffer (Qiagen 1053393) and stored at $-80^{\circ} \mathrm{C}$. To

1030 minimize technical biases in readouts from cases and controls, we carried out the RNA

1031 sequencing in mixed pools of both genotypes. Sequencing libraries were generated from $100 \mathrm{ng}$

1032 of total RNA using the TruSeq RNA Sample Preparation kit (Illumina RS-122-2303) and

1033 quantified using the Qubit fluorometer (Life Technologies) following the manufacturer's

1034 instructions. Libraries were then pooled and sequenced by high output run on a HiSeq 2500

1035 (Illumina). The total population RNA-seq fastq data was aligned against ENSEMBL human

1036 reference genome (build GRCh37.p13/hg19) using STAR (v.2.5) ${ }^{93}$. Prior to genome aligning, we

1037 used Trimmomatic (v.0.36) ${ }^{94}$ to clip Illumina adapters and low-quality base-pairs from the ends 
1038 of the sequence reads and removed reads with length $<36$ base-pairs. The gene-wise read-counts

1039 were generated from the aligned reads by featureCounts in Rsubread (v.1.32) ${ }^{95}$ using GENCODE

1040 GTF annotation version 19. The reads from the three experimental replicates were summed

1041 together. The final read counts did not differ between cases and controls $\left(11.0 \times 10^{6}\right.$ and $10.8 \times$

$104210^{6}$ reads, respectively; $\mathrm{p}=0.68$, two-sided $\mathrm{t}$-test). The deleted cis genes accounted for 0.53 to

$1043 \quad 0.71 \%$ and 0.97 to $1.29 \%$ of all read counts in carriers and controls, respectively.

1044 The plot in Figure 2a was generated as follow: we used normalized read counts from

1045 DeSeq2 for a set of 18 canonical marker genes for pluripotency (SOX2, POU5F1, NANOG, and

1046 MKI67), neuronal progenitor cells (NEUROD1, SOX2, EMX2, OTX2, HES1, MSI1, and

1047 MKI67), and neuronal marker genes (RBFOX3, SYN1, DCX, MAP2, TUBB3, NCAM1, and

1048 MAPT) to address the progress of neuronal differentiation in the data set. The normalized gene-

1049 wise read counts were scaled to a standard score $\left(z=\frac{x-\mu}{\sigma}\right)$ so that the gene expression of the

1050 different genes was presented as a difference from the average in units of standard deviations.

1051 The mean z-score for each gene set was then calculated and plotted as a line plot across the three

1052 cell stages (stem cells, NPCs, and neurons) with 95\%-confidence intervals using inbuilt statistics

1053 in ggplot2.

1054

1055 Differential gene expression analysis

For differential gene expression analysis, we applied Wald's test for read counts that

1057 were normalized for library size internally in DESeq $2^{96}$. The differential expression analysis was

1058 conducted separately for each cell stage to avoid any biases in gene variance modeling resulting

1059 from gene expression differences in between SCs, NPCs, and neurons. The experimental batch

1060 was included to the design formula in DESeq2 to correct for the 6 experimental batches in which 
1061 the data was generated in. We used SVA package (version 3.32) ${ }^{97}$ in R to search for latent

1062 factors to remove any unwanted variation in the data. We first estimated the number of latent

1063 factors using the leek method in num.sv function that was then used for calculating surrogate

1064 variables with irw method and five iterations in sva function. The design model for sva included

1065 experimental batch and deletion genotype. One latent factor was identified for the neuron data

1066 and was included to the design formula in DESeq2 for differential expression. For Stem cells and

1067 NPCs no latent factors were identified. The results for differential expression were obtained for

1068 FDR adjusted $p$-value of $<0.05$. A principal component analysis was performed for all genes

1069 with more than 10 reads after normalizing the read counts by variance stabilizing transformation

1070 in DESeq2. For differential expression analysis in the edited isogenic deletion cell lines we used

1071 Limma-voom package ${ }^{98,99}$ that enabled to model the non-independent experimental replicates

1072 from each clone with the "duplicateCorrelation" function, which was included in the design

1073 model by the block design in Limma.

1074

\section{Power analysis}

The power estimates were calculated using RNASeqPower ${ }^{100}$ (R package version 1.18.0).

1077 We calculated the median expression and variance in carriers and controls for all genes with one

1078 or more reads $(25,264$ genes $)$ in the pilot data sets. We assumed equal number of cases and

1079 controls, while the coefficient of variance was calculated separately for cases and controls. The

1080 alpha level was set to nominal significance of 0.05 . For the final data set the power to detect fold

1081 changes of $>2$ was calculated for each gene separately.

1082 


\section{Enrichment for neurodevelopmental and constraint genes}

Gene lists for neurodevelopmental disorder genes were compiled from the deciphering

1086 developmental delay project ${ }^{45,46}$, and recent large scale exome sequencing study in autism ${ }^{27}$. We

1087 included genes for which there was statistical overrepresentation of loss of function variants in

1088 patients compared to controls (total 97 genes for ASD ${ }^{27}$ and 93 for ID $^{46}$ genes). From the earlier

1089 DDD-study ${ }^{45}$ we included all "confirmed" developmental disorder genes that affect the brain.

1090 We included only those that had "hemizygous" and "monoallelic" as the allelic requirement, and

1091 mutation consequence defined as: "loss of function", "cis-regulatory" or "promotor mutation",

1092 and "increased gene dosage" (total 158 genes). This resulted in a list of total 295 disease genes

1093 for neurodevelopmental disorders (Table S5). P-values for the enrichment analyses were

1094 calculated with hypergeometric test and binomial test in R. GO-term overrepresentations were

1095 calculated with hypergeometric test implemented in GoStats v. $1.7 .4^{101}$ in $\mathrm{R}$ with gene

1096 identifiers from org.Hs.eg.db. All p-values were calculated for overrepresentation using all

1097 mapped genes from each experiment as the background gene universe. False discovery rate (fdr)

1098 was used to adjust the raw p-values from the hypergeometric test for overrepresentation using

1099 p.adjust function in R. Significance threshold for overrepresentation was set to fdr-adjusted p-

1100 value smaller or equal to 0.05 . The overrepresentation of synaptic GO terms was estimated by

1101 Fisher exact test in the SYNGO online portal (www.syngoportal.org) using a custom background 1102 gene set from the RNASeq data set.

1104 Protein-protein interaction network analysis

1105 Previous efforts have shown that the observed distribution of the p-values from

1106 differential expression studies could be modeled as a mixture of the distributed signal and 
1107 uniformly distributed noise components ${ }^{102,103}$. In such approach, a threshold value could be

1108 estimated for observed p-values to discriminate between the likely true signal from noise. Hence,

1109 genes could be scored with logarithm of signal to noise ratio (log for making scores additive).

1110 Further, using a reference functional network we can leverage gene weights on the map of

1111 functional interactions to construct a node-weighted graph. Within this graph a search for the

1112 most-weighted connected subgraph (MWCS) could be performed. This search returns a

1113 functional module that has the strongest cumulative association to a trait being investigated.

1114 Appearance of genes in MWCS is driven both by their differential expression p-value and

1115 reference network topology. Thus, non-randomness of each gene's appearance could be

1116 evaluated by randomly permuting p-values and creating a random reference network with

1117 preserved node degrees. Estimates of how often a gene will be observed in MWCS by chance

1118 provide an empiric metric of significance and could be used to prioritize genes within MWCS.

1119 We implemented this strategy in R-package "PPItools" which provides a set of functions to

1120 identify MWCS, describe its statistical properties and prioritize genes within it. We used the

1121 InWebIM ${ }^{52}$ direct protein-protein interactions network as a reference.

1122 For every time point a beta-uniform mixture distribution was fitted to a distribution of

1123 observed p-values. Bonferroni adjusted significance threshold (0.05 / \#Genes expressed) was

1124 selected as a threshold to discriminate positively and negatively scoring genes. Scores were

1125 estimated as a ratio between values of probability density function of Beta distribution at given

$1126 \mathrm{p}$-value and threshold $\mathrm{p}$-value or $(\alpha-1) \times\left(\log (\mathrm{x})-\log \left(\mathrm{x} \_\right.\right.$threshold $\left.)\right)$, where $\alpha$ is an estimated

1127 parameter of Beta distribution. MWCSs for every time point of the experiment (iPSC, neuronal

1128 progenitors and neuronal cells) were identified (Fig. 4g and Extended Data Fig. 8). Using

1129 described above permutational scheme, for every module we assessed a non-randomness of 
1130 presence for every gene found in the module (Table S8). After multiple hypothesis testing

1131 correction (Bonferroni method used) several genes from each data set come up as significantly

1132 functionally enriched (adjusted $\mathrm{p}<0.05$ ). 36 out of 50 genes in the iPSC module were seen in

1133 random MWCS with less than 5/1000 frequency.

1134 We further tested for excessive connectivity between significantly differentially

1135 expressed genes and known neurodevelopmental disease genes. We selected 295 likely disease-

1136 causing genes from the Deciphering developmental delay (DDD) project, and a recent, large

1137 exome-sequencing study in autism (Table S5). Curated inflammatory bowel disease (IBD) and

1138 Parkinson's disease (PD) risk gene lists (Table S5) were included as a negative control set in this

1139 analysis. We estimated the number of connections between genes found in each of the disease

1140 gene lists and a list of differentially expressed genes with FDR $<5 \%$ normalized to the total

1141 number of connections observed for all genes in both tested sets (disease and expression) in

1142 reference data. The obtained result could be interpreted as a proportion of all connections that are

1143 linking disease and differentially expressed genes. To evaluate significance, we generated

1144 random gene sets of the same size as the disease gene sets and estimated an expected number of

1145 connections with each set of differentially expressed genes. It is important to note that genes co-

1146 expressed within the same tissue or cell type tend to have a greater number of connections

1147 between them than would be expected for a random pair of genes. Hence, in generating random

1148 gene sets we specifically selected genes at random to match the expression pattern of a disease

1149 gene set in a given cell type (iPSC, neuronal progenitors or neurons). For every dataset, the

1150 expression distribution was binned into deciles and every gene was assigned to an appropriate

1151 bin using mean counts. Random gene sets were selected to match the distribution of genes into 
1152 deciles for disease gene sets. Empirical p-values were adjusted for two disease gene sets tested

1153 with Bonferroni correction.

1154 The PPItools package for finding MWCS and performing network prioritizations along

1155 with documentation and source code to perform described analysis is available through GitHub

1156 https://github.com/alexloboda/PPItools.

\section{SNP heritability analysis}

LD Score regression ${ }^{104}$ and MAGMA ${ }^{60}$ were used for evaluating common variant

1160 associations in and near differentially expressed genes. Briefly for LD score regression, it can be

1161 shown that under a basic polygenic model we expect the GWAS statistics for SNP $j$ to be:

$$
E\left[\chi_{j}\right]=N \sum_{c} \tau_{c} l(j, c)+1
$$

1163 where $N$ is the sample size, $c$ is the index for the annotation category, $1 \mathrm{j}, \mathrm{c}$ is the LD score of SNP

$1164 j$ with respect to category $C_{c}$, and $\mathrm{c}$ is the average per-SNP contribution to heritability of category

$1165 C_{c}$. That is, the 2 statistic of SNP $j$ is expected to be a function of the total sample $N$, how much

1166 the SNP tags each category $C_{c}$ (quantified by $1 \mathrm{j}, \mathrm{c}$, the sum of the squared correlation coefficient

1167 of SNP $j$ with each other SNP in a $1 \mathrm{cM}$ window that is annotated as part of category $C_{c}$ ) and $\mathrm{c}$,

1168 the effect size of the tagged SNPs.

1169 With this model, LD Score regression allows estimation of each c. Each c is the

1170 contribution of category Cc after controlling for all other categories in the model (we included 74

1171 annotations that capture different genomic properties including conservation, epigenetic markers,

1172 coding regions and LD structure similar to ${ }^{105}$ and can be interpreted similarly to a coefficient

1173 from a linear regression. Testing for significance of $\mathrm{c}$ is useful because it indicates whether the

1174 per-SNP contribution to heritability of category $C$ is significant after accounting for all the other 
1175 annotations in the model. In addition to considering the conditional contribution of category $C_{c}$

1176 with c, the total marginal heritability explained by SNPs in category $C_{c}$, denoted hg2(Cc), is

1177 given by

1178

$$
\hat{h}^{2}\left(C_{c}\right)=\sum_{C: j \in C_{c}} \sum_{\dot{c}: j \in C_{\dot{c}}^{\prime}} \hat{\tau}_{\dot{c}}
$$

In other words, the heritability in category $C_{c}$ is the sum of the average per-SNP

1180 heritability for all SNPs in $C_{c}$, including contributions to per-SNP heritability from other

1181 annotations $\mathrm{c}^{\prime}$ that overlap with category $C_{c}$ (as indicated by terms of the inner sum where $\mathrm{c}^{\prime} \neq \mathrm{c}$ ).

1182 Importantly, $\hat{h}_{g}\left(C_{c}\right)$ does not depend on the categories chosen to be in the model and provides an

1183 easier interpretation. Therefore, this quantity is the main focus of the analysis.

1185 downstream of each gene differentially expressed gene. $\hat{h}_{g}\left(C_{c}\right)$ was calculated for three sets of

1186 differentially expressed genes using two $\mathrm{p}$-value thresholds (FDR $<5 \%$ and $\mathrm{p}<0.05$ ). Genes

1187 surpassing $\mathrm{p}<0.05$ cut-off were further divided to up and down-regulated genes. Heritability

1188 estimates were calculated for 6 sets of summary statistics from large GWAS of educational

1189 attainment ${ }^{54}$ and 5 psychiatric/neurodevelopmental disorders: ADHD $^{55}$, autism spectrum

1190 disorder ${ }^{56}$, bipolar disorder ${ }^{57}$, major depressive disorder ${ }^{58}$ and schizophrenia ${ }^{59} \mathrm{OR}^{32}$. In addition,

1191 the $\hat{h}_{g}\left(C_{c}\right)$ was calculated for the up-regulated genes in neurons (p-value $<0.05$ ) and summary

1192 statistics for 650 phenotypes from the UK-biobank that have a significant heritability, defined by

1193 having a heritability $\mathrm{p}$-value $<0.05$ after Bonferroni correction for multiple testing

1194 (https://www.nealelab.is/uk-biobank/).

1195 Similar to what was done for LD-score regression we considered gene-lists of

1196 differentially expressed genes to ask whether the differentially expressed genes are more strongly 
1197 associated with each of the six phenotypes. We then used competitive gene set enrichment

1198 analysis using gene-wise p-values ${ }^{56}$ that were calculated for each trait in MAGMA v 1.06 with

1199 standard settings ${ }^{60}$. All the results are adjusted for a set of baseline set of covariates with the goal

1200 to minimize bias due to gene-specific characteristics: gene size, $\log$ (gene size), SNP density,

$1201 \log ($ SNP density), inverse of the minor allele count, $\log$ (inverse of minor allele count) and

1202 number of exons in the gene. Gene-wise p-values were calculated by gene analysis in MAGMA

1203 and were used to identify genes underlying the stronger association signal among the upregulated

1204 genes in neurons. LD-score regression and MAGMA competitive gene set enrichment analyses

1205 were repeated for schizophrenia with 100 random genes lists that were matched with expression

$1206( \pm 10 \%)$ to that of genes that were upregulated in deletion carriers in neurons.

\section{Analysis of enrichment of differentially expressed genes in whole-exome sequencing data}

1209 We investigated if up- and down-regulated genes in 22q11.2 deletion carriers are

1210 significantly disrupted by ultra-rare coding variants (URVs) in the whole-exomes of

1211 schizophrenia cases and controls (previously described ${ }^{63,64}$ ). In the cohorts separately, we

1212 regressed case status on the number of damaging URVs in the gene set of interest while

1213 controlling for the total number of URVs, sex, and the first five principal components. We define

1214 damaging URVs as putatively protein-truncating variants (stop-gain, frameshift, and splice-

1215 donor and acceptor variants), and damaging missense variants as variants with a MPC score of

$1216>=2$, as previously described ${ }^{106}$. We applied inverse-weighted meta-analysis to combine the test-

1217 statistics from both studies to get a single joint P-value. We tested for enrichment in up- and

1218 down-regulated genes, and a collection of randomly sampled neuronally-expressed genes. 


\section{Motif enrichment analysis}

The motif enrichment analysis was carried out by Homer software for genes whose

1222 transcripts were found upregulated ( $\log _{2}$ Fold change $>0$ ) at day 28 neurons and p-value below $<$

1223 0.05. We performed a de novo motif analysis for human motifs using findMotifs.pl with len $=$

122410 . We curated the obtained results by setting a stringent $p$-value threshold $\left(p<10^{-10}\right)$, visually

1225 inspecting that observed motifs do not match only from the edges, excluded repeat sequences,

1226 and required that the motif had a frequency of above $5 \%$.

1228 CRISPR generation of isogenic $22 q 11.2$ cell lines

1229 To generate an isogenic 22q11.2 line in H1 hESCs, oligonucleotides (IDT) targeting LCR

1230 A (ACACTGGGCACATTATAGGG) and LCR D (CATTCATCTGTCCACCCACG) were

1231 cloned into a pU6-sgRNA vector generate sgRNA plasmids pPN298 and pPN306, respectively,

1232 via procedures described previously ${ }^{107}$. For transfection, cells were pre-incubated with " $1: 1$

1233 medium" composed of a 1:1 mixture of mTeSR1 medium and "hPSC medium" [hPSC medium:

1234 KO DMEM (Gibco 10829-018) with 20\% KOSR (Gibco 10828-028), 1\% Glutamax (Gibco

1235 35050-061), 1\% NEAA (Corning 25-025-Cl), 0.1\% 2-mercaptoethanol (Gibco 21985-023) and

1236 20ng/ml bFGF (EMD Millipore GF0003AF) supplemented with 10 $\mu$ M ROCK inhibitor (Y-

1237 27632). $7 \mu \mathrm{g}$ Cas9 nuclease plasmid (pX459, Addgene \#62988) $1.4 \mu \mathrm{g}$ pPN298 and $1.4 \mu \mathrm{g}$

1238 pPN306 were electroporated into $2.5 \times 106$ cells at 1050V, 30ms, 2 pulses (NEON, Life

1239 Technologies MPK10096), as described ${ }^{108}$. Individual hPSC colonies were selected with

1240 puromycin treatment and seeded into Geltrex-coated 96-well plates, expanded for 1-2 weeks and

1241 duplicated for cell freezing and gDNA extraction. Clones were frozen in 96-well plates using

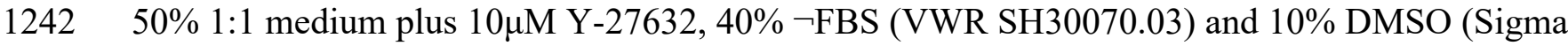


1243 D2650). gDNA was extracted overnight at $55^{\circ} \mathrm{C}$ in Tail Lysis Buffer (Viagen 102-T) with

1244 Proteinase K (Roche 03115828001 ) followed by a $1 \mathrm{hr} 90^{\circ} \mathrm{C}$ incubation. Droplet digital PCR

1245 (ddPCR) was performed to determine for copy numbers of the HIRA and ZNF74 genes using

1246 probes previously described ${ }^{109}$. SNP genotyping was performed using the Illumina Infinium

1247 PsychArray-24 Kit on the lines to confirm the microdeletion (Broad Institute, Cambridge, MA).

1248 Differential expression for the isogenic lines was performed by DESeq2. The results from

1249 isogenic lines were compared to the results obtained from the discovery sample. The overlap

1250 between the direction of fold-changes in isogenic samples were tested using binomial test for all

1251 genes that were differentially expressed in the discovery sample. The expected probability for

1252 overlap was calculated from all genes and was on average 0.5 . The differences in gene

1253 expression were tested by Mann-Whitney test including all genes with nominally significant p-

1254 value in differential expression in the isogenic lines.

1255

\section{DNA FISH analysis}

FISH (Fluorescent In-Situ Hybridization) analysis was conducted in the isogenic control

1258 and $22 \mathrm{q} 11.2$ deletion lines to analyze the copy number of the $22 \mathrm{q} 11.2$ region and validate the

1259 isogenic deletion. We generated the probe using a bacterial artificial chromosome (BAC)

1260 located in the 22q11.2 region, CTD-2300P14 (Thermo Fisher Scientific, Supplier Item: 96012),

1261 labeled with Cy3 dUTPs (GE healthcare: PA53022), by means of nick translation (Abbott: 32-

1262 801300), and visualized the labeled cells using confocal microscopy.

1263

1264 


\section{Multielectrode Arrays (MEA)}

MEA experiments and analysis were performed exactly as previously described ${ }^{34}$.

1268 Briefly, neuronal progenitors (at day 4) were seeded on 8x8 MEA grids, each with 64

1269 microelectrodes, in the absence or presence of mouse glia, and routinely sampled these for 42

1270 days after Ngn2 induction and dual SMAD and WNT inhibition. Each MEA plate contained

1271 wells from both deletion carrier and control neurons to minimize technical biases. Extracellular

1272 spikes (action potentials) were acquired using Axion Biosystems multi-well MEA plate system

1273 (The Maestro, Axion Biosystems; 64 electrodes per culture well). During the recording period,

1274 the plate temperature was maintained at $37 \pm 0.1^{\circ} \mathrm{C}$, environmental gas composition was not

1275 maintained outside of the incubator. Unless otherwise stated, descriptive statistics for MEA

1276 data is presented as Tukey style box plots, showing the 1st, 2nd, and 3rd quantile (Q1, Q2,

1277 \& Q3 respectively; inter-quartile range, IQR = Q3- Q1). Box plot whiskers extend to the

1278 most extreme data points between Q1-1.5*IQR and Q3+1.5*IQR ${ }^{110-112}$. All data points

1279 outside the whiskers are plotted. Non-parametric $95 \%$ confidence intervals for $\mathrm{M}$ are

1280 calculated using fractional order statistics ${ }^{113}$.

1281

\section{TMT-processing workflow}

1283 Cell pellets were lysed and 50ug protein per TMT channel were subjected to disulfide bond

1284 reduction and alkylation. Methanol-chloroform precipitation was performed prior to protease

1285 digestion with LysC/trypsin. Obtained peptides were labeled with the respective TMT reagents

1286 and pooled. Enhanced proteome coverage was achieved by high-pH reversed phase fractionation

1287 to reduce sample complexity. Peptide fractions were analyzed on an Orbitrap Fusion mass

1288 spectrometer using SPS-MS ${ }^{114}$. Mass spectra were processed using a Sequest-based in-house

1289 software pipeline. Peptide and protein identifications were obtained following database searching 
1290 against all entries from the human UniProt database. For TMT-based reporter ion quantitation, we

1291 extracted the summed signal-to-noise $(\mathrm{S}: \mathrm{N})$ ratio for each TMT channel. For protein-level

1292 comparisons, peptide-spectrum-matches (PSM) were identified, quantified, and collapsed to a $1 \%$

1293 peptide false discovery rate (FDR) and then collapsed further to a final protein-level FDR of $1 \%$.

1294 Moreover, protein assembly was guided by principles of parsimony to produce the smallest set of

1295 proteins necessary to account for all observed peptides. Proteins were quantified by summing

1296 reporter ion counts across all matching PSMs using in-house software. Protein quantification

1297 values were exported for further analysis.

1298

1299 Analysis of protein abundances

1300 Differences in protein abundances between deletion carriers and controls were estimated

1301 in day 28 neurons derived from two patient (SCBB1962 and SCBB-1825) and two control lines

1302 (SCBB1828, SCBB1827) in total 18 replicates. The abundances for the detected 8811 gene

1303 products were $\log _{2}+1$ transformed and quantile normalized in Limma package ${ }^{99}$ (v. 3.3.49) in R.

1304 A linear model including instrument run and deletion status was used to analyze differences in

1305 the normalized protein abundances between deletion carriers and controls in Limma. The

1306 correlation of the non-independent experimental replicates was estimated with

1307 "duplicateCorrelation" function (average estimated inter replicate correlation was 0.83 ) and was

1308 taken into account in the design model using block design in Limma. Overlap of gene products

1309 between RNA sequence data and proteomics data (total 8585 gene products detected by both

1310 methods) was compared using p-value $<0.05$ threshold. The overlap of direction of effect was

1311 estimated with binomial test with expected probability of 0.5 . The density coloring was

1312 calculated from Kernel density estimation using densCols in R. 


\section{Immunohistochemistry}

1314 Cultured induced neurons were fixed in 4\% paraformaldehyde $+20 \%$ sucrose in DPBS for 20

$1315 \mathrm{~min}$ at room temperature. Cells were incubated with blocking buffer containing $4 \%$ horse serum,

$1316 \quad 0.1 \mathrm{M}$ Glycine, and $0.3 \%$ Triton-X in PBS for 1 hour at room temperature. Primary antibodies,

1317 diluted in 4\% horse serum in PBS, were incubated overnight at 4oC. Secondary antibodies were

1318 diluted in 4\% horse serum and applied for 1 hour at room temperature. Samples were washed 3x

1319 with PBS and imaged on spinning disc confocal microscope (Andor Dragonfly) with a 20x air

1320 objective. The following antibodies were used: rabbit anti-SV2A (1:1000, Abcam ab32942),

1321 chicken anti-MAP2 (1:10,000, Abcam ab5392), rabbit anti-Synaptotagmin-11 (1;1000, Synaptic

1322 Systems 270 003). Alexafluor plus-555 and Alexafluor plus-488 conjugated secondary

1323 antibodies (1:5,000) were obtained from Invitrogen.

1325 Image acquisition and analysis

1326 Fluorescent images were acquired on spinning disc confocal microscope (Andor Dragonfly) at

1327 room temperature using 20x air interface objective using Fusion software. For quantification at

1328 least four 1024x1024 pixel fields of view from 2 different wells were taken for each line. The

1329 images were analyzed using ImageJ software.

1331 Immunoblotting

1332 For collection, neurons grown on glia were washed with DPBS and lysed with RIPA buffer and

1333 1x protease inhibitor cocktail. Lysates were boiled, sonicated and centrifuged at 16,000xg for 5

1334 minutes. The soluble fraction was separated on SDS-PAGE using Bolt system (Novex). The

1335 proteins were transferred onto nitrocellulose membrane using iBlot2 Gel Transfer Device and 
1336 immunostained using Neurexin-1 antibody (Millipore ABN161-I) and Tuj1 (Biolegend 801201)

1337 and detected via HRP-conjugated secondary antibodies on the Chemidoc system.

1339 qPCR analysis

1340 RNA isolation was performed with the Direct-Zol RNA miniprep kit (ZYMO: cat\# R2051)

1341 according to the manufacturer's instructions. To prevent DNA contamination, RNA was treated

1342 with DNase I (ZYMO: cat\# R2051). The yield of RNA was determined with a Denovix DS-11

1343 Series Spectrophotometer (Denovix). 200ng of RNA was reverse-transcribed with the iScript

1344 cDNA Synthesis Kit (Bio-Rad, cat\# 1708890). For all analyses, RT-qPCR was carried out with

1345 iQ SYBR Green Supermix (Bio-Rad, cat\# 1708880) and specific primers for each gene

1346 (Supplementary Table) with a CFX384 Touch Real-Time PCR Detection System (Bio-Rad).

1347 Target genes were normalized to the geometric mean of control genes, RPL10 and GAPDH, and

1348 relative expression compared to the mean $\mathrm{Ct}$ values for control and wild-type isogenic samples,

1349 respectively.

1350 The following primers were used:

1351 MEF2C_forward 5'-CTGGTGTAACACATCGACCTC-3'

1352 MEF2C_reverse 5'-GATTGCCATACCCGTTCCCT-3'

1353 TBX1_forward 5'-ACGACAACGGCCACATTATTC-3'

1354 TBX1_reverse 5'-CCTCGGCATATTTCTCGCTATCT-3'

1355 RPL10_forward 5'-GCCGTACCCAAAGTCTCGC-3'

1356 RPL10_reverse 5'-CACAAAGCGGAAACTCATCCA-3'

1357 GAPDH_forward 5'-GGAGCGAGATCCCTCCAAAAT-3'

1358 GAPDH_reverse 5'-GGCTGTTGTCATACTTCTCATGG-3' 


\section{$\underline{\text { References }}$}

13611 Edelmann, L., Pandita, R. K. \& Morrow, B. E. Low-copy repeats mediate the common 3-

$1362 \quad$ Mb deletion in patients with velo-cardio-facial syndrome. Am J Hum Genet 64, 1076-1086 (1999).

13642 Hoeffding, L. K. et al. Risk of Psychiatric Disorders Among Individuals With the 22q11.2 Deletion or Duplication: A Danish Nationwide, Register-Based Study. JAMA Psychiatry 74, 282-290, doi:10.1001/jamapsychiatry.2016.3939 (2017).

1368

3 Swillen, A. \& McDonald-McGinn, D. Developmental trajectories in 22q11.2 deletion. Am J Med Genet C Semin Med Genet 169, 172-181, doi:10.1002/ajmg.c.31435 (2015).

4 Horowitz, A., Shifman, S., Rivlin, N., Pisante, A. \& Darvasi, A. A survey of the 22q11 microdeletion in a large cohort of schizophrenia patients. Schizophr Res 73, 263-267, doi:10.1016/j.schres.2004.02.008 (2005).

5 Kates, W. R. et al. Neurocognitive and familial moderators of psychiatric risk in velocardiofacial (22q11.2 deletion) syndrome: a longitudinal study. Psychol Med 45, 16291639, doi:10.1017/S0033291714002724 (2015). Monks, S. et al. Further evidence for high rates of schizophrenia in 22q11.2 deletion syndrome. Schizophr Res 153, 231-236, doi:10.1016/j.schres.2014.01.020 (2014).

7 Schneider, M. et al. Psychiatric disorders from childhood to adulthood in $22 q 11.2$ deletion syndrome: results from the International Consortium on Brain and Behavior in 22q11.2 Deletion Syndrome. Am J Psychiatry 171, 627-639, doi:10.1176/appi.ajp.2013.13070864

1382 (2014). genome-wide study of 41,321 subjects. Nat Genet 49, 27-35, doi:10.1038/ng.3725 (2017). Treatment. Neurotherapeutics 12, 620-630, doi:10.1007/s13311-015-0352-z (2015). short-term synaptic plasticity and working memory through dysregulation of mitochondrial calcium. Mol Psychiatry 22, 1313-1326, doi:10.1038/mp.2016.75 (2017). from mouse models of 22q11.2 deletion syndrome: Hemizygous deletion of several mitochondrial genes in the $22 q 11.2$ genomic region can lead to symptoms associated with neuropsychiatric disease. Bioessays 39, doi:10.1002/bies.201600177 (2017). schizophrenia-related phenotypes in a mouse model of the 22q11.2 deletion. Proc Natl Acad Sci U S A 114, E6127-E6136, doi:10.1073/pnas.1615719114 (2017).

13 Fenelon, K. et al. Deficiency of Dgcr8, a gene disrupted by the 22q11.2 microdeletion, results in altered short-term plasticity in the prefrontal cortex. Proc Natl Acad Sci U S A 108, 4447-4452, doi:10.1073/pnas.1101219108 (2011).

$14 \mathrm{Hsu}, \mathrm{R}$. et al. Nogo Receptor 1 (RTN4R) as a candidate gene for schizophrenia: analysis using human and mouse genetic approaches. PLoS One 2, e1234, doi:10.1371/journal.pone.0001234 (2007). 
140115 Karayiorgou, M. \& Gogos, J. A. The molecular genetics of the 22q11-associated

1402 schizophrenia. Brain Res Mol Brain Res 132, 95-104,

1403 doi:10.1016/j.molbrainres.2004.09.029 (2004).

1404

16 Kimura, H. et al. A novel rare variant R292H in RTN4R affects growth cone formation and possibly contributes to schizophrenia susceptibility. Transl Psychiatry 7, e1214, doi:10.1038/tp.2017.170 (2017).

17 Meechan, D. W., Maynard, T. M., Tucker, E. S. \& LaMantia, A. S. Three phases of DiGeorge/22q11 deletion syndrome pathogenesis during brain development: patterning, proliferation, and mitochondrial functions of 22q11 genes. Int J Dev Neurosci 29, 283-294, doi:10.1016/j.ijdevneu.2010.08.005 (2011).

1412

18 Mukai, J. et al. Evidence that the gene encoding ZDHHC8 contributes to the risk of schizophrenia. Nat Genet 36, 725-731, doi:10.1038/ng1375 (2004).

19 Paronett, E. M., Meechan, D. W., Karpinski, B. A., LaMantia, A. S. \& Maynard, T. M. Ranbp1, Deleted in DiGeorge/22q11.2 Deletion Syndrome, is a Microcephaly Gene That Selectively Disrupts Layer 2/3 Cortical Projection Neuron Generation. Cereb Cortex 25, 3977-3993, doi:10.1093/cercor/bhu285 (2015). Stark, K. L. et al. Altered brain microRNA biogenesis contributes to phenotypic deficits in a 22q11-deletion mouse model. Nat Genet 40, 751-760, doi:10.1038/ng.138 (2008). of brainstem hypoglossal neurons in DiGeorge/22q11.2 Deletion Syndrome. Neuroscience 359, 1-7, doi:10.1016/j.neuroscience.2017.06.057 (2017).

22 Bassett, A. S. et al. Rare Genome-Wide Copy Number Variation and Expression of Schizophrenia in 22q11.2 Deletion Syndrome. Am J Psychiatry 174, 1054-1063, doi:10.1176/appi.ajp.2017.16121417 (2017).

23 Bergen, S. E. et al. Joint Contributions of Rare Copy Number Variants and Common SNPs to Risk for Schizophrenia. Am J Psychiatry, appiajp201817040467, doi:10.1176/appi.ajp.2018.17040467 (2018). Cleynen, I. et al. Genetic contributors to risk of schizophrenia in the presence of a 22q11.2 deletion. Mol Psychiatry, doi:10.1038/s41380-020-0654-3 (2020). and risk prediction in 22q11.2 deletion syndrome. Nat Med 26, 1912-1918, doi:10.1038/s41591-020-1103-1 (2020). spectrum disorder. Science 362, doi:10.1126/science.aat6576 (2018). Minshi Peng, Ryan Collins, Jakob Grove, Lambertus \& Klei, C. S., et al and, Bernie Devlin,\#, Stephan J. Sanders\#, Kathryn Roeder\#, Joseph D. Buxbaum, Mark J. Daly. Novel genes for autism implicate both excitatory and inhibitory cell lineages in risk. Biorxiv (2018). consortium. Nat Neurosci 20, 1661-1668, doi:10.1038/s41593-017-0017-9 (2017).

Weiner, D. J. et al. Polygenic transmission disequilibrium confirms that common and rare variation act additively to create risk for autism spectrum disorders. Nat Genet 49, 978985, doi:10.1038/ng.3863 (2017). 
144430 Finucane, H. K. et al. Heritability enrichment of specifically expressed genes identifies disease-relevant tissues and cell types. Nat Genet 50, 621-629, doi:10.1038/s41588-0180081-4 (2018).

31 Koopmans, F. et al. SynGO: An Evidence-Based, Expert-Curated Knowledge Base for the Synapse. Neuron 103, 217-234 e214, doi:10.1016/j.neuron.2019.05.002 (2019).

32 Schizophrenia Working Group of the Psychiatric Genomics, C. Biological insights from 108 schizophrenia-associated genetic loci. Nature 511, 421-427, doi:10.1038/nature13595 (2014).

33 Zhang, Y. et al. Rapid single-step induction of functional neurons from human pluripotent stem cells. Neuron 78, 785-798, doi:10.1016/j.neuron.2013.05.029 (2013).

34 Nehme, R. et al. Combining NGN2 Programming with Developmental Patterning Generates Human Excitatory Neurons with NMDAR-Mediated Synaptic Transmission. Cell Rep 23, 2509-2523, doi:10.1016/j.celrep.2018.04.066 (2018).

35 Fan, L. Z. et al. All-optical synaptic electrophysiology probes mechanism of ketamineinduced disinhibition. Nat Methods 15, 823-831, doi:10.1038/s41592-018-0142-8 (2018). Mitchell JM, N. J., Ghosh S, Handsaker RE, Mello CJ, Meyer D, Raghunathan K, de Rivera M, Tegtmeyer M, Hawes D, Neumann A, Nehme R, Eggan K, McCarroll SA. . Mapping genetic effects on cellular phenotypes with "cell villages". . BioRxiv and Cell, in revision (2020).

1463 Wells M, S. M., Piccioni F, Hill E, Mitchell J, Worringer K, Raymond J, Kommineni S, Chan K, Ho D, Peterson B, Siekmann M, Pietilainen O, Nehme R, Kaykas A, Eggan K. . Genomewide screens in accelerated human stem cellderived neural progenitor cells identify Zika virus host factors and drivers of proliferation BioRxiv (2018).

38 Biswas, A. B. \& Furniss, F. Cognitive phenotype and psychiatric disorder in 22q11.2 deletion syndrome: A review. Res Dev Disabil 53-54, 242-257, doi:10.1016/j.ridd.2016.02.010 (2016).

40 Lin, M. et al. Integrative transcriptome network analysis of iPSC-derived neurons from

41 Khan, T. A. et al. Neuronal defects in a human cellular model of 22q11.2 deletion syndrome. Nat Med, doi:10.1038/s41591-020-1043-9 (2020).

42 Lek, M. et al. Analysis of protein-coding genetic variation in 60,706 humans. Nature 536, 285-291, doi:10.1038/nature19057 (2016).

43 McDonald-McGinn, D. M. et al. 22q11.2 deletion syndrome. Nat Rev Dis Primers 1, 15071, doi:10.1038/nrdp.2015.71 (2015). 22q11.2 deletion syndrome. Hum Genet 138, 93-103, doi:10.1007/s00439-018-01967-6 (2019). 
148746 Deciphering Developmental Disorders, S. Prevalence and architecture of de novo mutations in developmental disorders. Nature 542, 433-438, doi:10.1038/nature21062 (2017).

47 The Schizophrenia Working Group of the Psychiatric Genomics Consortium, S. R., James TR Walters, Michael C O'Donovan. Mapping genomic loci prioritises genes and implicates synaptic biology in schizophrenia. medRxiv, doi:https://doi.org/10.1101/2020.09.12.20192922 (2020). Yap, E. L. \& Greenberg, M. E. Activity-Regulated Transcription: Bridging the Gap between Neural Activity and Behavior. Neuron 100, 330-348, doi:10.1016/j.neuron.2018.10.013 (2018).

1501

51 Rossin, E. J. et al. Proteins encoded in genomic regions associated with immune-mediated deacetylation of the anterior heart field enhancer. Dis Model Mech 11, doi:10.1242/dmm.029967 (2018).

55 Demontis, D. et al. Discovery of the first genome-wide significant risk loci for attention deficit/hyperactivity disorder. Nat Genet 51, 63-75, doi:10.1038/s41588-018-0269-7 (2019). disorder. Nat Genet 51, 431-444, doi:10.1038/s41588-019-0344-8 (2019). disorder identifies a new susceptibility locus near ODZ4. Nat Genet 43, 977-983, doi:10.1038/ng.943 (2011).

Wray, N. R. et al. Genome-wide association analyses identify 44 risk variants and refine the genetic architecture of major depression. Nat Genet 50, 668-681, doi:10.1038/s41588-018-0090-3 (2018). genes and in regions under strong background selection. Nat Genet 50, 381-389, doi:10.1038/s41588-018-0059-2 (2018). analysis of GWAS data. PLoS Comput Biol 11, e1004219, doi:10.1371/journal.pcbi.1004219 (2015). 
$153061 \quad$ Purcell, S. M. et al. A polygenic burden of rare disruptive mutations in schizophrenia. Nature 506, 185-190, doi:10.1038/nature12975 (2014).

62 Fromer, M. et al. De novo mutations in schizophrenia implicate synaptic networks. Nature 506, 179-184, doi:10.1038/nature12929 (2014). Genovese, G. et al. Increased burden of ultra-rare protein-altering variants among 4,877 individuals with schizophrenia. Nat Neurosci 19, 1433-1441, doi:10.1038/nn.4402 (2016). Singh, T. et al. The contribution of rare variants to risk of schizophrenia in individuals with and without intellectual disability. Nat Genet 49, 1167-1173, doi:10.1038/ng.3903 (2017). Singh T, P. T., Curtis D, Akil H, Eissa MA, Barchas JD, Bass N, Bigdeli TB, Breen G, Bromet EJ, Buckley PF, Bunney WE, Bybjerg-Grauholm J, Byerley WF, Chapman SB, Chen WJ, Churchhouse C, Craddock N, Curtis C, Cusick C, DeLisi L, Dodge S, Escamilla MA, Eskelinen DM, Howrigan DP, Huang H, Hwu HG, Kahn RS, Kang HM, Karczewski K, Kirov G, Knowles JA, Lee FS, Lehrer DS, Lescai F, Malaspina D, Marder SR, McCarroll SA, Medeiros H, Milani L, Morley CP, Morris DW, Mortensen PB, Myers RM, Nordentoft M, O'Brien NL, Olivares $A M$, Ongur D, Ouwehand WH, Palmer DS, Paunio T, Quested D, Rapaport $M H$, Rees $E$, Rollins B, Satterstrom FK, Schatzberg A, Scolnick E, Scott L, Sharp SI, Sklar P, Smoller JW, Sobell JI, Solomonson M, Stevens CR, Suvisaari J, Tiao G, Watson SJ, Watts NA, Blackwood DH, Borglum A, Cohen BM, Corvin AP, Esko T, Freimer NB, Glatt SJ, Hultman CM, McQuillin A, Palotie A, Pato CN, Pato MT, Pulver AE, Clair DS, Tsuang MT, Vawter MP, Walters JT, Werge T, Ophoff RA, Sullivan PF, Owen MJ, Boehnke M, O'Donovan M, Neale BM, Daly MJ. Exome sequencing identifies rare coding variants in 10 genes which confer substantial risk for schizophrenia. Medrxiv, doi:medRxiv 2020.09.18.20192815; doi: https://doi.org/10.1101/2020.09.18.20192815 (2020).

Flavell, S. W. et al. Activity-dependent regulation of MEF2 transcription factors suppresses excitatory synapse number. Science 311, 1008-1012, doi:10.1126/science.1122511 (2006). synaptic target genes and neuronal activity-dependent polyadenylation site selection. Neuron 60, 1022-1038, doi:10.1016/j.neuron.2008.11.029 (2008). Becher, A. et al. The synaptophysin-synaptobrevin complex: a hallmark of synaptic vesicle maturation. J Neurosci 19, 1922-1931 (1999). Chang, W. P. \& Sudhof, T. C. SV2 renders primed synaptic vesicles competent for Ca2+ induced exocytosis. J Neurosci 29, 883-897, doi:10.1523/JNEUROSCI.4521-08.2009 (2009). with schizophrenia. Schizophr Res 141, 262-265, doi:10.1016/j.schres.2012.08.027 (2012). 
$157373 \quad$ Inoue, S. et al. Synaptotagmin XI as a candidate gene for susceptibility to schizophrenia.

1574

1575

1576

1577

$1578 \quad 75$

1579

$1580 \quad 76$

1581

1582

1583

1584

1585

1586

1587

1588

1589

1590

1591

1592

1593

1594

1595

1596

1597

1598

1599

1600

1601

1602

1603

1604

1605

1606

1607

1608

1609

1610

1611

1612

1613

1614

1615

1616 Am J Med Genet B Neuropsychiatr Genet 144B, 332-340, doi:10.1002/ajmg.b.30465 (2007).

74 Lelieveld, S. H. et al. Meta-analysis of 2,104 trios provides support for 10 new genes for intellectual disability. Nat Neurosci 19, 1194-1196, doi:10.1038/nn.4352 (2016).

75 Finnema, S. J. et al. Imaging synaptic density in the living human brain. Sci Transl Med 8, 348ra396, doi:10.1126/scitransImed.aaf6667 (2016).

76 Onwordi, E. C. et al. Synaptic density marker SV2A is reduced in schizophrenia patients and unaffected by antipsychotics in rats. Nat Commun 11, 246, doi:10.1038/s41467-01914122-0 (2020).

77 Araujo, D. J. et al. FoxP1 orchestration of ASD-relevant signaling pathways in the striatum. Genes Dev 29, 2081-2096, doi:10.1101/gad.267989.115 (2015).

78 Sugathan, A. et al. CHD8 regulates neurodevelopmental pathways associated with autism spectrum disorder in neural progenitors. Proc Natl Acad Sci U S A 111, E4468-4477, doi:10.1073/pnas.1405266111 (2014).

$79 \mathrm{Li}, \mathrm{M}$. et al. Integrative functional genomic analysis of human brain development and neuropsychiatric risks. Science 362, doi:10.1126/science.aat7615 (2018).

80 Forsyth, J. K. et al. Synaptic and Gene Regulatory Mechanisms in Schizophrenia, Autism, and 22q11.2 Copy Number Variant-Mediated Risk for Neuropsychiatric Disorders. Biol Psychiatry 87, 150-163, doi:10.1016/j.biopsych.2019.06.029 (2020).

81 Kahn, J. B., Port, R. G., Anderson, S. A. \& Coulter, D. A. Modular, Circuit-Based Interventions Rescue Hippocampal-Dependent Social and Spatial Memory in a 22q11.2 Deletion Syndrome Mouse Model. Biol Psychiatry 88, 710-718, doi:10.1016/j.biopsych.2020.04.028 (2020).

82 Ellegood, J. et al. Neuroanatomical phenotypes in a mouse model of the $22 q 11.2$ microdeletion. Mol Psychiatry 19, 99-107, doi:10.1038/mp.2013.112 (2014).

83 Long, J. M. et al. Behavior of mice with mutations in the conserved region deleted in velocardiofacial/DiGeorge syndrome. Neurogenetics 7, 247-257, doi:10.1007/s10048006-0054-0 (2006).

84 Mukai, J. et al. Molecular substrates of altered axonal growth and brain connectivity in a mouse model of schizophrenia. Neuron 86, 680-695, doi:10.1016/j.neuron.2015.04.003 (2015).

85 Meng, Q. et al. The DGCR5 long noncoding RNA may regulate expression of several schizophrenia-related genes. Sci Transl Med 10, doi:10.1126/scitranslmed.aat6912 (2018).

86 Won, $\mathrm{H}$. et al. Chromosome conformation elucidates regulatory relationships in developing human brain. Nature 538, 523-527, doi:10.1038/nature19847 (2016).

87 Spielmann, M., Lupianez, D. G. \& Mundlos, S. Structural variation in the 3D genome. Nat Rev Genet 19, 453-467, doi:10.1038/s41576-018-0007-0 (2018).

88 Zhang, X. et al. Local and global chromatin interactions are altered by large genomic deletions associated with human brain development. Nat Commun 9, 5356, doi:10.1038/s41467-018-07766-x (2018).

89 Busskamp, V. et al. Rapid neurogenesis through transcriptional activation in human stem cells. Molecular systems biology 10, 760, doi:10.15252/msb.20145508 (2014). 
$161790 \quad$ Chambers, S. M. et al. Highly efficient neural conversion of human ES and iPS cells by dual

1618

1619

1620

1621

1622

1623

1624

1625

1626

1627

1628

1629

1630

1631

1632

1633

1634

1635

1636

1637

1638

1639

1640

1641

1642

1643

1644

1645

1646

1647

1648

1649

1650

1651

1652

1653

1654

1655

1656

1657

1658

1659 inhibition of SMAD signaling. Nat Biotechnol 27, 275-280, doi:10.1038/nbt.1529 (2009).

91 Eroglu, C. \& Barres, B. A. Regulation of synaptic connectivity by glia. Nature 468, 223-231, doi:10.1038/nature09612 (2010).

92 Pfrieger, F. W. Roles of glial cells in synapse development. Cellular and molecular life sciences : CMLS 66, 2037-2047, doi:10.1007/s00018-009-0005-7 (2009).

93 Dobin, A. et al. STAR: ultrafast universal RNA-seq aligner. Bioinformatics 29, 15-21, doi:10.1093/bioinformatics/bts635 (2013).

94 Bolger, A. M., Lohse, M. \& Usadel, B. Trimmomatic: a flexible trimmer for Illumina sequence data. Bioinformatics 30, 2114-2120, doi:10.1093/bioinformatics/btu170 (2014).

95 Liao, Y., Smyth, G. K. \& Shi, W. featureCounts: an efficient general purpose program for assigning sequence reads to genomic features. Bioinformatics 30, 923-930, doi:10.1093/bioinformatics/btt656 (2014).

96 Love, M. I., Huber, W. \& Anders, S. Moderated estimation of fold change and dispersion for RNA-seq data with DESeq2. Genome Biol 15, 550, doi:10.1186/s13059-014-0550-8 (2014).

97 Leek, J. T., Johnson, W. E., Parker, H. S., Jaffe, A. E. \& Storey, J. D. The sva package for removing batch effects and other unwanted variation in high-throughput experiments. Bioinformatics 28, 882-883, doi:10.1093/bioinformatics/bts034 (2012).

98 Law, C. W., Chen, Y., Shi, W. \& Smyth, G. K. voom: Precision weights unlock linear model analysis tools for RNA-seq read counts. Genome Biol 15, R29, doi:10.1186/gb-2014-15-2r29 (2014).

99 Ritchie, M. E. et al. limma powers differential expression analyses for RNA-sequencing and microarray studies. Nucleic Acids Res 43, e47, doi:10.1093/nar/gkv007 (2015).

100 Hart, S. N., Therneau, T. M., Zhang, Y., Poland, G. A. \& Kocher, J. P. Calculating sample size estimates for RNA sequencing data. J Comput Biol 20, 970-978, doi:10.1089/cmb.2012.0283 (2013).

101 Falcon, S. \& Gentleman, R. Using GOstats to test gene lists for GO term association. Bioinformatics 23, 257-258, doi:10.1093/bioinformatics/btl567 (2007).

102 Beisser, D., Klau, G. W., Dandekar, T., Muller, T. \& Dittrich, M. T. BioNet: an R-Package for the functional analysis of biological networks. Bioinformatics 26, 1129-1130, doi:10.1093/bioinformatics/btq089 (2010).

103 Dittrich, M. T., Klau, G. W., Rosenwald, A., Dandekar, T. \& Muller, T. Identifying functional modules in protein-protein interaction networks: an integrated exact approach. Bioinformatics 24, i223-231, doi:10.1093/bioinformatics/btn161 (2008).

104 Finucane, H. K. et al. Partitioning heritability by functional annotation using genome-wide association summary statistics. Nat Genet 47, 1228-1235, doi:10.1038/ng.3404 (2015).

105 Gazal, S. et al. Linkage disequilibrium-dependent architecture of human complex traits shows action of negative selection. Nat Genet 49, 1421-1427, doi:10.1038/ng.3954 (2017).

106 Samocha KE, K. J., Karczewski KJ, O’Donnell-Luria AH, Pierce-Hoffman E, MacArthur DG, Neale BM, Daly MJ. Regional missense constraint improves variant deleteriousness prediction. Biorxiv (2017). 
1660107 Cong, L. et al. Multiplex genome engineering using CRISPR/Cas systems. Science 339, 819-

1661

1662 823, doi:10.1126/science.1231143 (2013).

1663 Hazelbaker, D. Z. et al. A Scaled Framework for CRISPR Editing of Human Pluripotent Stem Cells to Study Psychiatric Disease. Stem Cell Reports 9, 1315-1327, doi:10.1016/j.stemcr.2017.09.006 (2017).

109 Hwang, V. J. et al. Mapping the deletion endpoints in individuals with 22q11.2 deletion syndrome by droplet digital PCR. BMC Med Genet 15, 106, doi:10.1186/s12881-014-01065 (2014).

$1668110 \quad$ Krzywinski, M. \& Altman, N. Visualizing samples with box plots. Nature methods 11, 119120 (2014).

111 McGill, R., Tukey, J.W. and Larsen, W.A. . Variations of Box Plots. The American Statistician 32, 12-16 (1978). order statistics. . Journal of Applied Statistics 26 343-353 (1999).

114 McAlister, G. C. et al. MultiNotch MS3 enables accurate, sensitive, and multiplexed detection of differential expression across cancer cell line proteomes. Anal Chem 86, 7150-7158, doi:10.1021/ac502040v (2014). 